\title{
THE INFLUENCE OF LIFE EXPERIENCES ON LEADERSHIP PRACTICES: \\ A CASE STUDY OF INDONESIAN SCHOOL PRINCIPALS
}

\section{By}

\section{DWI PURWESTRI SRI SUWARNINGSIH}

A thesis submitted to Victoria University of Wellington in partial fulfilment of the requirements for the degree of Master of Education

Victoria University of Wellington

March 2014 


\begin{abstract}
The purpose of this research study was to explore how individuals' life-stories impact on their leadership development and affect their educational leadership practices. The context for the study is the Nusa Tenggara Timur Province of Indonesia, where the overall educational achievement statistics rank very low compared to other provinces. There is currently a lack of appropriate educational policy or strategy in this province to enhance academic results. Previous research has identified that the quality of leadership may have an impact on school effectiveness and student outcomes, particularly the leadership of the school principals. Thus, this current research focuses on leadership practices of school principals. This qualitative study employed a case study design and semi-structured interviews and document analysis were used. Data were collected from six school principals from the highest achieving schools in Nusa Tenggara Timur Province, Indonesia and analysed used thematic analysis. Four factors identified from principals' life experience that appeared to influence leadership practices were: childhood experiences; previous leadership experiences; learning from role models; and values. This study highlights the impact on life experiences on leadership practices such as setting goals and strategies, ensuring the quality of teaching, supporting teachers' professional development, and creating healthy and safe environments. This study contributes to the existing literature regarding school principal leadership practices, and also makes recommendations to the Nusa Tenggara Timur Province government on the selection processes for educational leaders.
\end{abstract}




\section{ACKNOWLEDGMENT}

This thesis is dedicated to the Nusa Tenggara Timur Government and my scholarship donor, New Zealand Aid Programme. I would like to take this opportunity to express my gratitude for a number of people who support and encourage me during my thesis completion:

Dr Kate Thornton, for her superb supervision, kindness, encouragement and ongoing support during this thesis completion. You are one of my role models and inspired me to become a better leader. Thank you very much.

Dr Xiaodan Gao, Laila Faisal, Kirsten Reid, Student Learning Support advisers, for their support in improving the quality of my thesis. All PGSA executive members: Neil, Douglas, Bridget, Monique, Keely, Jumoke, Alison, Matt, Tim, Maryam, Behnam and Sue Kelly, thank you guys.

Siti Romlah Nurhidayati, my wonderful mother who expected one of her children would study abroad: your wish comes true, Mom! Panut Raharjo Mulyo Saputro, my supportive and dedicated father, thanks Pak. Fathoni Septiawan, my lovely husband, thanks for your eternal love, support and believing in me. Thank you for your patience in listening to me through skype and viber. I Love You. Bapak and Ibu Muryanto, thank you for all the prayers.

Mas Eko, Mbak Nining and Adik Estin, my brother and sisters, Mas Budi, Itsar and Mbak Ayu, my brothers and sister in law, I love you all. Thank you for my Indonesian-Kiwi family in Wellington, Pak Richard Holmes, Teteh Lia, Lina, and Endah; my Australian family mbak Gula and Ari: I love you all. Special thanks for my research participants, provincial education office staff, UNICEF staff and friends in NTT.

My critical friends: Yusuf, Elisante, Lili, Lan, Sukuna, Lubna, Amanda, Mabel, Hien Pham, Pak Zaki and Ben, thanks for your support. House member at 33 Campbell: Sokalyan, Richard, Marian, Dinath, Sovandanh, Ibu Tuti, ibu Cici, Margareth, Wei Dai, Bernie, Tinh, Dinh, Lifang, Lukman, and Houng, thanks for your friendship. All students in 31A and 31B: Ms Thuy, Johnny, Joster, 
Ribut, Little Dwi, Farzad, Syerina, Bee, Anna Joskin, Anita, Angela, Raewyn, Antonio, Hue \& Husband, Truphena, Zawadi, Upendo, Thilegawathy, Donna, Milka, Campbell St, thanks for being a wonderful PG community in Karori. Post Graduate Staff in Karori Campus: Sheila, Alex, Amy and Noeleen, thank you for your support.

All Indonesian friends in KAMASI, Mas Budi, mbak Wiwin and mbak Candra. PPI-Wellington, Ardya, Gaby, Candy, Sonia, Arya, Regina, Rory, Andre, Kia, Ubay, and Keni. Indonesian Moslem community, especially for mbak Alida, pak Zen, Bude Anik, Mas Tomo, Rini, Fenti, Farida, Marko, mbak Uli, mbak Nunki, Anna, Syifa \& Restu, thank you very much guys. Last of All, thank you for all beautiful people: Atin \& Andrew, Nia \& Kirk, Aak and Eneng, Enrico, Linda, Hana and David, Om Rudy, Om Away and Om Iwang, thank you for having me around Richard \& Lya's family in Wellington. 


\section{Table of Contents}

ABSTRACT I I

$\begin{array}{ll}\text { ACKNOWLEDGMENT II } & \text { II }\end{array}$

$\begin{array}{lll}\text { LIST OF TABLES } & \text { VIII }\end{array}$

$\begin{array}{lll}\text { LIST OF FIGURES IX } & \text { IX }\end{array}$

GLOSSARY

$\begin{array}{lr}\text { CHAPTER ONE } & 1\end{array}$

$\begin{array}{lr}\text { INTRODUCTION } & 1\end{array}$

1.0 CHAPTER OVERVIEW

1.1 CONTEXT FOR THE STUDY

1.2 BACKGRoUnd OF THE PROBLEM

1.3 RESEARCHER BACKGROUND 4

1.4 STATEMENT OF THE PROBLEM 4

1.5 PURPOSE OF THE STUDY

1.6 SigNIFICANCE OF THE STUDY

$\begin{array}{ll}1.7 \text { RESEARCH QUESTIONS } & 6\end{array}$

$\begin{array}{lc}1.8 \text { ORGANISATION OF THE THESIS } & 6\end{array}$

$\begin{array}{lr}\text { CHAPTER TWO } & 7\end{array}$

$\begin{array}{lr}\text { LITERATURE REVIEW } & 7\end{array}$

$\begin{array}{ll}\text { 2.0 CHAPTER OVERVIEW } & 7\end{array}$

2.1 CONCEPTUALISATION OF LEADERSHIP $\quad 7$

2.2 LEADERSHIP CONSTRUCTS 8

$\begin{array}{ll}\text { 2.2.1 Transformational leadership } & 8\end{array}$

$\begin{array}{lr}\text { 2.2.2 Distributed leadership } & 9\end{array}$

2.2.3 Authentic/Ethical leadership 10

2.3 LEADERSHIP IN SCHOOL SETTINGS

2.3.1 Instructional leadership 11

2.3.2 Educational leadership $\quad 12$

2.3.3 Impact of leadership on student outcomes 13

2.4 Authenticity, AuthentiC LEAdERS AND AuthENTIC LEADERShIP 14

$\begin{array}{lc}2.5 \text { THE DEVELOPMENT OF AUTHENTIC LEADERSHIP } & 16\end{array}$

2.5.1 Leader development and leadership development 16

$\begin{array}{ll}\text { 2.5.2 Authentic leadership development processes } & 17\end{array}$

2.5.3 Authentic Leadership antecedents 18

2.6 LIFE-STORIES APPROACH 21 
2.7 EDUCATIONAL LEADERSHIP RESEARCH IN INDONESIAN CONTEXT

2.8 GAPS IN THE RESEARCH

2.9 CHAPTER SUMMARY

CHAPTER THREE

METHODOLOGY

3.0 CHAPTER OVERVIEW

3.1 PhILOSOPHICAL WorldVIEWS AND RESEARCH DESIGN

3.2 Case Study as a Research Strategy

3.3 ETHICAL CONSIDERATION

3.4 RESEARCH Methods

3.4.1 The Setting

3.4.2 Schools selection and principals selection processes

3.5 DATA COLLECTION

3.5.1 Interviews

3.5.2 Document analysis

3.5.3 Data Analysis

3.6 TRUSTWORTHINESS

3.7 LiMiTATIONS

3.8 CHAPTER SUMMARY

CHAPTER FOUR

ELEMENTARY SCHOOL FINDINGS

4.0 Chapter OVERVIEW 39

4.1 CASE ONE: VAMA 39

4.1.1 Life experiences 39

4.1.2 Leadership Practices 41

4.1.3 School Documents 44

4.2 CASE: LOUISA 45

4.2.1 Life experience 45

4.2.2 Leadership practices 49

4.2.3 School documents

4.3 CHAPTER SUMMARY

CHAPTER FIVE

5.1 CASE: GERSON

5.1.1 Life experience

5.1.2 Leadership practices. 
5.2.1 Life experience

5.2.2 Leadership practices

5.2.3 School documents

5.3 CHAPTER SUMMARY

$\begin{array}{lr}\text { SENIOR HIGH SCHOOLS FINDINGS } & 66\end{array}$

6.0 CHAPTER OVERVIEW

6.1 CASE: FANGgidAe $\quad 66$

6.1.1 Life experience $\quad 66$

6.1.2 Leadership practices $\quad 69$

$\begin{array}{ll}\text { 6.1.3 School documents } & 72\end{array}$

6.2 CASE: NDOEN

$\begin{array}{ll}\text { 6.2.1 Life experience } & 73\end{array}$

$\begin{array}{ll}\text { 6.2.2 Leadership practices. } & 76\end{array}$

$\begin{array}{ll}\text { 6.2.3 School documents } & 79\end{array}$

6.3 CHAPTER SUMMARY $\quad 80$

$\begin{array}{lr}\text { CHAPTER SEVEN } & 81\end{array}$

$\begin{array}{lr}\text { DISCUSSION } & 81\end{array}$

7.0 CHAPTER OVERVIEW $\quad 81$

7.1 CHILDHOOD EXPERIENCES

$\begin{array}{ll}\text { 7.1.1 Childhood challenges } & 81\end{array}$

7.1.2 Childhood experiences: impact on leadership practices 84

7.2 ROLE MODELS 86

7.2.1 Significant role models $\quad 86$

7.2.2 Role models: impact on leadership practices 89

7.3 PREVIOUS LEAdERSHIP EXPERIENCES 91

$\begin{array}{ll}\text { 7.3.1 Previous leadership experiences } & 91\end{array}$

7.3.2 Previous leadership experiences: impact on leadership practices. 93

7.4 VALUES 96

$\begin{array}{ll}\text { 7.4.1 Key values } & 96\end{array}$

7.4.2 Values: impact on leadership practices 99

7.5 THE INFLUENCE OF LIFE EXPERIENCES ON THE DEVELOPMENT OF AUTHENTIC LEADERSHIP PRACTICES102

$\begin{array}{ll}7.6 \text { CHAPTER SUMMARY } & 106\end{array}$

$\begin{array}{lr}\text { CHAPTER EIGHT } & 107\end{array}$

$\begin{array}{lr}\text { CONCLUSION } & 107\end{array}$

$\begin{array}{ll}\text { 8.0 CHAPTER OVERVIEW } & 107\end{array}$ 
8.1 THE INFLUENCE OF LIFE EXPERIENCES ON THE DEVELOPMENT OF AUTHENTIC LEADERSHIP AND PRACTICES

8.2 IMPLICATIONS FOR THE NTT PROVINCIAL EDUCATION OFFICE

8.3 IMPLICATIONS FOR SCHOOL PRINCIPALS' LEADERSHIP PRACTICES

8.4 RESEARCH LIMITATIONS

8.5 FutURE RESEARCH

8.6 CHAPTER SUMMARY

\section{REFERENCES}

APPENDIX A: ETHIC APPROVAL

APPENDIX B: INFORMATION SHEET

APPENDIX C: CONSENT FORM FOR PARTICIPANTS

APPENDIX D: PERMISSION FROM THE GOVERNMENT

APPENDIX E: LEADERSHIP JOURNEY

APPENDIX F: LIST OF VALUES

APPENDIX G: INTERVIEW QUESTIONS

APPENDIX H: INFORMATION SHEET FOR PROVINCIAL EDUCATION OFFICE

APPENDIX I: CONSENT FORM FOR PROVINCIAL EDUCATION OFFICE

APPENDIX J: TRANSCRIBERS CONFIDENTIALITY AGREEMENT 136

APPENDIX K: EXAMPLE OF CODING

APPENDIX L: SUMMARY OF LIFE EXPERIENCES AND LEADERSHIP PRACTICES (VAMA)

APPENDIX M: SUMMARY OF LIFE EXPERIENCES AND LEADERSHIP PRACTICES (LOUISA)

APPENDIX N: SUMMARY OF LIFE EXPERIENCES AND LEADERSHIP PRACTICES (GERSON)

APPENDIX O: SUMMARY OF LIFE EXPERIENCES AND LEADERSHIP PRACTICES (SERAN)

APPENDIX P: SUMMARY OF LIFE EXPERIENCES AND LEADERSHIP PRACTICES (FANGGIDAE) 


\section{List of Tables}

Table 2.1. Possible factors that contributing to the development of authentic leadership

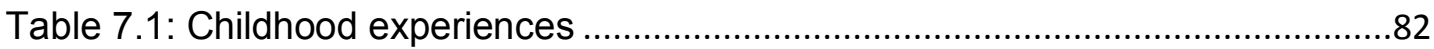

Table 7.2: Leadership practices of childhood experiences........................................86

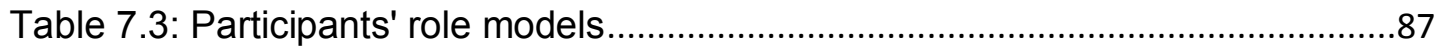

Table 7.4: Leadership practices of learning from role models ...............................89

Table 7.5: Significant leadership experiences ...........................................................91

Table 7.6: Leadership practices learning from previous experiences .......................93

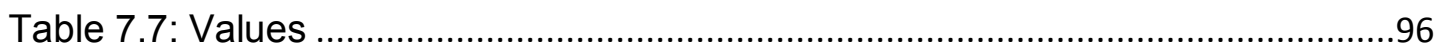

Table 7.8: Values impact on leadership practices ...................................................100 


\section{List of figures}

Figure 3.1: Research design (single-embedded design) .........................................30

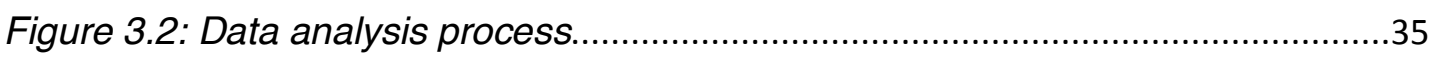

Figure 4.1: School rule, vision and mission (Case: Vama).....................................45

Figure 4.2: Vision, mission and school objectives (Case: Louisa) ............................51

Figure 5.1: School rule of 'shamed culture' (Case: Gerson).....................................58

Figure 5.2: Subject teachers' working group document (Case: Seran)......................64

Figure 6.1: School vision and mission (Case: Fanggidae) ......................................72

Figure 6.2: School vision and mission (Case: Ndoen) ............................................79

Figure 7.1: An example in what ways childhood experiences influence the development of authentic leadership practices.

Figure 7.2: How life experience impacts on the development of authentic leadership and practices.... 105 


\section{GLOSSARY}

ENT/NTT: East Nusa Tenggara/Nusa Tenggara Timur

WNT/NTB: West Nusa Tenggara/Nusa Tenggara Barat

MKKS: Principals' working group/Musyawarah Kerja Kepala Sekolah

MGMP: Subject teachers' working group/Musyawarah Guru Mata Pelajaran

KKG: Teachers' working group/Kelompok Kerja Guru 


\section{CHAPTER ONE}

\section{Introduction}

\subsection{Chapter Overview}

Over the past three decades, there has been increased interest in educational leadership development due to the belief that the quality of leadership may have an impact on school and student outcomes (Leithwood \& Day, 2008; Leithwood \& Levin, 2005). Many approaches have been discussed in relation to the leadership of school principals. Authentic leadership emphasises the importance of morals, values, and ethical issue on effective leadership (Avolio \& Luthan, 2005). Research on school leadership has paid little attention to the possibility of leadership antecedents, trigger events or life experiences that may have impact on authentic practices of school principals.

This chapter provides an overview of this study. It starts with the context for the study and is followed by information about the researcher's background. A discussion of the significance and purpose of the study and the problem it intends to address are then provided. Next, the research questions and the limitations of the study are outlined. The last section provides a description of the organisation of this thesis.

\subsection{Context for the Study}

Indonesia has an area of 1.9 million square kilometres and is inhabited by more than 230 million people. This makes it the world's fourth most populous country and the world's largest archipelago country consisting of more than 17000 islands and more than 500 ethnic groups. The country consists of both urban areas and rural areas, and more than $60 \%$ of the population live in the rural areas. In addition, the country includes 33 provinces, 440 districts or municipalities, 5641 sub-districts, and 71,555 villages (Alwasilah \& Furqon, 2010). The country's official religions include Islamic $(191,303,211)$, Christian $(13,242,316)$, Catholic $(7,846,779)$, Hindu $(4,022,993)$, and Buddhist $(2,789,701)$ (Alwasilah \& Furqon).

The Indonesian educational system is divided into primary, secondary and higher education (Bedi \& Garg, 2000). Primary education starts at the 
age of seven and consists of 6 years schooling. This is followed by 3 years of junior secondary (junior high school) and an optional 3 years of general (senior high school) or vocational higher secondary education. Secondary education leads the way to higher education, which is delivered through a variety of academies, polytechnics and universities.

Nusa Tenggara Timur Province (NTT) / East Nusa Tenggara (ENT) province is one of the eastern provinces in Indonesia, and is very culturally diverse. The five large islands of the more than 100 islands in the province have their own cultural values. Nusa Tenggara Barat (NTB) / West Nusa Tenggara (WNT) is the closest neighbour province of NTT, apart from Bali province. However, all three provinces have different main religions: Bali's population is mostly Hindu, NTB is influenced by Islamic culture, and NTT is mostly Christian. Among the three provinces, NTT province is considered the poorest, least urbanized and possessed of the lowest quality of education (Jones, Nagib, Sumoro \& Handayani, 1998).

\subsection{Background of the Problem}

Between 2009 and 2011, NTT province ranked very low in the overall educational achievement statistics compared to other provinces (Ado, 2013; Seo, 2012). In 2010, the Governor of NTT declared 'National Exam Preparedness' as his educational strategy to improve student outcomes in NTT (Seo, 2010). Another movement was initiated by the head of the provincial educational office in 2011, who declared a strategy called 'Gong Belajar' or 'Time for Learning'. In this strategy parents were expected to support their children to study at home in the evening, and watch no television (Masrafi, 2011). The two strategies, 'National Exam Preparedness' and 'Time for Learning', reflected that the NTT government felt they had a moral responsibility to create a culture of learning for students, parents and school communities in order to improve the quality of education. Educational practitioners, such as school principals, teachers, and lecturers, and other professionals outside educational institutions (for example, women's organizations and the military) have also acknowledged the benefit of those strategies (Napitupulu, 2011; Meba, 2011). However, legislative and educational experts in NTT have claimed that 'National Exam Preparedness' and 'Time for Learning' have not been effective in improving student 
outcomes (Bau, 2012; Mauleti, 2012). Journalists have also argued that those strategies are politically motivated rather than morally motivated, suggesting that; the intention is to simply raise the ranking instead of actually increasing positive learning outcomes for students (Padje, 2012; Rawambaku, 2012).

The head of the provincial education office in NTT and the head of the district educational offices as well as the school principals have been blamed for the low educational results by politicians, education experts and public opinion (Mauleti, 2012; Pietono, 2012). A number of sources in NTT have quoted professional pedagogical developers, national politicians and provincial politicians suggesting that all parties need to be blamed ( $\mathrm{Bau}$, 2012; Rudin, 2012), and arguing that; while teachers and students may be blamed because of their lack of capacity, the main responsibility falls on the government of NTT and the school principals' lack of capacity in meeting academic challenges. Even though educational strategies have been applied to increase moral responsibility in terms of academic achievement, the debate in the media fails to clearly conclude why the poor educational results in NTT have remained the same for a number of years.

Further, there have been corruption cases in educational sectors in NTT province. The former head of the education office in Kupang city (the capital city of NTT province), together with the secretary of the office and other stakeholders including, the head of curriculum divisions, a school principal and a chief of school committee were sent to jail in 2012 because of corruption (Seo, 2013). Local media also reported similar cases in other districts, involving government staff from high-level educational offices as well as staff at schools level. It was headlines news in print and online media that the former Kupang city Mayor was arrested for similar reasons (Dama, 2013), while other media reported that the current NTT Governor was suspected of having misappropriated government funds (Regional Kompas, 2013). Based on these cases, it could be seen that leaders in this particular province failed to be role models for good leadership with a subsequent impact on educational results. 


\subsection{Researcher Background}

Researchers' personal experiences may influence their choice of how they conduct and plan their research (Cresswell, 2009). I have been involved in a number of educational programmes in Jogjakarta, Central Java, East Java, and ENT/NTT provinces during my service for International NGOs and the United Nations in Indonesia. I have been in close contact with a number of government officials, school principals, teachers and students while monitoring programmes. I noticed that successful schools or pilot project schools had responsible principals who 'walked the talk' and had good relationships with all school members and stakeholders. It appeared they had a more 'relaxed' personality, transparent relationships with other people, were less hierarchical and less bureaucratic. This led me to conclude that improving student outcomes must first start from an authentic leader who has a genuine relationship with others.

In terms of NTT province context, even though based on educational statistics in Indonesia the students' achievement was poor, I found a number of schools which were considered as high achieving schools. I formed a belief that these types of schools could be studied to get a better understanding of effective leadership practices. This knowledge could be used to inspire other school leaders to reflect on their practices.

Leadership was one subject I wanted to study at Victoria University of Wellington, New Zealand. An educational leadership course was my first choice when I had to select some courses for my graduate diploma. While I was taking the leadership course, the interaction between the lecturer and the students, as well as the interactions among the students, broadened my knowledge about leadership. Thus, study about how leadership develops caught my attention.

\subsection{Statement of the problem}

The main issue is that the NTT province has had the lowest ranking in the Indonesian educational statistics for the last five years. The strategies of the NTT governor and every head of the provincial education office have developed policies and practices to solve this educational issue. Yet, despite the development of policies and regulations at provincial and district levels, 
implementation is often carried out at school level, meaning that while school level leadership is needed to enhance the desired effects of policies (Fullan, 2007; Hall \& Hord, 2002, as cited in Hallinger, 2011), it is not often addressed by policy. In fact, it is believed that the selection of school principals is often politically motivated, similar to selection processes for other leaders. Besides this, many unethical practices involving educational leaders at districts/municipality level, as well as at school level have been reported, as noted in the previous section. Thus, it is worthwhile studying school principals' leadership practices in the highest achieving schools, and considering what life experiences may influence their practices.

\subsection{Purpose of the Study}

The purpose of this study is to explore how principals' life experiences influence the development of authentic leadership practices. The approach used in this study is a narrative life-stories approach. A case study design will be used to look at the commonalities and differences and main themes in participants' life-stories, as these will likely give insights into the relative significance of factors influencing principal practice. School principals from the two highest achieving elementary, junior high and senior high schools based on the last national examinations in NTT were selected as research participants. Principal interviews and school documents were used as research data.

\subsection{Significance of the Study}

The school principal has always been expected to perform a variety of roles (Hallinger, 2005), and is often generally responsible for what occurs academically at the school level (Robinson, Hohepa \& Lloyd, 2009). School principals' roles can be researched through their practices. Exploring principals' leadership may highlight practices in the higher achieving schools that may not be found in the lower achieving schools and may lead to a greater understanding of effective leadership practices in Indonesian schools. 


\subsection{Research Questions}

The main research question is in what ways do life experiences influence the development of authentic leadership practices of school principals? Sub-questions that will be explored within this research are:

1. What aspects of leaders' life-stories have the greatest impact on their authentic leadership practices?

2. In what ways do these principals practice authentic leadership?

\subsection{Organisation of the Thesis}

This thesis is presented in eight chapters. This chapter provided an introduction for the study. A review of literature relevant to this research is presented in chapter two, including literature on leadership, educational leadership, authentic leadership, leadership development and the life-story approach to studying leadership. Chapter three outlines the methodology used in this study, with a discussion of the selection of a case study research design. Chapters four, five and six present the findings of this research, followed by Chapter seven which presents a discussion of the research findings. Last of all, Chapter eight reviews the research questions and attempts to draw conclusion. 


\section{CHAPTER TWO}

\section{Literature Review}

\subsection{Chapter Overview}

This chapter presents a review of literature that is relevant to this study. It begins with the conceptualisation of leadership to outline the general topic of the study. Secondly, it reviews the literature on leadership constructs; this section includes an explanation of transformational, distributed, and authentic and ethical leadership. Leadership in school settings is discussed in the third section. Next, a review of literature on authenticity, authentic leaders and authentic leadership is presented. In part five, the development of authentic leadership is considered. In the next section, the life-stories approach, as a method to look at authentic leadership development is reviewed. Section seven describes educational leadership research in Indonesian context. This chapter then concludes with a discussion of the gaps in the existing research.

\subsection{Conceptualisation of Leadership}

Researchers usually define leadership according to their individual perspectives and the aspects of the phenomenon of most interest to them (Yukl, 2013). Yukl explains that most definitions of leadership reflect the assumption that leadership involves a process whereby intentional influence is exerted over other people to lead, structure, and facilitate activities and relationships in a group or organization.

A number of definitions of leadership are proposed in the literature. These include that leadership is the ability of an individual to influence, motivate, and enable others to contribute toward the effectiveness and success of the organisation (House, Hanges, Ruiz-Quintanilla, Dorfman, Javidan, Dickson \& Associates, 1999); leadership is the capacity of the leader to influence people working together as a team to achieve an agreed objective within their group (Dickson, 2008); and leadership is a process of influencing other group members to act and think uniquely in the form of indirect or direct interaction (Robinson, et al., 2009). Based on these above definitions of leadership, there are two similarities: the first is influencing 
other people, and the second is working to reach a common goal or a shared vision.

The numerous definitions of leadership appear to have little else in common. For example, for some leadership is considered as a social construction (Dimmock \& Walker, 2000; Southworth, 2002), and for others leadership is seen as a trait, an ability, a skill, a behaviour, a relationship, and a process of influence (Northouse, 2012). Yukl (2013) proposes a further conception of leadership that includes characteristics of the leader. He explains that leaders have particular traits (motives, personality), values, integrity, and moral development. In addition, he proposes that leaders also have particular characteristics such as confidence, optimism, specific skills and expertise, influence tactics, and mental models (or beliefs and assumptions). Northouse (2013) also proposes a trait approach to studying leadership. He describes major leadership traits as intelligence, selfconfidence, determination, integrity and sociability.

\subsection{Leadership constructs}

There are many constructs of leadership discussed in the literature, including transformational, instructional, educational, distributed, ethical, and authentic (Harris, 2008; Leithwood, Jantzi \& Steinbach, 1999; May, Chan, Hodges \& Avolio, 2003; Robinson et al., 2009; Starrat, 2004). A review of these types of leadership will give more insight into the strengths and limitations of these constructs.

\subsubsection{Transformational leadership}

A transformational leadership approach has been applied in an increasing number of studies, not only in traditional fields like management and social psychology, but also in other disciplines such as nursing, industrial engineering and education (Antonakis, 2012). Northouse (2013) defines transformational leadership as a process that changes and transforms people. Further, Northouse emphasizes that this construct is concerned with emotions, values, ethics, standards, and long-term goals. Avolio (1999) notes that transformational leadership is concerned with improving the performance of followers, and with developing followers to reach their fullest potential. Leithwood and Jantzi (2005) reviewed 33 studies including studies by Marks 
and Printy (2003) and Griffith (2004), and found half of those studies showed that transformational leadership had a small influence on student outcomes.

Lynch (2012) describes transformational leadership as relationshipbuilding and establishing good working conditions between a leader and their followers. In contrast, Bass and Riggio (2006) describe transformational leadership as involving charismatic influence, inspirational motivation, intellectual stimulation, and individual consideration. Transformational leaders offer goals that transcend short-term goals, and focus on higher order intrinsic needs (Conger \& Kanungo, 1998). However, according to Day (2003), transformational leadership approaches do not sufficiently mirror current effective leadership practices. Furthermore, Fink (2005) claims that transformational leadership is conceptually flawed. As a result transformational leadership may not be relevant or effective in current educational settings because of its emphasis on the individual leader.

\subsubsection{Distributed leadership}

According to Duignan (2006), distributed leadership is a form of shared leadership that is distributed to key stakeholders throughout the organisation. Similarly, Robinson (2008) explains that distributed leadership focuses on two main concepts; a task distribution and an influence processes. However, Scriber, Cockrell, Cockrell and Valentine (1999) point out that distributed leadership is most likely to be successful when leadership depends not only on personal results based on distributing tasks effectively, but also on a new model of interaction and influence among school staff. Scriber et al.'s research agrees with research conducted by Spillane, Halverson, and Diamond (2004) that found distributed leadership focuses on how school leaders promote and maintain certain conditions for successful schooling, while also maintaining effective interaction with teacher and students and other stakeholders. Empirical research by Harris (2008; 2009) indicates a positive relationship between distributed leadership, organizational improvement, and student achievement. A study by Leithwood, Anderson, Mascall, and Strauss (2012) support Harris's findings that even though modest, distributed leadership could have a significant indirect effect on student achievement. 


\subsubsection{Authentic/Ethical leadership}

Ethical leadership has been described as the willingness to behave based on fundamental rules, beliefs, premises, and values in the leader's ethical ideology (Starratt, 2004). Ciulla (2004) defines ethical leadership as the influence of a moral person who moves others to do the right thing in the right way for the right reasons. Northouse (2012) argues that ethical leadership is about the character of the leader or the qualities, disposition, and core values of the leader. Besides the leaders' character, Northouse's definition includes actions, goals, honesty, power and values of the leader.

Calls for ethical leadership are based on the view that without moral, values centred leadership, educational leaders could be manipulative and exploit others in order to achieve their individual interests (Begley, 2012). Thus, Begley explains that ethical leadership is relevant to environments that are facing ethical scandals in educational issues in order to avoid manipulation and exploitation between educational leaders and followers.

Authentic leadership is defined in the literature as a process that draws from both positive psychological capacities (i.e., confidence, optimism, hope and resiliency) and a highly developed organizational context, and which results in both greater self-awareness and self-regulation (Avolio, Gardner, Walumbwa, Luthans \& May, 2004; Avolio, Luthans \& Walumbwa, 2004). Previous research explains that authentic leaders encompass a positive moral perspective (Luthan \& Avolio, 2003; May, Chan, Hodges \& Avolio, 2003).

Authentic leadership has been described as a foundation construct for other leadership theories, such as transformational and ethical leadership (Avolio \& Gardner, 2005). Other authors describe authentic leadership in terms of what is and is not 'genuinely' good leadership (Avolio, et. al., 2004; Gardner, Avolio, Luthans, May, \& Walumbwa, 2005). Authentic leadership definitions emphasise that the ways leaders lead must be based on values and beliefs and they need to be aware of their strengths and weaknesses (Gardner, Cogliser, Davis \& Dickens, 2011). It is suggested that ethical and authentic leadership emphasise positive and developmental interactions between leaders and followers that are consistent with positive organizational environment (Luthans \& Avolio, 2009) 
These authentic leadership definitions highlight that this type of leadership offers a positive moral perspective and promote values-based leadership. Therefore, any leadership type, whether transactional, transformational, ethical, distributed or instructional may have authentic leadership roots beneath the surface. However, this discussion of leadership has been related to a variety of contexts, and as the research for this thesis was conducted in a school setting, it is important to discuss leadership in an educational setting, specifically leadership of school principals.

\subsection{Leadership in school settings}

In recent years the number of studies on leadership in education settings has increased (Begley, 2012). Educational leadership is defined by Robinson (2004) as leadership of teaching and learning. Others propose a definition of leadership in the school setting as the ability to move the school forward, and concern with long term school strategy (Dunfor, Fawcet \& Bennet, 2000). This section will describe two related leadership constructs, instructional and educational leadership.

\subsubsection{Instructional leadership}

There are challenges in defining instructional leadership due to lack of agreement among the researchers in conceptualising this type of leadership (Lynch, 2012). Early formulations of instructional leadership assumed that this type of leadership is to be the responsibility of the principal (Robinson, Lloyd \& Rowe, 2008). Most studies provide dimensions for instructional leadership roles or behaviour rather than theoretical definitions (Louis, Dretzke \& Wahlstrom, 2010; Reardron, 2011). Hallinger (2001) proposes three dimensions for the instructional leadership roles of school principal: defining the school's mission; managing the instructional programme; and promoting a positive school-learning climate. Instructional leadership may positively relate to student academic achievement both directly and indirectly (Higgins \& Bonne, 2011; Kythreotis, Pashiardis \& Kyriakides, 2010; Louis, et al., 2010; Ross \& Gray, 2006; Wildy \& Dimmock, 2002). Moreover, a review of the impact of instructional leadership on student outcomes concluded that the effects that principals indirectly have on student learning, though statistically significant, is small (Hallinger, 2005). 


\subsubsection{Educational leadership}

Elmore (2004) defines educational leadership as the guidance and direction of instructional improvement, such as overseeing a change of direction sustained over time, and raising the average level of quality and performance. Moreover, the objectives of educational leadership are not only to improve cultural engagement, or to encourage better communication with stakeholders, or to conduct monitoring and evaluation, but doing all those things in order to support teaching and learning (Robinson, 2004). As the literature indicates, educational leadership aims to improve the quality of teaching and learning with a clear direction to sustain long-term school strategies.

There is a large body of research on leadership in school settings focuses on school principals, teachers, students, and parents (Bryk \& Schneider, 2003; Goddard, 2003; Leithwood, 2006; York-Barr \& Karen Duke; 2004). Various studies exploring the impact of leadership on school cultures and performance have concluded that principals play a significant role (Day, Harris \& Hadfield, 2001; Southworth, 1995). School principals have also been shown to make significant contributions to a variety of school outcomes (Hallinger, 2003; Heck \& Hallinger, 2009).

Principal leadership has been studied empirically by Reardon (2011). He concluded that learning centred leadership of school principals enhanced the prediction of student outcomes in reading scores. The highest correlation between leadership and reading score in all three-grade levels was found with respect to high standards for student learning and rigorous curriculum. Reardon's study provides support for the direct impact of learning centred leadership on student learning outcomes. Reardon's study suggests that principal leadership is a significant factor in improving pupils' academic achievement and contains a message for educational institutions to provide adequate programmes for school principals. These programmes should include knowledge and understanding of curricula, pedagogy, and student learning because learning-centred leadership needs very specific knowledge related to teaching and learning and culture of learning and professional behaviour. 
Dunfor, Fawcett and Bennett (2000) suggest a school principal must ensure that: a good communication system is in place; expectations are clear and consistently applied; procedures are unambiguous and fit the purpose; and policies are articulated and appropriate. Robinson (2011) proposes three leadership capabilities to support effective leadership, these are applying relevant knowledge, solving complex problems and building relational trust.

\subsubsection{Impact of leadership on student outcomes}

According to researchers, leadership has both indirect and direct impacts on student academic results (Kythreotis et al., 2010; Louis et al., 2010). Although most educational leadership research concludes that leadership has indirect impacts on student learning (Leithwood, Anderson, Mascall \& Strauss, 2012; Ross \& Gray, 2006; Wildy \& Dimmock, 1993); direct impact of leadership has been found in a number of research (Marzano, Waters, \& McNulty, 2005; Witziers, Bosker \& Kruger, 2003). A study conducted by Silva, White and Yoshida (2011) concluded that principal one-on-one discussions with students had a direct and significant effect on subsequent reading achievement. Based on the recent studies above, it is possible to conclude that leadership has both indirect and direct impacts on student outcome.

Robinson et al. (2009) examined the impact of five leadership dimensions on student outcomes. The dimensions are:

1. Establishing goals and expectations

2. Resourcing strategically

3. Planning, coordinating, and evaluating teaching and the curriculum

4. Promoting and participating in teacher learning and development

5. Ensuring orderly and supportive environment

Robinson et al.'s meta-analysis suggests that dimension 4 has a large effect, while dimensions 1 and 3 have moderate effects and dimensions 2 and 5 have small effects on student outcomes. Robinson et al. (2008) found that the average effect of instructional leadership was three to four times that of transformational leadership. The three capabilities of leadership; applying relevant knowledge, solving complex problems, and building relational trust support the five leadership dimensions derived from the Best Evident Synthesis (Robinson, 2011). 


\subsection{Authenticity, Authentic Leaders and Authentic Leadership}

Many explanations have been given to clarify conceptions of authenticity, from different disciplines ranging from philosophy, sociology, and clinical and social psychology. According to Harter (2002) authenticity has its roots in Greek philosophy, meaning 'to thy own self be true'. Authenticity is also described as a self-referential state of being (Sartre, 1943, as cited in Chan, Hannah \& Gardner, 2005). In addition, Chan et al. argue that authenticity develops in parallel to morality, thus to be inauthentic is to betray one's own relationship with oneself. Authenticity includes a commitment to one's identity and values (Erikson, 1995). In summary, the key components of authenticity include self-awareness, being true to one's self, being selfreferential, and having self-identification that is linked with morality and values.

Gardner, Avolio and Walumbwa (2005) claim that the concept of authentic leadership is perhaps the oldest leadership construct. However, Northouse (2012) explains that authentic leadership represents one of the newest areas of leadership research and is still in the formative phase of development. Duignan (2003) states that authentic leaders have a strong understanding of their personal values. This view is supported by Avolio et al., (2004), who suggest that leaders are fully aware of their own values. In addition, authentic leaders are portrayed as possessing self-knowledge and a personal perspective which reflects clarity in their values and convictions (Shamir \& Eilam, 2005). Moreover, Erickson (1995) argues that by knowing their values, leaders are able to resist social pressures to adjust their values. In summary, authentic leaders are those who are fully aware of how they think and act based on their values, knowledge and strengths, and are aware of how to operate those capacities (Avolio et al.).

Among scholars, there is no single accepted definition of authentic leadership (Northouse, 2013). Multiple definitions have been offered, each written from a different view-point and with a different emphasis (Chan et al., 2005). For example, the definitions of authenticity can be seen through intrapersonal, interpersonal, and developmental perspectives (Northouse, 2013). Authentic leadership from the intrapersonal perspective described by Norhouse focuses on the leader and it incorporates the leader's self- 
knowledge, self-regulation, and self-concept. Shamir and Eilam (2005) suggest that authentic leaders have four characteristics: they are truthful to themselves rather than conforming to others' expectation; motivated by personal conviction, rather than pursuing status, honour or other personal benefits; original and not a copy of other people's behaviour, leading from their own personal point of view, and basing their actions on their personal values and convictions.

An interpersonal perspective suggests that authentic leadership is a relational process created by leaders and followers (Eagly, 2005). The focus of this conception is the reciprocal interactions between leaders and followers (Northouse, 2013). It is suggested that leaders influence followers' attitude and behaviours through key psychological processes such as hope, positive emotions, optimism, and trust (Avolio et al., 2004).

Authentic leadership can be viewed as something that can be nurtured in a leader, rather than a fixed trait (Northouse, 2013). As discussed in the previous section authentic leadership is specifically grounded in the fundamental role that moral and ethical issues play in effective leadership (Avolio \& Luthans, 2005; Hannah, Lester \& Vogelgesang, 2005). As a foundation construct of leadership, authentic leadership is concerned with leader behaviours and characterised by self-awareness, relational transparency, balanced information processing, and ethical and moral perspectives (Walumbwa, Avolio, Gardner, Wernsing, \& Peterson, 2008). Gardner et al. (2005) also identify possible elements of the self that are beneficial to the development of authentic leadership which are selfawareness and self-regulation. Self-awareness according to Gardner et al. (2005) including values, identity, emotions, motives and goals; and selfregulation components are internalized, balanced processing, relational transparency and authentic behaviour.

Authentic leadership has been positioned as the most effective form of leadership because it is value informed and value led and more likely to achieve desired outcomes (Begley, 2003; Day, 2000). Thus it is worthwhile to examine some factors that influence the development of authentic leaders and authentic leadership. 


\subsection{The development of authentic leadership}

Before discussing development of authentic leadership, it is essential to review some significant studies that examine core aspects of leadership development.

\subsubsection{Leader development and leadership development}

Leadership development has emerged as an active construct of theory building and research over the last 10 to 15 years (Day, Fleenor, Atwater, Sturm, \& McKee, 2014). It is important to distinguish between leader and leadership development. Leader development focuses on individual skill development (Day et al.; Northouse, 2012) and has been defined as individual-based knowledge, skills, and abilities associated with formal leadership roles (Day, 2000). Leader development includes self-awareness, self-regulation, and self-motivation (McCauley, 2000). Most studies agree that leader development emphasizes on enhancing personal or individual skill including self-knowledge. Positive role models such as parents, teachers, siblings, coaches or mentors have been asserted as important antecedents of a leader's development (Gardner et al., 2005). Other studies also agree with the idea of role models playing a significant part as antecedents of various types of leadership (Avolio, 2005; Cooper, Scandura, \& Schriesheim, 2005; Smith \& Piele, 2006; Toor \& Ofori, 2008).

Leadership development focuses on a process of development that inherently involves multiple individuals (Day et al., 2014), e.g.: leaders and followers; or among colleagues or peers in a self-managed work team. Unlike individual skill development of leaders' personal capabilities, the emphasis of leadership development is on building networks among people in the organization to enhance cooperation and resource exchange and create organizational value (Bouty, 2000; Tsai \& Ghoshal, 1998). Based on this definition, leadership development creates organizational value that could be achieved through interaction among the members of organizations.

Authors such as Goleman (1995) and McCauley (2000) argue that leadership development consists of developing social awareness and social skills. These authors explain that social awareness includes empathy, service orientation, and developing others, while social skills include collaboration 
and cooperation, building strong connection with others and conflict management. Similarly, Day (2000) argues that social skills and social awareness are effective interpersonal skills required for leadership development.

The importance of relational trust as a relevant skill to develop principal leadership in a pedagogical context is supported by Bryk and Schneider (2003) through their study in an urban Chicago elementary school in the 1990s. Robinson et al. (2009) proposed four capabilities that could a leader should have that could encourage trust: respect for others, personal regard for others, competence in the role, and personal integrity. An Indonesian study by Lolowang (2009) showed the importance of building relational trust between the schools and the communities. Hence, relational trust seems an important skill for a school principal to develop, in order to work with the school community.

\subsubsection{Authentic leadership development processes}

This section identifies and discusses the components of authentic leadership development processes. Northouse (2013) offers two approaches to explain how to become an authentic leader. The first is the practical approach, which is drawn from real-life examples and training and development literature. The second is the theoretical approach, which is based on findings from social science research.

The practical approach proposed by Northouse (2013) draws on two practical authentic leadership approaches by Terry (1993) and George (2003). Terry's approach to authentic leadership is practice and actionoriented and deals with 'how to do' leadership, while George's (2003) approach focuses on building essential qualities of authentic leadership and how individuals can develop these qualities if they want to become authentic leaders. Specifically, George highlights five basic characteristics of authentic leaders: they understand their purpose; have strong values about the right thing to do; establish trusting relationships with others; demonstrate selfdiscipline and act on their value; and they are passionate about their mission.

Authentic leadership processes identified in the literature include positive psychological capacities, moral reasoning, and critical life events (Northouse, 2013). The positive psychological capacities in the development 
authentic leadership proposed by Luthans and Avolio (2003) are confidence, hope, optimism, and resilience. Moral reasoning is the leader's capacity to make ethical decisions about issues of right or wrong and good or bad (Northouse). In addition, Northouse notes that developing the capacity for moral reasoning is a lifelong process. A final factor of authentic leadership identified in the literature is critical life events (Northouse) also referred to as trigger events of life experience or crucible experiences (Bennis \& Thomas, 2002; Gardner et al., 2005; George, 2003). A number of basic factors may significantly contribute to the development of authentic leadership including learning from the past experiences and potential challenges (Cooper, Scandura, \& Schriesheim, 2005).

\subsubsection{Authentic Leadership antecedents}

A perspective on the development of authentic leadership is the significance of leadership antecedents. Gardner et al. (2005) have proposed two antecedents to authentic leadership development: personal history and trigger events. Personal history includes family, childhood, culture, education, occupation, work experience, role models, and prior leadership experiences (Gardner et al.). Further, Hoyle et al. (1999, as cited in Gardner et al., 2005) explain that personal history of life experience is stored as self-knowledge in people's memory and helps leaders to shape their identity. For authentic leaders, a parent, teacher, sibling, coach or mentor are likely to be positive role models who shown high levels of integrity, transparency, and trustworthiness (Gardner et al.). These role models help leaders' personal growth and resulting self-awareness and self-regulation. Trigger events as proposed by Gardner et al. have traditionally been viewed as involving crises and negative events (e.g. loss of a significant person, a health problem, or financial crisis). However, positive events might include a major promotion to a position with expanded responsibilities; a voluntary decision to change careers; an expatriate assignment to a radically different culture; reading a book with a unique view of leadership; or meeting someone who is inspiring (Avolio, 2005; Luthans \& Avolio, 2003). Furthermore, Avolio, Luthan and Avolio explain that certain trigger events in a leader's life can trigger positive growth and development. The literature suggests that personal history and both positive and negative triggers events may continue to shape positive growth and authentic leaders' development. 
Values are learned through socialization processes, and it is important for authentic leaders to know their own values and have internalized those values as part of the self (Gardner et al., 2005). Shamir and Eilam (2005) also suggest that authentic leaders are leaders whose actions are based on their values and convictions. Therefore, in the development of authentic leadership, an authentic leader should become more aware of how their core values support their actions.

Northouse (2013) suggests that authentic leadership is a lifelong developmental process, which is formed and informed by each individual's life story. Cooper et al. (2005) promote genuine interventions for authentic leadership development rather than seminars. Branson (2007) explored the concept of authentic leadership of seven principals in Brisbane, Australia. This study concluded that the development of authentic leadership practices may be achieved by self-reflection in order to increase leaders' knowledge of their personal values.

To summarize, table 2.1 indicates any factors that may contribute to the development of authentic leadership. 
Table 2.1. Possible factors that contribute to the development of authentic leadership

\begin{tabular}{|c|c|c|}
\hline Possible factors & Components & Authors \\
\hline $\begin{array}{l}\text { Practicing authentic } \\
\text { leadership }\end{array}$ & $\begin{array}{l}\text { - Meaning: guiding, values, principles, } \\
\text { ethics } \\
\text { - } \text { Mission: goals, objectives, desires } \\
\text { - } \text { Power: energy, motivation, morale, } \\
\text { - } \quad \text { Structure: systems, policies, } \\
\text { procedures } \\
\text { - Resources: people, capital, } \\
\text { information, equipment, time } \\
\text { - Existence: history and identity }\end{array}$ & Terry (1993) \\
\hline $\begin{array}{l}\text { Building essential } \\
\text { qualities of authentic } \\
\text { leadership }\end{array}$ & $\begin{array}{ll}- & \text { Purpose (passion) } \\
\text { - } & \text { Values (behaviour) } \\
\text { - } & \text { Trusting relationship (connectedness) } \\
\text { - } & \text { Demonstrate self-discipline } \\
& \text { (consistency) } \\
\text { - } & \text { Passionate about their mission (act } \\
& \text { from their heart) }\end{array}$ & George (2003) \\
\hline $\begin{array}{l}\text { Building positive } \\
\text { psychological capacities }\end{array}$ & $\begin{array}{ll}\text { - } & \text { Confidence } \\
\text { - } & \text { Hope } \\
\text { - } & \text { Optimism } \\
\text { - } & \text { Resilience }\end{array}$ & $\begin{array}{l}\text { Luthans and } \\
\text { Avolio (2003) }\end{array}$ \\
\hline Building moral reasoning & $\begin{array}{l}\text { - Capacity to make ethical decision (i.e } \\
\text { right or wrong, good or bad) }\end{array}$ & Northouse (2013) \\
\hline $\begin{array}{l}\text { Building possible } \\
\text { elements of the self }\end{array}$ & $\begin{array}{ll}\text { - } & \text { Values } \\
\text { - } & \text { Identity } \\
\text { - } & \text { Emotions } \\
\text { - } & \text { Motives } \\
\text { - } & \text { Goals. }\end{array}$ & $\begin{array}{l}\text { Gardner et al. } \\
(2005)\end{array}$ \\
\hline $\begin{array}{l}\text { Personal history of life } \\
\text { experience }\end{array}$ & $\begin{array}{l}\text { - } \text { Family } \\
\text { - } \quad \text { Childhood experience } \\
\text { - } \text { Edture } \\
\text { - } \text { Occupation } \\
\text { - } \text { Work experience } \\
\text { - Role models } \\
\text { - Previous leadership experiences }\end{array}$ & $\begin{array}{l}\text { Gardner et al. } \\
(2005)\end{array}$ \\
\hline $\begin{array}{l}\text { Critical event (trigger } \\
\text { events) }\end{array}$ & $\begin{array}{l}\text { Negative events (loss of a significant } \\
\text { person, a health problem, financial } \\
\text { crisis) } \\
\text { Positive events (a major promotion, a } \\
\text { voluntary decision to change careers, } \\
\text { assignment to a radically different } \\
\text { culture, reading a unique leadership } \\
\text { book, meeting someone inspiring) }\end{array}$ & $\begin{array}{l}\text { Gardner et al. } \\
\text { (2005) } \\
\text { Avolio (2005) } \\
\text { Luthans and } \\
\text { Avolio (2003) }\end{array}$ \\
\hline Self-narrative & $\begin{array}{l}\text { - } \quad \text { Personal narrative (i.e life-story) } \\
\text { - Individual/personal life-story }\end{array}$ & $\begin{array}{l}\text { Shamir and Eilam } \\
(2005) \\
\text { Sparrowe (2005) } \\
\text { Northouse (2013) }\end{array}$ \\
\hline Self-reflection & - $\quad$ Regular self-reflection & Branson (2007) \\
\hline
\end{tabular}


Day et al. (2014) identified advances in leader and leadership development in a review of 25 years of research and theory, and noted that self-narrative is an intervention that may be suitable for the development of authentic leadership. Shamir and Eilam (2005) advanced a self-narrative approach in which leaders' self-stories contribute to their ongoing development. Writing personal narratives (i.e., life stories) provides leaders meaning to their life experiences. This approach is similar to that of Sparrowe (2005), who offers an explanation of the narrative process through which a leader's authentic self emerges. Day et al. argue that personal narrative or life story enhances the effectiveness of programme and interventions to increase self-awareness important for developing authentic leaders. Thus, to examine the development of authentic leadership processes, personal narrative or life story is perhaps relevant to identify leaders' life experiences. This approach will be clarified below.

\subsection{Life-Stories Approach}

A life-story is simply an individual's story of his or her life that is considered a significant part of their life (Peacock \& Holland, 1993). In addition, Peacock and Holland note that life-story is spoken word, even if the story is transcribed, edited, and printed. Bertaux and Kohli (1984, as cited in Mann, 1992) describe a life story as an oral autobiographical narrative generated through interaction. Therefore, life story is formed by a personal narrative of personal experience through conversation.

A life-story is not a confession or testimony (Titon, 1980). Life-story, according to the narrative approach, is the manifestation and expression of events as perceived and interpreted by the story-teller (Widdershoven, 1993, as cited in Shamir, Dayan-Horesh \& Adler, 2005). Neisser (1994) argues that life story is constructed and involves thinking more than memory. In life story, construction of reality has less to do with facts and more to do with meanings (Shamir et al.). Through a life-story approach, Shamir et al.'s study found that backgrounds of the leaders for example coming from disadvantaged families, low socio-economic status or minority ethnic group affected their authentic leadership development. In life stories, participants make sense of their past experience and share that experience with others. To conclude, a life story 
approach explores personal experiences which are a meaningful and significant part of the person's life.

Life experience is the most authentic leadership development programme, and leadership interventions are meant to positively accelerate the life's events of the leaders (Avolio \& Luthan, 2005). A life story provides the leader with a self-concept from which he or she can lead, and telling the life story can be part of important leadership behaviour (Shamir et al., 2005).

Shamir and Eilam (2005) offer a life-story approach to the development of authentic leaders. The role of life-story proposed by Shamir and Eilam is as a source of self-knowledge and as a self-justification. Lifestories as a source of self-knowledge mean that life stories can express the storytellers' identities, because they present an internal model of 'who I was, who I am and why, and who I might become in the future' (Shamir \& Eilam, p. 403). Furthermore, Shamir and Eilam note that life-stories may also provide authentic leaders with a self-concept that can be seen through leadership roles.

Life-stories as self-justification mean that through life experiences, leaders may develop a self-concept that supports and justifies their leadership actions. Shamir et al. (2005) studied leaders' autobiographies, while Shamir and Eilam (2005) used the life story method to study leader's experiences. Both studies found similar themes in the development of authentic leaders: leadership development as a natural process; leadership development out of struggle; leadership development as finding a cause; and leadership development as learning from experience. Therefore, the construction of a life-story might be a major element in the development of authentic leaders.

Shamir and Eilam (2005) explain that leadership development as a natural process is found in a leader's life story, for example: leaders who never sought to be a leader, leadership simply came to them. Leadership out of struggle indicates how leaders' stories consist of struggling with difficulties and disadvantages not only for themselves, but also for their groups or communities, i.e., the case of Nelson Mandela (Shamir \& Eilam). Further, Shamir and Eilam explain leadership development as finding a cause found in Anwar Sadat's and Nelson Mandela's autobiographies, where these 
leaders gradually developed their identity and purpose in life. Leadership development as learning from experience found in leader's published and oral life stories has been identified by Shamir et al. (2005). For example, lifestory as a series of training and learning experiences, including learning from failures, mistakes, and positive and negative role models. These experiences became the basis of self-knowledge, lessons learned and conviction for the leaders.

\subsection{Educational leadership research in Indonesian context}

There are three studies in the educational leadership context in Indonesian that relate to the leadership development field. The first study was conducted by a non-Indonesian researcher in NTB Province. The second study was conducted in South Sulawesi, and the third study conducted in Java Island, both by Indonesian researchers.

Atwell (2006) conducted a study in the central Lombok village community in NTB Province, Indonesia, in June 2004. Atwell's study involved designing an Indonesian leadership training programme, by exploring the nature of the design decisions that evolved in leadership perceptions and the dynamics of school programme implementation. After receiving leadership training, participants were asked to conduct reflective activities such as journal writing and other additional activities such as poetry, drawings and photographs. The 15 participants including school principals, teachers and school committees study found that journal writing and site visits were related to positive outcomes in highlighted changes in leadership understanding. In addition, Atwell's study found that photographing leadership activities provided a visual record during a 6 month research period and offered a powerful tool to expand leadership skills. In the Indonesian context, the use of photography and journal writing are considered new methods, apart from site visits that are commonly used in leadership development. As a result of this research in Lombok, the author claims there was a move from authoritarian, hierarchical leadership to school leadership that was shared, dispersed and open to all the school community.

The second study, conducted in nine primary schools in South Sulawesi, Indonesia (Lolowang, 2009), showed that principals' characteristics could be developed through caring with others, learning motivation, 
discipline, role modelling and relational trust in the school environment. In addition, this study found that to build relational trust in the school setting, transparency between the schools and the communities was necessary as without trust, schools' goals could not be achieved. The principal's capacities, such as transparency, cooperation, accountability, and independence were found to be not the only ways to manage the schools, but skills in building relational trust from the principal might also have significant impact on the whole school community. Therefore, building relational trust not only applies in western research (Bryk \& Schneider, 2003), but may also be relevant in Indonesian context.

The third study was an Indonesian model of successful school leadership research conducted in three secondary schools' in Yogyakarta, Java Island (Raihani, 2008). This study found out that the religious beliefs and values of the principals in these schools were very strong and exerted much influence on their leadership practices. Those values were amanah (meaning accountability and responsibility) and Iman and Tagwa (Imtaq) (meaning faith and piety). It is important to acknowledge that amanah, iman and taqwa are underpinning Islamic beliefs, and these values are explicitly stated as one of the Indonesian national education objectives (Departemen Pendidikan Nasional, 2003). Therefore, Raihani's study suggests that accountability, responsibility, faith and piety are some of the school principals' values that influence their practices.

\subsection{Gaps in the research}

The literature on leadership in educational settings tend to focus on the link between principal leadership and student achievement as suggested by Hallinger (2005), Reardon (2011) and Robinson et al. (2009). Many constructs of leadership have been discussed and principal leadership has been found to make a small but statistically significant contribution to student learning (Hallinger; Kythreotis et al., 2010). Robinson et al.'s meta-analysis highlights the importance of school leaders having a set of relevant knowledge, skills and dispositions that support them to be effective principals. Therefore, this current research focuses on the leadership of school principals rather than teachers or students. 
Studies on leadership have suggested that authentic leadership is a foundation for other leadership constructs such as transformational or ethical leadership. Multiple definitions of authenticity, authentic leaders and authentic leadership have been proposed by a number of authors such as Northouse (2013) and Chan et al., (2005). However, a framework of the development of authentic leadership for school principals has not been well developed. Hence, the underlying processes of developing authentic leadership especially for school principal are the focus of this study.

Personal history and trigger events are viewed as important sources in a leader's personal growth and positive development (Avolio, 2005; Gardner et al., 2005; Luthans \& Avolio, 2003). These studies provide insight into how positive and negative experiences may impact on the leaders' personal development. However, most studies in the development of authentic leadership are conducted in business settings, and focus on managers or CEOs (Shamir et al., 2005; Shamir \& Eilam, 2013). There is a lack of information on how trigger events impact on educational leaders, especially school principals. Moreover, George's (2003) and Luthans and Avolio's studies are conducted in western societies, and may reflect western characteristics and capacities of authentic leadership. These raise a question, whether those characteristics and capacities may apply in principal leadership practices in an Indonesian context.

A number of authors explained that authentic leaders have strong understandings of their personal values (Avolio, et al., 2004; Duignan, 2003; Shamir \& Eilam, 2005). By knowing their values, leaders are able to resist social pressures to adjust these values (Erickson, 1995). Research on leadership and authentic leadership values has been conducted in Australia and Indonesia (Branson, 2007; Raihani, 2008). The values of the school principals in the Australian study were different from the values in the Indonesian study. The values in the Indonesian study were underpinned by Islamic belief, while people in NTT province are mostly Catholics or Protestants. This raises the question of whether the values of the principals from Raihani's (2008) study are similar to values of school principals in NTT province, and how the values influence on their leadership practices. 
Thus, this thesis intends to explore principals' life history in order to examine in what ways principals develop and practise authentic leadership.

\subsection{Chapter Summary}

This literature review has provided a discussion and analysis of concepts including leadership, educational leadership, and authentic leadership as well as authentic leadership development. The links between school principal leadership practice and students' outcomes were discussed. Leadership practices and studies on authentic leadership processes were also reviewed. Lastly, this literature review has established gaps in the literature in the area of authentic leadership for school principals, and authentic leadership processes that explore leader's life history and values particularly in an Indonesian context. 


\section{CHAPTER THREE}

\section{Methodology}

\subsection{Chapter Overview}

This chapter outlines the research methodology. First, the philosophical worldview and research design will be explained. The second section explains the use of case study as a research strategy. Next, the research methods including the setting and the participants will be described. Then, methods of data collection and analysis will be presented including the interview procedure, document analysis and data analysis. Following this, trustworthiness and ethical considerations will be explained. Lastly, research limitations will be discussed.

The main research question addressed by this thesis is: in what ways do life experiences influence the development of authentic leadership practices of school principals? Sub-questions that will be explored within this research are:

1. What aspects of leaders' life-stories have the greatest impact on their authentic leadership practices?

2. In what ways do these principals practice authentic leadership?

\subsection{Philosophical Worldviews and Research Design}

Creswell (2009) uses the term 'worldview' instead of research paradigm to describe a basic set of beliefs that guide action. A worldview in research explains a general orientation about the world and the nature of research that a researcher holds such as post positivism, constructivism, advocacy or participatory, or pragmatism (Creswell).

This study was conducted within a social-constructivist worldview. Social constructivists hold assumptions that individuals seek understanding of the world in which they live and work (Creswell, 2009). Applying a social constructivist worldview, the researcher will "rely as much as possible on the participants' view of the situation being studied" (Creswell, p. 8). Thus, in a 
social-constructivist worldview, the researcher assumes that individuals seek understanding about the world by making subjective meaning of their experiences.

There are two main reasons a social constructivist view is taken in this current research. First, a social constructivist researcher focuses on the specific contexts in which people live and work, in order to gain more understanding about the historical and cultural setting of participants (Creswell, 2009). A social constructivist perspective suits the nature of my research approach, which is a life-stories approach. Secondly, in a social construction worldview, the researchers often use open-ended questions to study the phenomenon (Creswell). A social constructivist worldview is relevant as the research participants have specific attributes as school principals, and work in a province that is historically and culturally different from other neighbouring provinces.

This research takes a qualitative approach in order to explore the influence of life experiences on authentic leadership practices. Unlike quantitative research, qualitative research relies on reasons behind various aspects of behaviour (Yin, 2003). In addition, Yin explains that qualitative research investigates the why and how of decision-making, as compared to what, where, and when of quantitative research. There are two main reasons why qualitative methods were used. First, qualitative research enables the researcher to explore and develop an understanding of the meaning individuals assign to a social phenomenon (Creswell, 2009). In this study, qualitative research design helped the researcher to explore participants' life stories. Second, previous research on life stories has used more qualitative research than quantitative research (Shamir \& Eilam, 2005; Shamir et al., 2005; Peacock \& Holland, 1993). Many authentic leadership measurements have been developed using quantitative methods such as Authentic Leadership ( $A L)$ scales or questionnaires (Goldman \& Kernis, 2002; Toor \& Ofori, 2009; Walumbwa, et al, 2008), however, as this research did not investigate the degree of leader's authenticity, quantitative research was not appropriate. 


\subsection{Case Study as a Research Strategy}

This study took the form of a qualitative case study. Case study is one out of five examples of qualitative designs proposed by Creswell, Hanson, Plano and Morales (2007); the others are narrative research, grounded theory, phenomenology, and participatory action research. Other researchers argue that case study is not a methodology but a research strategy (Denzin \& Lincoln, 2005; Merriam, 1998; Yin, 2003). A case study was most suitable to address this current research question about how life experiences influence authentic leadership development and leadership practices of school principals. In a case study, a researcher may focus on a single individual, several individuals separately or in a group, a programme, events, or activities (Creswell, 2012). In this research, the case study included several units of analysis: elementary school principals, junior high principals and senior high school principals.

Yin (2003) argues that one unique characteristic of case study is to build a deeper understanding of the context of the case and to rely on multiple data sources. Similarly, Creswell et al. (2007) explain that in a case study, multiple sources of information such as observations, interviews, audio-visual resources, and documents can be included. In order to present in-depth understanding of the cases, this current study used not only interviews, but also school documents.

There are four types of case study design proposed by Yin (2003): single-case (holistic); single-case (embedded); multiple-case design (holistic); and multiple-case designs (embedded). Based on Yin's theory, single case represents the critical test of a significant theory, while multiplecase designs have been considered a different "methodology" from singlecase studies, for example doing a set of "comparative' studies" (p. 46). This current research applied a single-case (embedded) design, as illustrated in the figure 3.1. 
How life experiences impact on leadership practices

Case of School Principals in the highest achieving schools in Nusa Tenggara Timur

\begin{tabular}{|l|l|l|}
\hline Principal 1 & Principal 3 & Principal 5 \\
\hline \hline Principal 2 & Principal 4 & Principal 6 \\
\hline
\end{tabular}

Figure 3.1: Research design (single-embedded design)

Figure 3.1 illustrates the phenomenon being studied. First, this research explored how life-story influences authentic leadership development. Second, this present study discussed how life story impacts on leadership practices. Third, the units of analysis in this current study are six individual school principals from the highest achieving schools. The leader's life story includes family influences, role models, early life challenges, and educational and work experiences. Within the life story, authentic leadership antecedents (personal experiences and trigger events) were identified and linked with leadership practices.

\subsection{Ethical consideration}

Ethics approval was obtained from the Victoria University of Wellington Human Ethics Committee (appendix A) to ensure that ethical considerations were met, including protecting the participants' confidentiality. After approval of the ethics application, permission was sought and given by the Governor of NTT. The next step was coordinating with the head of secondary school division at the Provincial Education Office of NTT to select the schools and then the principals. Principals from elementary schools, junior high schools and senior high schools were sent invitation letters and consent forms. All principals could choose whether to participate in this research and needed to sign a consent form. I made it clear that they could withdraw their participation at any time before the data analysis stage. Participant 
permission to access school documents such as school plans, school rules and policies was sought. For ethical reasons, digital recordings were saved securely and used for this research only. Pseudonyms were used to refer to the principals to protect their identity. At the end of each interview, I gave small gifts from New Zealand to each participant as a form of appreciation.

\subsection{Research Methods}

This section will explain research methods including the setting, the participants, and the forms of data collection, data analysis and interpretation. The selection of the principals from the six highest achieving schools in NTT Province, the way interviews were conducted and the collection of school document will be explained as wells.

\subsubsection{The Setting}

This research was conducted in the province of NTT, one of the eastern parts of Indonesia. This province has 4684 elementary schools, 1128 Junior high schools and 325 Senior high schools. At the end of each level, the sixth grade in elementary schools, third grade in junior and senior high school, it is compulsory for students to participate in national examinations. My research involved two school principals from the two highest achieving schools at each level. The highest achieving schools were selected from the national examination results in 2013. National examination in Indonesia is usually conducted in May each year, and thus I obtained the results in early June 2013.

\subsubsection{Schools selection and principals selection processes}

There were two steps in selecting research participants, the first was school selection, which was followed by school principal selection. Selection of the schools was made through provincial education rankings (based on the 2013 national examination results). I made an official request to the head of the Provincial Education Office in NTT for the list of schools based on educational ranking at all levels (appendices $\mathrm{H}$ and I). Through the provincial data, I selected the best and the second best elementary schools, junior high schools and senior high schools. 
One inclusion criteria was that the schools had to be public schools. According to Bedi and Garg (2000), the majority of students in developing countries are educated in public schools. In addition, Jimenez and Lockheed (1995) claimed that almost $90 \%$ of all primary and $70 \%$ of all secondary enrolments in developing countries are in public schools. My decision was also based on the suggestion from an educational expert from NTT, that private schools typically have better facilities, more qualified teachers and the students come from the middle to high socio-economic family backgrounds which did not reflect the majority people of NTT. My supervisor agreed with this suggestion, therefore all private schools were taken off the list.

Six schools were selected through the inclusion criteria. At elementary level, I selected the first and second ranking from the public schools. At junior high school level, the first ranking based on the 2013 national examination was a private school, and I had to use the second and the third placed schools. Likewise, at senior high school level, the first four ranking were private schools, and thus I had to choose the first two highest public schools from the list, which were actually ranked fifth and sixth.

An inclusion criterion for participants was the length of their principalship (a minimum of 2 years). The reason for this criterion is that the school principals should not be 'new' to the school or be a less experienced leader. Prior to selection, I discussed with the authority the school principals' details, including the duration of each principalship. Five of the six schools selected had principals with more than two years in leading their schools. One senior high school principal had less than two years in the selected school, therefore, I chose the principal of the next school on the ranking list.

After selecting all six school principals, I sent an information sheet together with a consent form, via courier to those potential participants (appendices $B$ and $C$ ). I received confirmation in around 3-4 days via short message service on my phone. I then called to introduce myself and discussed the time I would visit the schools and bring the relevant documents (a research permission signed by the authority, a leadership reflection sheet, a list of values and a list of interview questions, (appendices D - G). I allocated one day to visit all schools in order to bring the relevant documents 
and decided on a time to conduct the interview. I visited all six schools and gave a brief introduction to the school principals. We arranged the interview schedule, and I collected the consent forms.

\subsection{Data Collection}

Data was collected through a leadership reflection sheet, individual in-depth interviews with the participants and from relevant school documents. The interviews focused on the principals' life stories and how these stories had affected on their leadership capacity.

\subsubsection{Interviews}

A researcher can gain in-depth understanding of participants' thoughts and beliefs about a topic through the interview process (Johnson \& Christensen, 2008). Semi-structured interviews are flexible, allowing new questions to be brought up as a result of what the interviewee says (Chirban, 1996; Wahyuni, 2012). I used semi-structured interview questions to encourage participants to express their leadership reflection. Reflection has the potential to enhance leadership ability through evaluating the significance of their experiences from a leadership perspective (Densten \& Gray, 2001). Interview questions in this study were of two kinds: the first were about life-story and the second about leadership practices. I began all interviews by asking about leadership reflection they had drawn.

The lists of interview questions were developed through summarizing a variety of literature (appendix $G$ ). The life-story questions were drawn from the work of Shamir and Eilam (2005) and Gardner et al. (2005) and focused on leadership antecedents, influential people, values and beliefs, and opportunities and challenges from the past events. Leadership practices questions were influenced by leadership dimensions (Robinson, 2011; Robinson et al., 2009). These included exploring the principals' goals and strategies, the quality of teaching, professional development and ensuring an orderly and safe environment.

All interviews were conducted in the third week of June 2013. Each interview was between 45 - 80 minutes long, digitally recorded, and took 
place at the principals' offices. All interviews were conducted in Bahasa and the local dialect. The interviews were digitally recorded and transcribed by a transcriber (appendix J). The transcriptions were sent back via email to all participants to check for accuracy. Two out of the six participants added information and one participant asked me to delete some details.

\subsubsection{Document analysis}

Other data were collected through document analysis. The procedure in collecting the school documents varied depending on the interview process. For example, if during the interview process, the principal mentioned that she/he developed school plans and the school's policies, after the interview finished, I asked the principal for access to the plans and school policies. Another example was when the principal mentioned that they had been involved in a specific professional development-working group; I asked whether they had the written document related to the group's activities. These data were contributed to an understanding of how the leaders' lifestories affected their leadership practices.

\subsubsection{Data Analysis}

Data analysis can be defined as the process of bringing order, structure, and meaning to the mass of collected data (Marshall \& Rossman, 1989, as cited in Wahyuni, 2012). Data analysis according to Yin (2003) consists of examining, categorising, tabulating, testing or recombining both quantitative and qualitative to address research objectives. Moreover, Yin (2003) argues that every case study should have a general analytic strategy, such as theoretical propositions, setting up a framework, or developing case description. According to Yin, analysing case study data is difficult because the strategies and techniques of this research design have not been well defined. Yin offers a theory to analyse data derived from a case study; this process includes reflection on a set of research questions, reviews of the literature, and creation of new hypotheses or propositions.

Braun and Clarke (2006) argue analysing qualitative data needs an accessible and theoretically flexible approach, such as thematic analysis. Although, thematic analysis is not well developed and rarely acknowledged, it 
is widely used in qualitative research analysis (Braun \& Clarke). Advantages of thematic analysis, according to Braun and Clarke include; its flexibility; it's easy of use; the accessibility of results to the educated general public; and usefulness for producing qualitative analyses suited for informing policy development. These advantages suggest that thematic analysis offers a broad range of analytic options. One of the advantages of the relevance to this study is the possibility to inform policy developers.

Therefore, this current research used thematic analysis to describe how data has been analysed, as shown in figure 3.2.

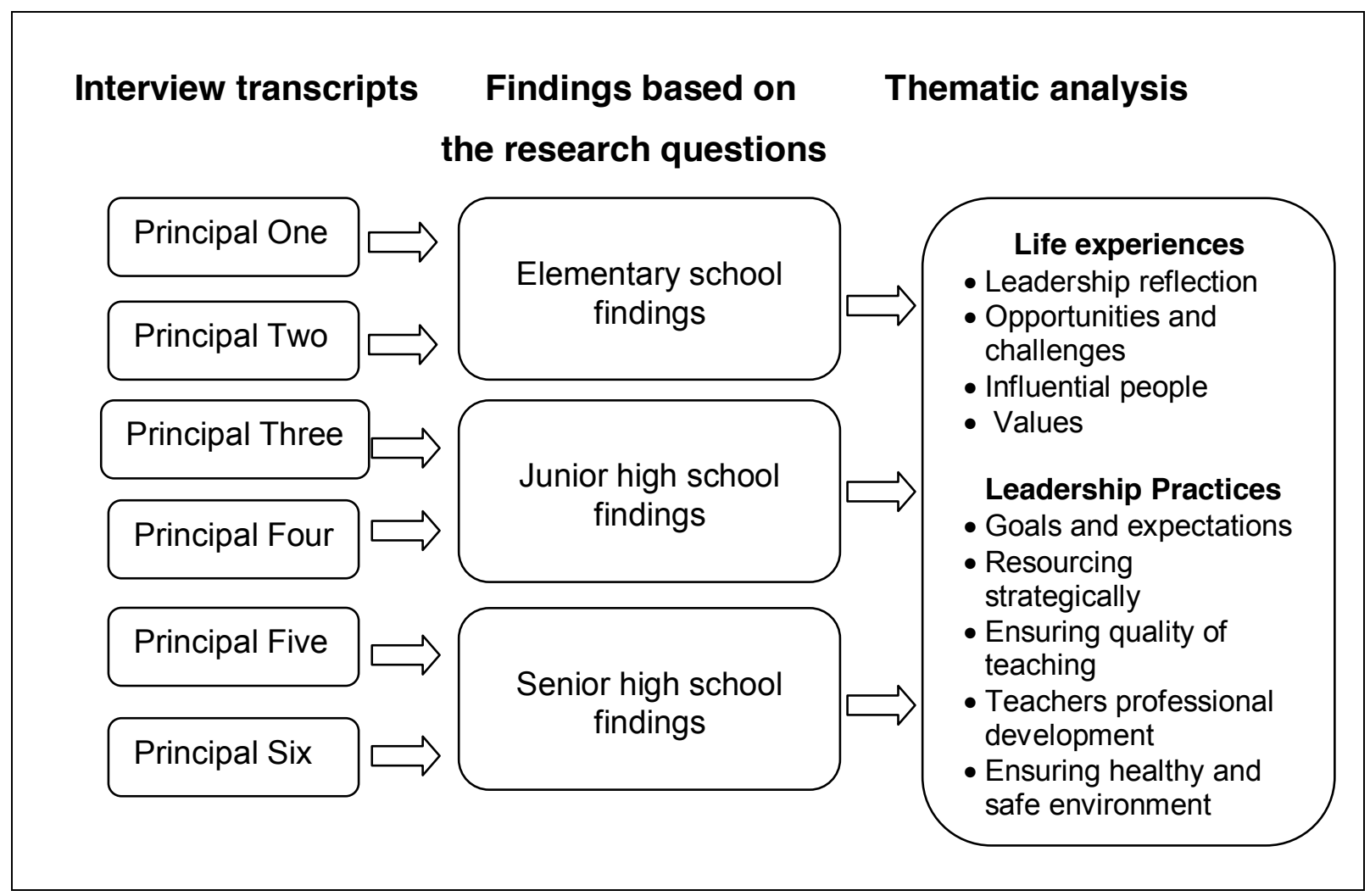

Figure 3.2: Data analysis process

After interview transcriptions were completed, necessary changes and additions were made based on participants checking for accuracy. Next, the findings from the research questions were identified. Each transcript was read through three times during this process and different markers were used each time to identify relevant themes (see appendix $\mathrm{K}$ for an example of the coding process). Next, the findings were organized according to the different levels of elementary school, junior high school and senior high school. To help organize the findings, tables were developed manually for each 
participant (appendices L - Q).

When a list of emerging themes was identified, I merged and renamed some codes, and kept some codes, while also revisiting the literature. This process reflects Bryman's (2008, as cited in Floyd, 2012) suggestion that a list of emerging themes be identified while the researcher revisits the literature. Therefore, these themes were analysed and contextualised in accordance with research questions and relevant literature review.

\subsection{Trustworthiness}

Qualitative research approaches are often criticized because of their lack of rigor and credibility (Decrop, 1999). It is suggested that researchers take into account the criteria of trustworthiness to increase reliability and validity in their research (Decrop). Cresswell and Miller (2010) suggest member checking and triangulation; while Johnson and Christensen (2008) suggest low-inference descriptors as procedures to increase the trustworthiness in a research.

Member checking was used in this study prior to the data analysis stage. According to Lincoln and Guba (1985, as cited in Creswell \& Miller, 2000), member checking is the most crucial technique for establishing credibility in a research. This can be done by taking data and interpretations back to the participants, so that they can confirm the credibility of the information and narrative account. I sent the interview transcripts to all the participants via email, and they replied back with comments, clarification or suggested deletions.

I also used triangulation to increase validity of the data. According to Decrop (1999), triangulation means looking at the same phenomenon or research question from more than one source of data. Data triangulation involves the use of a variety of data sources in a study, in this study, interviews were used to collect the primary data and school documents were also collected as secondary data.

I then used low-inference descriptors to write the research report and to increase the accuracy of my findings. Low-inference descriptors help the 
reader experience the participant's own words such as actual language, dialect and personal meaning (Johnson \& Christensen, 2008). In this research, for example, a participant used the terms of irama (rhythms) and tidur (sleeping). It is common in Indonesia to use these terms to explain that working environment or people performance is not effective and efficient, thus, they were kept in the findings and discussion chapter.

\subsection{Limitations}

This study has several limitations. As a project undertaken in fulfilment of the requirements for the degree of Master of Education, this study is limited in scope and size due to the length of the research study.

First, the sample is based on the six highest achieving school principals in each level: elementary schools and junior secondary schools (junior high and senior high schools) in NTT Province, and as a result the findings may not necessarily be generalised to a broader population or other schools such as low achieving or intermediate achieving schools. This choice was made to develop an in-depth understanding of each school principal's life experiences, because as described by Creswell et al. (2007), with more participants within case study design, the less detail a researcher has to develop meaning.

Second, it looks only at the school principals' self-report by describing their life experiences, and school documents, as a result, no other sources were collected (such as teachers' or students' perceptions about their school principals' leadership practice). There are several potential disadvantages and advantages to self-report proposed by Barker, Pistrang and Elliott (2002), including that the data will only rely on the person being studied and thus may bear little relationship to 'reality' as seen by the researcher or others. Moreover, people are not always truthful; they may deceive themselves and the researcher. Research participants may not be able to provide the level of detail that the researcher is interested in. The great advantage of self-report proposed by Barker et al. (2002) is however that it gives the respondents' own views directly; it gives access to phenomenological data, which are unobtainable in any other way. 
Furthermore, self-report methods can be used to obtain information in situations where observational data are not normally available.

\subsection{Chapter summary}

This chapter has outlined the research methodology used in this study. The choice of social construction and qualitative design using case study has been justified. The research methods including inclusion criteria for selecting the schools, and the participants have been considered. The data collection processes of interviews, document and data analysis have been explained. The used of low inference descriptor for the research trustworthiness was evaluated. Ethical consideration, including the participant selection process and how to protect their confidentiality were justified. Lastly, the research limitations were discussed. 


\section{CHAPTER FOUR}

\section{Elementary School Findings}

\subsection{Chapter Overview}

This chapter presents the findings from the two elementary school principals from high achieving schools in NTT Province. Results from the interviews will be presented for Principal One (Vama) and Principal Two (Louisa) based on the interview questions. The findings for each principal are presented either in relation to the themes that emerged from either the life-stories or leadership practices. In order to explain each theme, quotes from the interviews are provided. The findings from their life-stories will be presented through description of learning from experiences, past opportunities and challenges, influential persons and values. The findings will be presented according to the five dimensions of leadership proposed by Robinson (2011): establishing goals and expectations; strategies to achieve the goals; ensuring the quality of teaching; involving in the professional development; and providing an orderly and safe environment.

\subsection{Case one: Vama}

Vama is a female elementary school principal, 54 years old who leads 392 students and 23 teachers.

\subsubsection{Life experiences}

When Vama explained her leadership journey, she mentioned two particular leadership experiences. Firstly, she was one of the committee members on a teacher-working group, and secondly she was a team member of the examination development team at district and provincial level. Vama explained that she had a wide range of coordination with other teachers as well as district and provincial government officials.

Vama shared both positive and negative experiences when she was working at her first school as a teacher, and in her current school. She also discussed the dilemma of balancing her teaching career and her family. She spoke of how she sacrificed her valuable family time participating in the exam development team: 
It was the amount of time I spent that made my husband unhappy sometimes. He used to say: You can sleep in your office if it is difficult for you to come home on time. I replied: This is about trust from the Provincial Education Office for me. Not all teachers have been invited to do this job. This is an honour to be part of the team. But, other than that, he said he support me $100 \%$.

When Vama was asked whether all the activities in the teachers' working group had enhanced her leadership skills, she explained that she never thought to become a leader, particularly a school principal, however, she felt blessed to be a principal. She understood that the government appreciated her work, thus she was assigned the position of school principal. She was unsure whether she would become a good principal:

I never thought of being a leader, never imagined. I never thought to be a school principal, but now it is a grace and blessing to be a school principal. Maybe they (the government) evaluated my work and appreciated it. If you ask me, why I become a school principal, honestly I never thought about it and was a little bit worried whether I can be a good principal or not.

When Vama was asked what challenges she had on her first principalship, she explained that there wasn't a smooth transition between her and the previous principal. It took her more than a year to change the school environment.

I think, it is because it had been too long that the 'rhythms' of the school was too slow...It's like they had been 'sleeping' for a long time, and then when I came, I woke them up. It wasn't nice in the beginning, but finally I could push them (the teachers) to compete fairly with each other's teachers within the school. My second and third year of principalship in this school got better: We participated in the school competition at district level, and we had higher student test results until 2007/2008

Vama had difficulties when leading her first school, as the previous school principal was not a strong leader. When Vama said that the rhythm was too slow, she meant that teachers were not effective and efficient. Vama needed to make personal approaches to the teachers, and it took a year until the teachers were aware that they needed to change their teaching to be more effective and more focused on students' results.

The most influential role model for the principal was her husband. Vama was influenced by her husband's characteristics, which she considered as being patient, not easily irritated and always thinking positively. Those 
characteristics influenced her behaviour, and thus in many ways at school, she always remembered to keep calm if something made her feel uneasy when handling problems:

My husband is my primary influential person. He inspired me a lot in many ways. For example once a parent came to the school and complained about something that made me felt uneasy, or another time one teacher punished a student which made the parents angry and they complained to the school. Those situations made me uneasy. My husband is the one who always calms me down and motivates me a lot to keep focused on my work.

When Vama was asked 'what do you think your values are', she mentioned more than 10 values. However, when I asked her to think more about which one of the values was the most important value for her, she replied that it was self-discipline.

Vama explained that every action started from self-discipline, and that to work with teachers, students, and parents, self-discipline is important. Self-discipline could support other values such as patience, challenge, trust, and achievement. She also mentioned other values such as honesty, coordination, strength, productivity, and humility.

\subsubsection{Leadership Practices}

When Vama was asked what her goal was in order to get higher student achievement, she explained three main points: to make an effort, to be creative, and to be motivated. This was not only to motivate herself, but also to motivate the students to avoid failures. Vama explained that everyone could fail, however, if people make an effort in what they want to achieve, they need try to be successful.

Furthermore she gave her philosophy in working together with the teachers and the students:

My goal is when we work together; we strive together so that we can succeed together. On the other hand, if the students fail, it means the teachers also failed, and automatically the principal has failed.

Vama expressed her thoughts about the urgency of working together to reach goals. Her understanding of success and failure were always connected with her students and her teachers. For example she explained, "success is also domino a effect from principal to the teachers and to the students". 
When Vama was asked about her strategies to achieve the goals, she first described the daily morning prayer at her school. Further Vama explained other strategies she saw as important, such as achieving all indicators from the daily learning plans in a day, homework strategy, book availability and qualified teachers. All strategies were closely related to academic achievement. For the first strategy, she explained below:

If one day, there were three indicators which should be achieved for a subject, but the teacher only finished two, and one indicator couldn't be achieved, I asked the teacher to take 30 minutes extra to finish the indicator. I prefer that teachers finish all the learning indicators that day, rather than leave one indicator to the next day/the next session. I emphasize this to all teachers here. I have told them this is good for them and good for the students not to fall behind in their works.

The second strategy was aimed at increasing the students' understanding of their subjects. Formerly, the teachers had been giving a lot of homework. Vama asked them not to give the students more homework than they could successfully complete.

I have my own opinion about homework. Students should not be given too much homework. The important thing is that the students master the subject. What is the point of giving them 20 tasks if they can only finish 5 of them correctly?

She explained that her students have the potential to achieve academically. In her first year, even though none of her students won an academic competition at the national level, they at least represented the NTT province.

Another strategy explained by Vama related to book availability. She emphasised her policy that the textbooks for the students and for the teachers were compulsory. She explained when parents have high awareness of the importance of books; they would buy them without government assistance.

Vama mentioned two strategis to ensure the quality of teaching; monitoring and supervision. However, she added that she also did classroom observation together with the school supervisors in order to maintain teaching learning quality at her school.

Usually, when I am doing observation, I coordinated with the responsible school supervisor for this sub district. We have a format from the supervisor. Sometime I did it before the school supervisor 
came to our school, so that I can give the teachers some inputs. And then I can show what my findings during the observation to the school supervisor. At the end, after the school supervisor also did observation in other time, we could compare the findings. That's what I did to maintain the quality of teaching in this school.

Vama stated that she encouraged all teachers to join the teachers' association in their district. There is one teachers' association called Kelompok Kerja Guru (KKG) or teachers' working group. This was one of the government strategies to improve teachers' performance in the classrooms. The teachers' working group meetings in the principal's sub-district was well attended and conducted regularly, as she explained:

It works regularly, besides that we have principals working group (well known as MKKS in Bahasa)...Talking about training, I usually divided the teachers in each level to participate in the training, for example: we were invited to join the training in provincial level, I sent all teachers in grade 6, and then if there is another invitation, I would send all teachers in grade 5. Things like that, but sometimes it depends on the organizer of the training, sometimes the invited teachers from early grades (grade 1 or 2) or teachers from grade 3 or 4 . It depends.

When Vama was asked about her involvement in the principals' working group, she told me that she participated in this group. This group was similar with teachers' working group that was running regularly in their sub-district. Further she explained the kind of activities conducted during this group meeting:

The forum is mostly to evaluate our works and performance among the school principals. When we need to write a report to the educational office, we usually worked together to prepare the report. Sometime we wrote a joint report in our sub-district. In this forum, we also discussed about annual plans for our group, such as when we will conduct an exam try out, when we will celebrate Christmas in our sub district, etc. So, obviously are not all about academic issues but also some social issues we discussed in this forum

When Vama was asked whether she ever shared her problems in this working group, she said that she did not have any problems but more challenges, such as how to encourage all teachers to be punctual and disciplined, which were faced by other schools as well. She also included two recent major problems raised during the meeting with other school principals. First, some teachers have financial problems (in debt with the government), 
and secondly some provocative teachers led a protest or demonstration to the district government.

Vama confidently stated that her school was safe for all the school community. She explained that her school had a good quality relationships with the parents and the school committees in relation to school plans and implementation. Vama explained that the school committee was very supportive and she expressed how happy she was working in this school.

I enjoy working in this school, especially when we have a good planning as discussed with the school committee. All school plans are agreed by the committee, the parents and the school committee never said NO to our plans. This is one of my satisfactions working in this school. So, with coordination with parents and the school committee, if we succeed it means we succeeded together, or if we fail, we failed together.

When discussing her staff, Vama indicated that most teachers at her school were around $23-24$ years old. She suggested that this could be one of the key factors in the fact that she could easily manage her teachers. She was confident when emphasising that her teachers had good spirit because they were still young.

Vama suggested that the school was safe because they did not have any 'dangerous' facilities inside the school and the school was located in the army compound area. She also explained that her school had good coordination with the community health centre located not far from the school. Further she explained that the paramedics and the doctors visited her school almost every month to check students' health and environment.

\subsubsection{School Documents}

In her leadership practices, Vama mentioned that she had a good relationship with the parents and the school committee, thus the school vision and mission was requested in order to see how if reflected relationships between the school and the parents and school committee, as shows in figure 4.1 . 


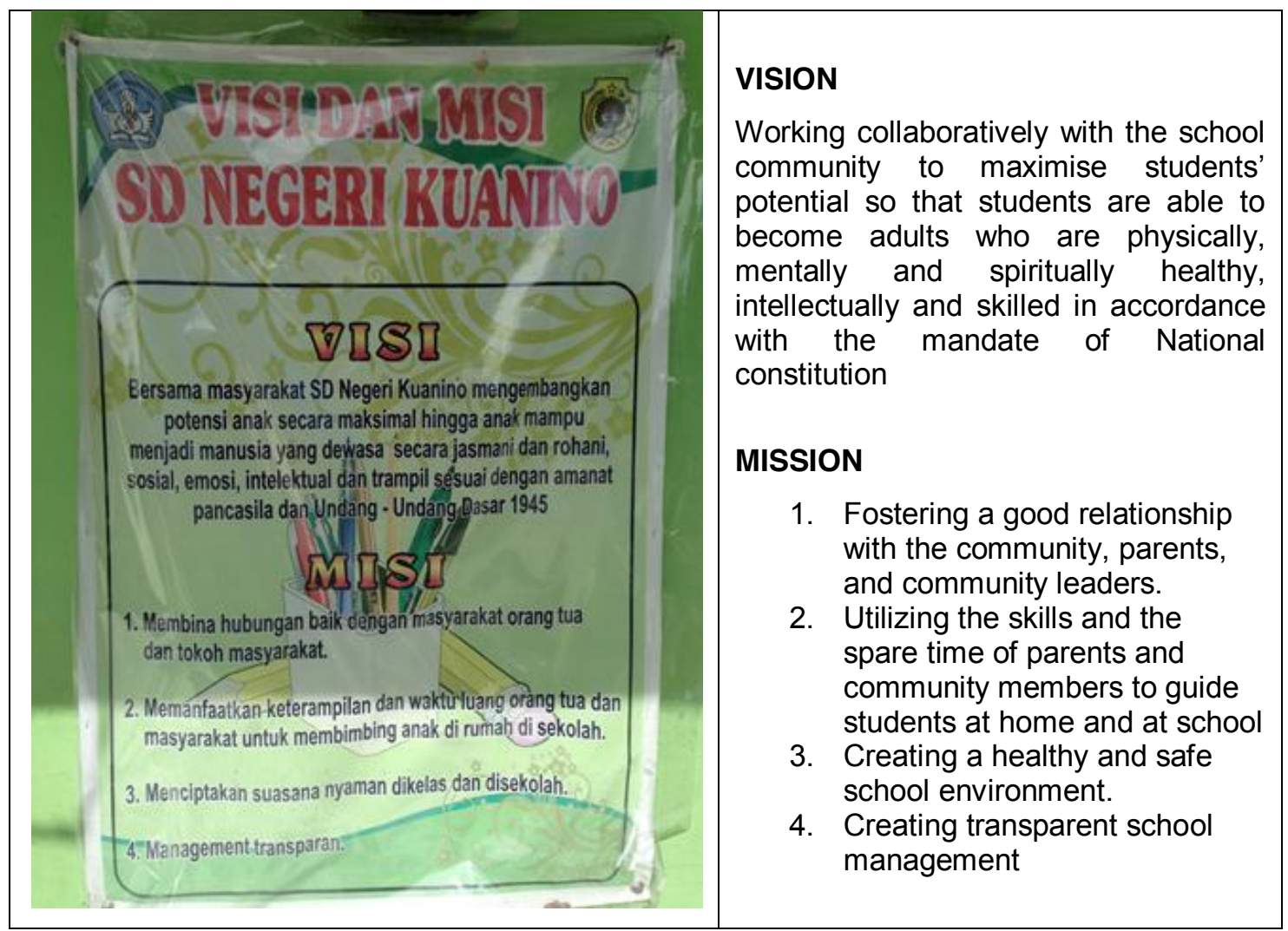

Figure 4.1: School rule, vision and mission (Case: Vama)

There appear to be coherence between Vama's leadership practices and the school vision and mission, in terms of working with parents and the school committee. Vama explained that she coordinated well with parents and the school committee, while in the school mission; it states that this school is fostering a good relationship with the school community, parents and community leaders.

\subsection{Case: Louisa}

Louisa is a female elementary school principal, 49 years old, and led 21 teachers with 265 students. It appears that Louisa's school is limited in its school building and its facilities.

\subsubsection{Life experience}

Louisa is a female elementary school principal in one of the rural sub-districts in a low social economic area. Her leadership skills developed when she was a teacher at elementary school, where the school principal often assigned her to attend principal meetings on his behalf. 
The district's school supervisors approached Louisa four times, beginning in 1999, to participate in the school principal selection and she agreed to join in 2009. The reason she could not participate in the selection process earlier was because her husband did not allow her to. She joined the test after her husband passed away.

Louisa was involved in social and religious activities outside the school. Her late husband was a police officer and as a police officer's wife she was actively involving in an association that conducted social events at the police compound. She was also on the jury for Indonesian Independence Day competitions and took religious services at the church. She considered herself as a strong Christian believer, thus in 2010 she received a 'gift' from the church to visit Jerusalem.

When Louisa was asked about her leadership experience, she described how she had developed leadership capacities. First, she explained that she had a high level of motivation to do a variety of jobs. Thus, she did not feel it was hard to do the work, instead, she felt comfortable in her responsibilities. Second, she learnt about her teachers' characteristics to know how to work with them effectively. For example, not all teachers could receive feedback in an 'open-hearted' way, and some of them were reluctant to be disciplined. On the other hand, some teachers were open for feedback and easy to talk to. Another capacity described by Louisa was having spiritual intelligence. She explained that praying to God should be followed by actions, with a strong faith to God; she believed that God would be guiding every step she took as a school principal. The next school leadership practice she described was to be fair with all teachers:

A school principal should not be easily influenced by only what one teacher says. For example, when teacher $A$ says something bad about teacher $B$. As a school principal, then instead of directly confronting and reprimanding $B$, I should seek better information on the matter from others, before deciding on an action. As a school principal I know that I should listen to everybody, and take a proper action wisely and fairly. Sometimes, to clarify my actions, I often reflected back to the school rules.

This statement reflected how Louisa tried to stay neutral and refer to the school rules. Furthermore, she explained that if the teachers break the school rules, they have to be warned verbally and non-verbally. However, 
before giving a verbal warning, she had to give them guidance on how to be a better teacher.

Louisa explained that one particular book about leadership had influenced her. This book suggested that there were four key successes for leadership: building vision; developing mission; receiving and implementing responsibilities; and developing professional skills. In developing professional skills, Louisa explained that since she was teaching, she used to attend workshops and training. Louisa never hesitated to ask for feedback from her school principals to develop her teaching skills. Mathematics and Language (Bahasa or Indonesian) were two subjects that Louisa was interested in and motivated to teach.

When Louisa was asked to share her challenges when she was a teacher and as a principal, she did not refer to her childhood, but explained that she had a very bad relationship with the school principal when she was a teacher. The problem in her opinion, was that the school principal listened to the other teachers who said bad things about her without asking her to explain, i.e.: she came late for about 5 minutes because there was no public transport or she had to walk to school for 2 kilometres. She became the 'topic' in every school meeting, which made her felt uncomfortable teaching in this school. When Louisa asked her principal permission to be placed in another school, the principal refused to sign the document she needed. He resisted signing as she explained:

When I handed the document at school, he said, 'Oh this is too early', let me sign it in the afternoon. When brought the document in the afternoon, he said, 'wait until I finish my work'. When I gave the document as the school was finished, he said 'come to my house in the evening'. I came to his house with my husband; do you know what he was saying...? He said 'school business; don't bring it at home'. I was still being patient at that time. Finally, in the following day I gave him again the document, and he still said no, I tore apart the document, because I was so angry

This explanation reflected Louisa's difficulties in her early teaching career. She explained that she had to go directly to the district education office and ask for a new placement in another school. She finally was able to move to another school without the principal's permission, and later got endorsement from the government. In the new school, she worked with a 
female principal. She had another unpleasant experience, when she needed to be absent from school because her daughter was sick and her principal did not allow her to miss teaching. These two experiences always reminded her how to communicate and respond to her teachers. She said she would not treat her teachers like her previous principals had.

When Louisa became a principal, she experienced some challenges working with her teachers, students and the local community. Some teachers did not communicate well with her and those teachers did not act as agreed in the school regular meetings. Thus she was disappointed and asked them to discuss every issue freely and openly in school meetings.

Another challenge came from the students. Louisa faced truancy at her school. She sent invitations to all parents whose children were playing truant. This was a big shock for the parents, as they were not aware that their children skipped school sometimes. This was not only her and her teachers' responsibility, so she also asked the parents' help in disciplining the students.

The last challenge discussed by Louisa was about how the local community often used the school's facilities such as the toilets/bathroom to get clean water for cooking and showering. One particular action was 'breaking into' the school outside school hours and unlocking the toilets/bathrooms forcibly. As a result, Louisa had met the head of the neighbourhood and report what the community members were doing at the school. As she used to be married to a police officer, she explained that to call the authorities such as the government or the police to charge the community members going to court was an easy job for her because she still had contact with her husband's institution. However, she preferred to collaborate with the community leaders to solve the problems.

The role models for Louisa were her parents, her husband, and her school supervisor and other colleagues. Her parents gave her suggestions about life and studies, thus she used to depend on her parents to decide any issues. Her school supervisor influenced her how to be a good teacher, for example how to act in front of the students while she was teaching in the classroom. However, she did not share her husband's influences on her career. 
When Louisa was asked about her values, she mentioned intelligence, honesty, trust, humility and humour. However, when she was asked what the most important value she held was, she stated that it was self-discipline, as she explained:

Self-discipline is the most important, if we apply discipline in our life, it will be leading to other values, such as openness, honesty, humble and power. However, I apply discipline in flexible manner, for example, discipline is one of our school rules, but it isn't a strict rule, we can always discuss when we have a problem with our school rules, something that we can add or dismiss depend on the situation

In the further discussion about how Ms Louisa was applying her values such as humility, she gave an example how when she lived in a police compound where other police families live glamorously; she was strict to her value of being humble.

\subsubsection{Leadership practices}

Louisa had been leading this school for 4years by the time the interview was conducted. When asked about her goals in leading this school, she mentioned improving students' quality of education. Strategies to achieve her goal included good quality teaching; qualified teachers; analysing students' weaknesses in terms of test results; and providing additional lessons for students in the $6^{\text {th }}$ grade. These additional lessons were conducted for 5 months before the national examination every year. There were some consequences when conducting these lessons, such as financial support to pay teachers' transportation.

Louisa had academic, non-academic and administration strategies to ensure the quality of teaching. Academic strategies included book availability for students and teachers, providing interactive teaching in the classrooms, and avoiding one-way teaching, where the teacher talks and students just listen. Non-academic strategies included good food intake by the students. Considering the school community was from a low economic background, the introduction of some healthy foods and milk was necessary. Administration strategies included checking daily learning plans developed by the teachers, preparing learning material and teaching aids. All those supporting documents and aids had to be signed and agreed by the principal. Louisa was aware of her teachers' educational background. Most the teachers had 
graduated from University, however there were a few teachers who graduated from high school. Before she has been assigned as a school principal in this school. The school's accreditation was at $\mathrm{C}$ level, but after she arrived and due to changes in the school management, the school got a $B$ level of accreditation. When she was asked what she did that might impact on the accreditation, she explained that, even though the school buildings were still insufficient, she maintained her teachers' quality and their teaching quality.

Louisa was asked how she enabled her teachers to join professional development working groups available at district and provincial level. There were principals' working group meetings at her district, and she usually invited her teachers. Besides the meetings, Louisa often sent her teachers to participate in workshops and training.

When Louisa was asked how she managed the school environment, she mentioned that her school had a security guard and a janitor. Unlike other schools that may have rooms for the security guards to stay at the school the whole time, her school did not have a place to stay. Thus, the security guard did not; therefore the security guard did not stay at night. Based on this situation, she asked the community members near the school to guarantee the school security. This meant, the community had 'kept an eye' on what was happening at the school day and night. Louisa also asked the community to help, the school during the registration week.

The last question was about critical friends. Louisa said that she had never really thought about critical friends and had rarely sought feedback from her friends. However, she explained that if she had to ask someone about her work, she would have gone to the people who had more knowledge and information than her. She mentioned some people, such as the head of curriculum section at the district education office, whom she contacted if she needed academic feedback, and the human resources department at the district education office, if she needed feedback about financial management.

\subsubsection{School documents}

Louisa gained her leadership experience through services in the church, while she explaining that her leadership goal was to improve students' 
achievement. The vision and mission of her school were looked at to identify a link between leadership practices and the school documents in figure 4.2.

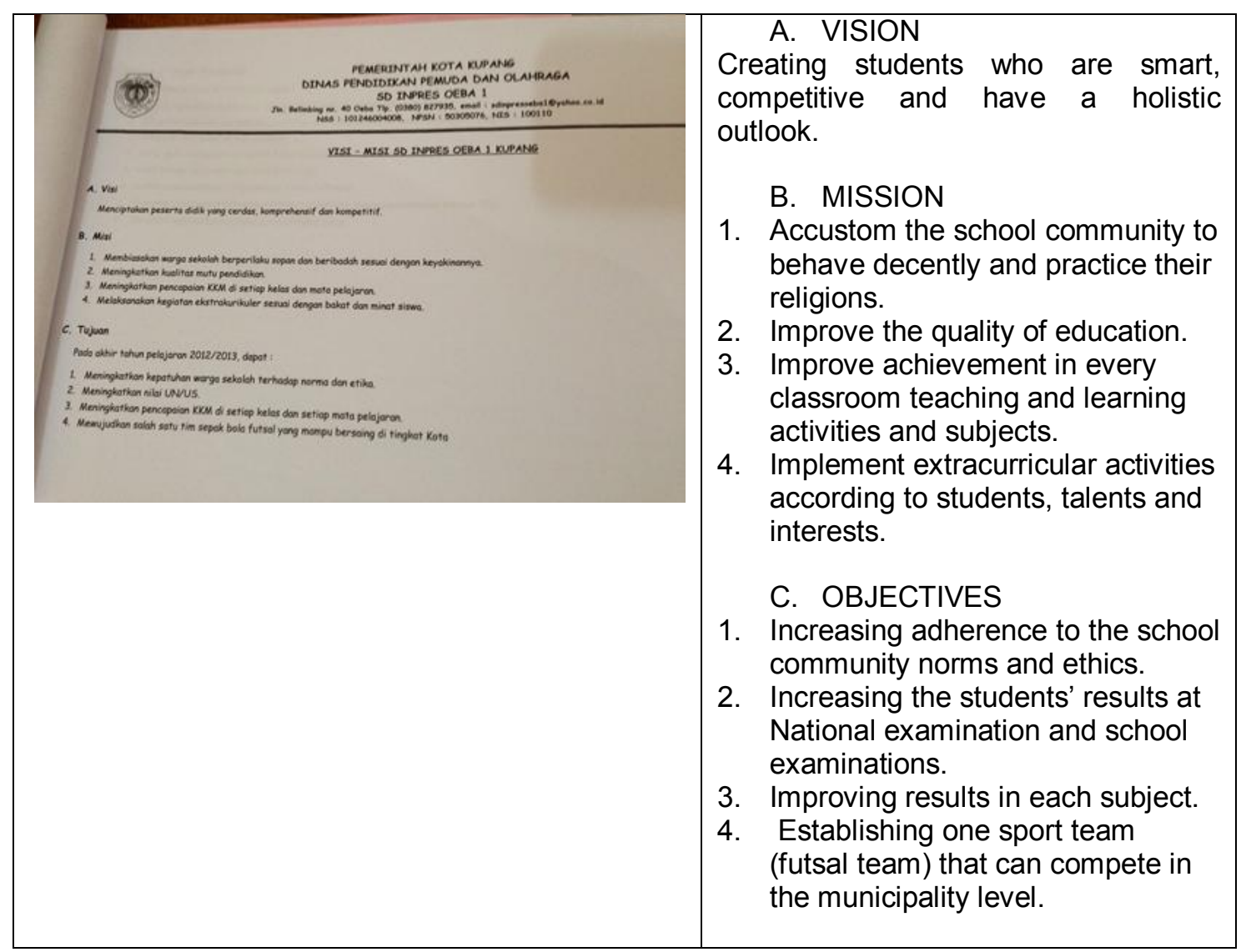

\section{Figure 4.2: Vision, mission and school objectives (Case: Louisa)}

There is a link between Louisa's leadership goal of improving the quality of teaching and the school mission statements. The school documents highlighted practicing the religion in the community, and increased adherence to the school community norms and ethics. This mission is also relevant to Louisa experience working in the church.

\subsection{Chapter summary}

This chapter describes findings of two elementary school principals. Both participants are female, and mention a lack of support from their husbands. Both of them, however, acknowledged that their husband was also a source of influence, as well as a role model. Previous leadership experiences were developed from participating in the examination development team for Vama, and participating in social and church activities in her community for Louisa. 
Self-discipline was the most important value for both principals and their leadership practices were focused on improving students' learning. A summary of these findings can be seen in appendices $L$ (Vama) and $M$ (Louisa). 


\section{CHAPTER FIVE}

\section{Junior High Schools Findings}

\subsection{Chapter Overview}

This chapter outlines the interview findings from the two principals from highest achieving junior secondary schools in NTT Province. Results will be presented individually from Gerson then Seran, based on the interview questions and document analysis. The findings for each principal are presented either in relation to the themes that emerged from the life-stories or leadership practices. As explained in the previous chapter, the findings will be focused on principals' life experiences and practices and the five dimensions of leadership by Robinson (2011) will be used to explore leadership practices.

\subsection{Case: Gerson}

Gerson is a junior secondary school principal. He is 54 years old, and led 1581 students and 85 teachers. Gerson used to be a Mathematic instructor from NTT province at the national level.

\subsubsection{Life experience}

Gerson shared he used to be an exemplary teacher (based on the provincial ranking), representing teachers from NTT province at the national level. Since then, he said he realized his leadership potential. As a vice principal, he was responsible for supervising the students' association at his school and managing the school curriculum. This gave him the confidence that he had potential talent to be a leader.

Gerson had a passion for teaching Mathematics. He realized that broadened his leadership skills based on his experience as a Mathematics instructor. Another significant experience he mentioned was when his teachers and his principal taught him about discipline. Gerson said that the keys for successful leadership were self-discipline and avoiding procrastination. Furthermore, he explained that school facilities were the 'second' business after academic results. This means he valued the students' results more than the school facilities. In the interview, he said "I don't want 
to be a follower; I want to be a leader who has effective strategies in achieving academic results"

One of his experiences related to the relationship between a principal and the teachers. When he was a teacher, he had requested the school principal to provide school facilities, such as sporting opportunities for students. However, the principal never approved his request. In the interview, Gerson promised he would listen to his teachers' requests.

When Gerson was asked about the opportunities he had in the past, he explained his financial problems in paying school fees. He received a 'talented and achievement' scholarship award. Gerson explained that the money was not a large amount, but was enough to pay his school fees. He explained further, that the money helped his parents a lot, because they were just farmers. While at University, he had the opportunity to work as a teacher assistant, he explained his experiences:

The school distance from my house to the school was about $4 \mathrm{Km}$, and I had to walk to school. We didn't have public transport at that time and my family was really poor... I was so tired between studying and working. I was sad sometimes, because l'm so tired, due to the distance from home to the university.

Gerson stated that his mother was his most influential person, because she has leadership skills. Other influential people were his algebra and geometry teachers, and his school principal.

It was my mother. Even though she was only a housewife, but she has the ability to lead. When I was in secondary school, it was my Algebra and Geometry teachers who inspired me a lot, they were really good and smart, they were very concerned with their students...When I was in senior high school, it was my school principal who inspired me

When he was asked about the most important value he held, he was clear that it was self-discipline and this came from his teachers and principal. Besides that, other important values were intelligence, patience, productivity and services. He added some more values that he also considered important which were honesty, open mindedness, humour, integrity and humility. 


\subsubsection{Leadership practices.}

Gerson had high expectations of his students' academic achievement. He managed his school to be the best in term of academic achievement, not only at the district level, but also at the provincial and national level. Thus, his school usually sent their student representatives to participate in competitions at the district and the national level. He also expected that his students could increase the minimum average academic results, and all students could pass the national standards.

In our monthly staff meeting, I always emphasized that we should reach a higher quality in students' achievement; we didn't need to reach the percentage (i.e. 100\% completed their study, but we had to reach a better quality in 2013 - 2014). We have analysed the exam results, and we knew in which level our students were. I have given my effort to reach the better academic results

Four strategies were applied to achieve the school's goal: obeying the school rules; improving school management; improving academic achievement; and managing financial support. Gerson encouraged all teachers and students to obey the school rules. However, an un-written school rule, 'shamed culture' also applied in this school. This rule motivated the school community to feel ashamed if they did not obey rules. Within the school's management, Gerson took steps such as school planning, implementation, monitoring and supervision, and objective evaluation for the teachers. To improve academic achievement, this school divided their students based on the classroom groups. Classroom management based on students results were divided into: outstanding, acceleration, and smartspecial classes. Another strategy to improve academic achievement was that the school had additional 90 minute-lessons (usually conducted after school hours). These lessons aimed to improve academic achievement, especially for the national exams. There were annual instances of what in Indonesian are termed 'try outs' (mock exams) was used to check the effectiveness of these lessons. The teachers who taught in this lesson had to write journals to monitor and evaluate students' results and to report to parents. The last strategy was financial support. It was explained that the school received government funding, however, it was not enough to implement all of the 
school programmes. Thus, Gerson coordinated with the school's alumni and the parents to provide financial support:

We also have a cross-subsidy for those who came from low economics background. This school has $40 \%$ students from low economics background; they have difficulty to come to school (transportation issue). So that, from school operational support's funds and from school committee funds we donated some money for those kids to pay their transportation fee. You cannot believe that there are a lot of poor students here. These students had to help their parent to work in the paddy fields for the family financial security, thus why some of them are absent from school. I am so concerned with these particular students, then I seek for help from the school alumni (graduated in from 1988 to 2002).

Gerson had at least four strategies to ensure the quality of teaching. First, he ensured that all teaching schedules were fixed at the beginning of the semester. This was to avoid teachers changing their schedule without coordination. Secondly, he selected only the qualified teachers to give the additional lessons. Next, Gerson checked the teachers' journals to monitor what teachers had been doing. The last strategy to ensure the quality of teaching was conducting monthly evaluations of the teachers.

Gerson confirmed that he supported his teachers to participate in Musyawarah Guru Mata Pelajaran (MGMP), a subject teachers working group. He explained that in the MGMP, teachers developed learning plans to be used in the classroom. This group was well managed by some teacher leaders. The teachers have the same daily learning plans; however they created their own tasks in each classroom. At the end of semester, all teachers have the same exam questions for the same grade. Even though it was not easy to meet regularly, the teachers in this working group always made times for group discussion.

At the district level, there were also regular meetings for the teacher leaders (instructor teachers). Despite the lack of financial support from the government for this teacher leaders' group, they were still able to meet. Some teachers from this school became the instructors, while Gerson used to be the Mathematics instructor. Gerson was the secretary of the Principals' working group (MKKS) at the time of this research. In this working group which met regularly, the junior high school principals discussed any relevant issues, such as school policies and activities. Gerson stated that he could not 
deny that security and safety were important, and all the school community members, depended on these two factors to feel comfortable at the school. When Gerson first arrived in this school, he discussed school security with parents and other relevant stakeholders, such as the police and the district government, because his school was located in the main 'busy' road in the city.

There was a health issues in this school relating to waste management. Some of the community members who lived near the school threw their household rubbish into the school's rubbish container. Gerson was not happy with that, thus he coordinated with government officials to be more regular in collecting the rubbish. In his opinion:

Other than this, I maintain a good relationship with the community related to the school security. Sometimes the community found some students didn't attend the school, instead they were playing outside the school during the school hour. In that point, the community helped the school to 'catch' the students and returned them back to school. I can say that the school community is quite concerned with our safety and security at this school, they have 'high' responsibility to take care of this school because this school in within their environment.

To maintain healthy school environment, Gerson coordinated with the nearest community health centre. The doctor or paramedics came to school to check students' health and also to observe the food stalls and the school canteen to see if all foods were healthy. Gerson explained that he never had serious medical or health issues in his school.

Gerson viewed his five senior teachers and five new teachers as his critical friends. Those people gave him input and feedback on his leadership practices. He used a format with some indicators that the critical friends (teachers) had to fill in anonymously. He explained that at first the teachers felt uncomfortable, but he kept encouraging the teachers to give the feedback honestly and objectively. He got some positive feedback and some of the feedback indicated that his work needed to be improved. Gerson said this mechanism worked really well to change some of his policy at school, as explained below:

There was input from them, i.e.: they didn't want me to handle their classrooms the whole day, if they came late at the school. Besides they felt ashamed and embarrassed, they also didn't know what to do 
at school when I taught their classes. I can accept the critics but I also told them my reasons why I did that. It was all for their own benefit to be more responsible.

Gerson took the suggestion, after explaining what he intended to do about this rule, he expected the teachers to obey the school rules such as arriving at school on time.

\subsubsection{School Documents}

Gerson stated that his school applied a shamed culture. This culture was not supposed to be a formal policy or rule, as he stated that it was "un-written" culture. However, in the the school administrator's office a shamed culture was actually "written".

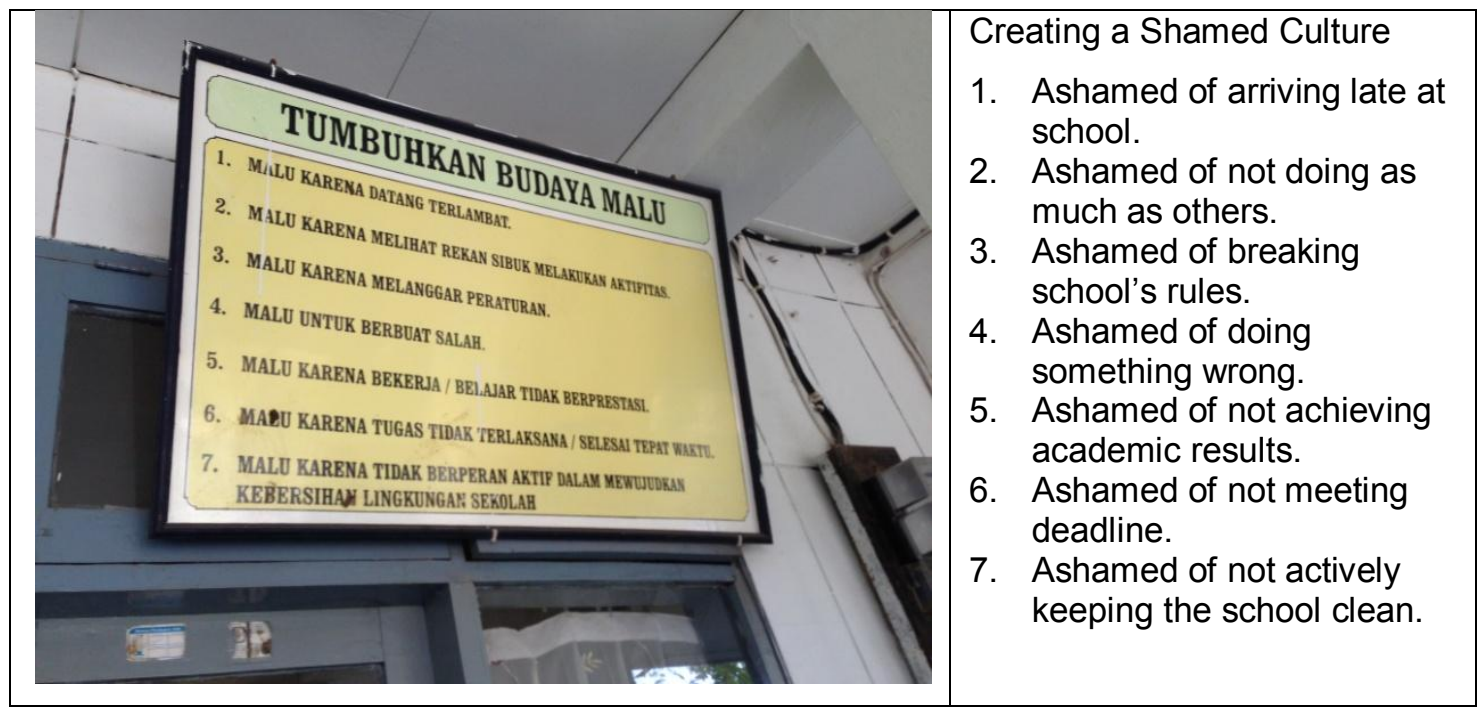

Figure 5.1: School rule of 'shamed culture' (Case: Gerson)

Figure 5.1 illustrates Gerson's life experience is in line with the school's document. There is a culture that you should be ashamed if you do or don't do something as stated in the display. Not achieving academic results is included within the 'shamed culture'.

\subsection{Case: Seran}

Seran is a male principal, and he is the youngest among the research participants, at 50 years old. However, he was responsible for 2020 students and 89 teachers at his school. Seran stated that he had the biggest student body as compared to other schools not only in Indonesian but also in other countries in Asia. 


\subsubsection{Life experience}

Seran reported that his leadership reflection as part of this study gave him some ideas how his leadership skills have developed. More precisely, he explained that leadership was about how to influence teachers and staff. $\mathrm{Mr}$ Seran recalled some of his leadership roles in his early life and commented that his role at the students' association at secondary school and at University increased his leadership skills. Being in the students' association increased his confidence and self-reliance. In addition his experience as a teacher and a vice principal at his current school also increased his skills. Seran used to be an 'honorarium' teacher at one of rural school, when he was still studying at university. This was a valuable experience in his early teaching career, in terms of building his courage working in the rural area and with only limited payment from the government. This experience was also one of the challenges he had in the past, when he had to recruit the students to attend school, due to the low awareness about the need to educate children in the rural community,

This was a school in the outskirt of Kupang city. It's different with schools in the city. In rural schools we must recruit the students. We had to promote to the community that it was good to send children to schools. You could see that there was low awareness about education.

During the interview, he mentioned that he was the leader of a principals' working group. He was chosen by other members of the group. When I asked why the other principals chose him as the leader, he said:

I was just an ordinary person, nothing special about me, I served the other principals and shared new information with them, I'm humble, if I get new information from the government, I would share it as soon as possible. I think, maybe for other people or other leaders, they don't share new information as soon as possible to other principals.

Seran added other information relating to his leadership type. He said that his leadership was based on friendship and familial values. He reflected that the principals' working group was like a big family who work together to solve some principals' problems, such as how to improve quality of education in this city and other administration problems. 
Seran explained that some of his early experiences were unpleasant, such as financial and transportation problems when he was young. However, during his time at school he also had encouraging experiences when the school principal asked him to attend several school principal meetings on his behalf, Seran learnt about being a good school principal.

Seran described three opportunities that broadened his leadership skills. First was the opportunity from his first time as a principal at the school where he used to be a teacher and then the vice principal. This enabled him to manage the school smoothly; become familiar with the school curriculum, and the other school principals at the district. The second opportunity came from his current school which always had high academic and non-academic achievement at the national level. Seran shared his strategy on how to maintain achievement. The last opportunity related to his students. Seran explained that the students in his school were doing really well in the national exams. Seran was confident that his graduates could compete with other graduates from other schools.

Seran explained that the large number of students he has at his current school was a challenge. Having 2020 students was difficult during registration week, because the number of registered students were more than the classroom capacity. All parents wanted their children to go to this school. Thus, he invited community members as well as parents' representatives to help the school during registration week. As a result, after coordinating with government officials, Seran decided to open a morning shift and afternoon shift for the first grade students.

Seran mentioned three different people as his role models. The first was his parent, although he did not clarify whether this was his mother or his father. His parent taught him how to be independent, responsible, disciplined and honest. Another influential person was his vice chancellor when he was studying at the university. He learnt how to be disciplined and to respect the school environment from the vice chancellor. He was also influenced by his first school principal, who inspired him to be a principal:

At work, my first school principal (when I was a teacher) was my inspiration. He inspired me a lot, his name is Mr FM. I learnt a lot from him, he asked me to attend some of the principal activities, sometimes I went on his behalf, I learnt so much from him. 
Seran chose five values: service; self-discipline; honesty; loyalty and integrity. The most important value for him was discipline. When he was asked why self-discipline was important for him and from whom he learnt to be discipline, he said:

This was from my dad and my mom, also my grandpa and grandma. I stayed with my grandparents when I was young. They were disciplined with time, I had to come home in time, they never let me sleep over at my friends' houses. Whenever I went to other places, I had to come home.

Sleeping over at a friend's house was common for a boy in Indonesia, however because of the rule from his parents and grandparents, Seran never slept over at his friends' house.

\subsubsection{Leadership practices}

In the second part of the interview, Seran began with a statement that he works hard to achieve his goals. Seran articulated two strategies to achieve goals, managerial strategies and academic strategies. The management strategies were: leading by example, such as applying discipline and obeying the school rules; observing teachers and staff's characteristics/personalities; understanding everybody's job in the school; and good planning and budgeting in each school divisions.

Academic strategies were also discussed by Seran as follows: knowing where the students' are in terms of academic achievement; being involved in the teachers' working group; and developing the school's extracurricular programmes. School's extracurricular programmes had given opportunities for students to develop their academic and non-academic skills, and Seran noted:

We have extracurricular subjects, we have sports (karate), we have drum-band, scout group, we have art, traditional music and dances, and we also have scientific group where every year we win competitions. Within the scientific group we have scientific writing group and scientific poster making. Recently we sent some students to join a competition at the national level. We won the scientific poster competition (first winner and second winner). 
Managing the 2020 students with 105 teachers was not easy for Seran; however he had some strategies to ensure consistent quality in teaching. Firstly he led teachers' working group (MGMP) regularly. There were several activities within MGMP workshops, such as role play/simulation to improve teachers' skills and capacity, develop daily lesson plans, and evaluate students' results:

I was involved in the classroom observation. I gave input to the teachers, I looked at the daily learning plans, I also checked the learning materials, teaching aids used by the teachers, and at the end I checked students' understanding toward the subject taught. All the process was being recorded. We could analyze teaching quality through this process.

Ensuring quality of teaching was also related to teachers' capacity and skills in using Information Technology (IT). Seran explained that all teachers had learnt Word, Excel and Power Point, and were able to use animation. All of the teachers had laptops. Seran motivated them to learn new technology. After the certification process all certified teachers had a payment. He told them to use the money wisely, such as to buy a laptop, and he kindly asked the teachers "not to throw a party for their family or another occasion". Seran helped the teachers in contacting a laptop provider and negotiated ways to pay for the laptops to the provider.

When Seran was asked how he encouraged his teachers to participate in professional development, he explained that it was easier in the centralized era (before 2003). Indonesian provinces were decentralized a decade ago so that every province has their own policies. It has become harder to participate in teacher training at the national level, because there is no more government assistance. Despite this limitation, however Seran always encouraged his teachers to join workshops and training.

Seran joined a principal working group and took a role as the leader for this association (MKKS). This working group provided self-development and other relevant knowledge and information, as he explained:

I got a lot from this association, such as new information related to school administration from the government, and I could represent other school principals, participating in the high level advocacy meetings; meeting head of district and meeting the head of provincial 
education office. For the new information, sometime I would get new info earlier than other principals.

The school environment was one of the issues raised in the beginning of the interview. This was because the school had won the environment competition several times at the national level. Seran contributed to the school policy, explaining how he managed the school environment to be healthy and hygienic:

Could you imagine how to manage the rubbish from 2020 students, plus the teachers it's about 2100 people? It's one of our school's rules to clean our own rubbish, we encouraged them to do that, when they found some rubbish, they're expected to throw it to the rubbish bins. Also we had some plantations, flowers and small flowers in the school garden.

Seran explained that he had a school health unit and a school canteen. He emphasized that he was inspired by his vice-chancellor regarding healthy environments when he was studying at the university. The vice-chancellor at his university managed the university which was always clean without any scratches. Thus, Seran applied the same rule at this school. The school was well painted, and the school community kept it clean. Seran closed the interview by saying:

A healthy environment makes us comfortable for working; when our environments aren't healthy we won't be healthy. Welfare doesn't indicate on how much money do you have, but also how healthy is your environment physically, and how "healthy" is relationship among school community (teachers, staff, principal and students). Some staff said, they could feel a 'healthy' environment physically and mentally after I led this school.

During the interview it was found that parent involvement helped the school to maintain school environment and school security. The principal sought feedback from the students and the teachers by giving them questionnaires. 


\subsubsection{School documents}

In the interview, Seran explained that he was actively involved in the teachers' working group at his school and he also mentioned that he supported his teacher in developing the schools' curriculum.

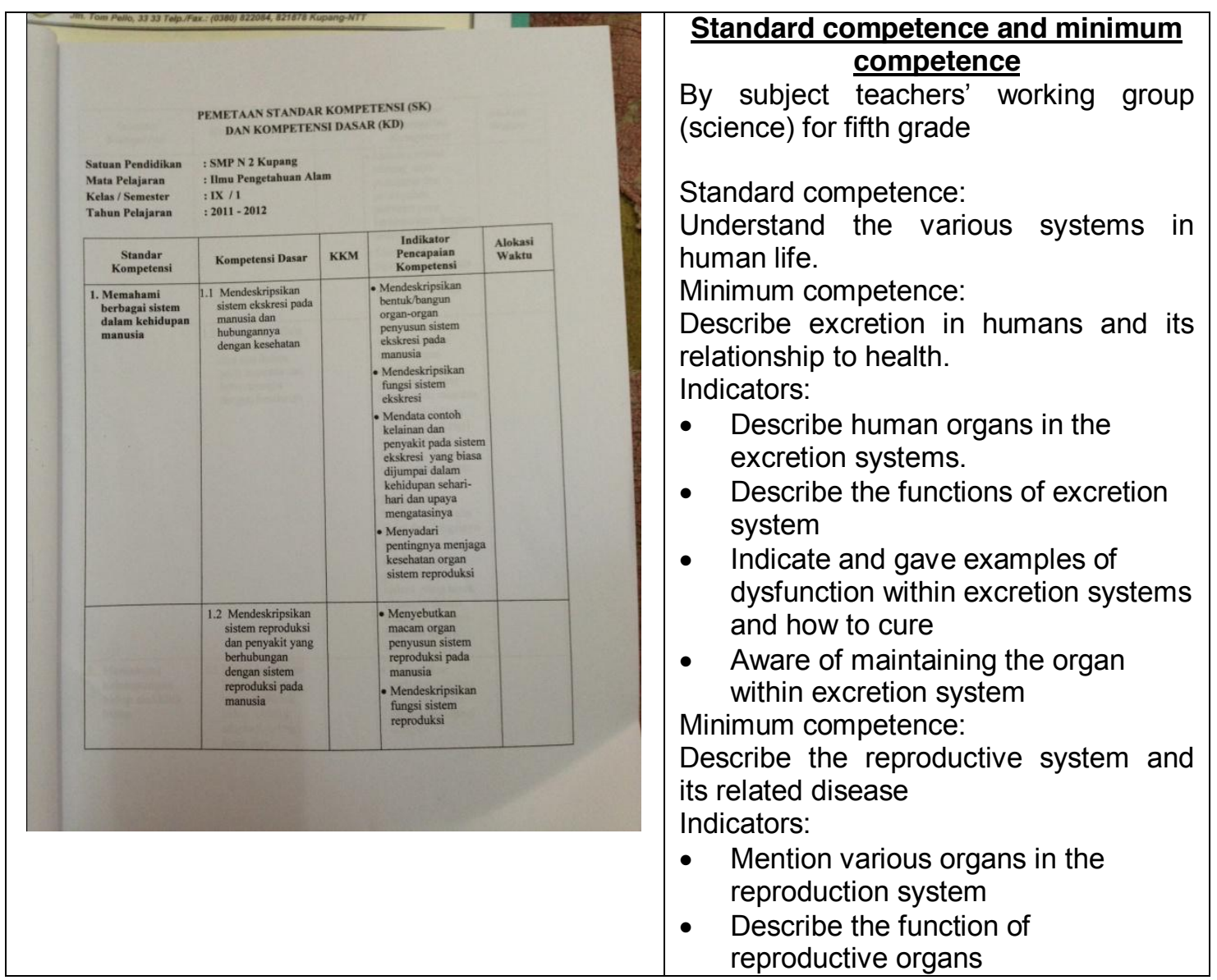

Figure 5.2: Subject teachers' working group document (Case: Seran)

Based on the school document (figure 5.2), it can be seen that Seran was actively involved in the development of standard competency, as his name always appeared in every meeting/session of the teachers' working group results.

\subsection{Chapter summary}

This chapter presents the findings of two school principals from the junior high school level (Gerson and Seran). Both principals came from a low socioeconomic background, which had resulted in difficult circumstances. Gerson realized his leadership talent when he represented exemplary teachers from NTT province, while Seran developed his leadership skills by joining students' associations. Both of them explained that their school principals 
had been one of their role models, and both of them put self-discipline as their most important value. The summary of these findings can be seen in appendices N (Gerson) and O (Seran) 


\section{CHAPTER SIX}

\section{Senior High Schools Findings}

\subsection{Chapter Overview}

This chapter outlines the interview findings from the two school principals from the highest achieving schools at senior high school level in NTT Province. Results from the interviews will be presented individually from Fanggidae then Ndoen, based on the interview questions. Findings will be presented in two sections for each principal: the first will explore principal life experience, and the second will explain leadership practices. As it was explained in chapter two, leadership practices will be assessed by five dimension of leadership suggested by Robinson (2011)

\subsection{Case: Fanggidae}

Fanggidae is a senior high school principal in Kupang City. She is 50 years old, and she led 1330 students and 36 teachers at the time of interview.

\subsubsection{Life experience}

Fanggidae's story about challenging childhood experiences indicated financial problems, transportation problems, and issues of time management between school/work and family. She came from a low socio-economic background, had six siblings, and her mother passed away when she was 12 years old. Three of her siblings were studying in different islands, thus she was the eldest at home taking care of her father and the youngest siblings. In the interview, Fanggidae explained how hard it was for her to manage her time between study and taking care of her three siblings.

Her father was an elementary school teacher, and always encouraged her to be an elementary teacher as well. Her father's salary was not enough to cover all the household expenses and besides teaching he was also a farmer. The distance from home to her junior high school was about 12 kilometres and she had to leave for school in the early morning, for the first trimester. After that she decided to stay with one of her relatives near the school, but still in the same district. When she was at senior high school, she had to move to the capital city (in a different island) to study and lived with 
another relative. When she was at school and at University, she received scholarships to pay her school fees. In Indonesia, it is a privilege to receive a scholarship, as they are only available to academically able students.

Fanggidae shared her experience of living away from her family. She emphasised that it was very hard, because her host family did not show love and care to her as they did their own children:

After school, I went to the wood to find some firewood and then carried it from the wood to my relative's house, as we didn't cook with a stove at that time...You can imagine, I didn't have time for studying at home, I had limited time to do my homework...that was the difference between me and other students who were living with their own parents, they could do their homework.

Fanggidae taught senior high school students while she was studying at University. Later on in her career, when she was finally accepted as a fulltime teacher, she worked with an inspirational school principal. However, in 1989 after she married, she had to follow her husband to a new place, Timor Timur Province (now the Democratic Republic of Timor Leste). Being a school principal in one of the conflict areas in Timor Timur Province between 1995 and 1998 was not easy for Fanggidae, for many reasons. The district where she was assigned as a school principal was called Fikeke district. This was located in the conflict area between Timor Leste militants and the Indonesian Army. To reach this district, she had to pass five districts from the capital city. She was pregnant by the time she had to move to Fikeke district. She took her two daughters with her, and left her husband in the capital city. As she explained;

Can you imagine, I took my two daughters, while I was pregnant. I had been working for more than three years in that school. I had many experiences related to the conflict, because I could hear the gun shots, people between two parties were killing each other. Even, I could hear cannons firing sometimes.

To get to the school, I had to pass a mountain. The mountain was usually used to cross the militia from the forest to the city...Some of my colleagues asked me whether I was scared or not. Believe it or not, I told them that in that place God was shaping my faith, I wasn't scared; I put my life in God's will, in God's hand.

Fanggidae learnt from her experiences working in Timor Timur Province. She admitted that those experiences made her more independent 
and more mature. Furthermore, she said that she felt older than her chronological age, because she had double roles as a mother and as a school principal. She observed that in Timor Timur, teachers worked very hard and were dedicated. They obeyed the school rules, and learnt to be patriots because they had to choose whether to keep their Indonesian citizenship or to be independent as Timor Leste citizens.

I talked to myself that I had to work harder for these vulnerable people because they were in the conflict areas. I felt like I had to devote myself to my country, working for the poor...When I moved to Kupang, I thought it should be better than in Timor Timur. On the contrary, I was so sad when the circumstances here were even better than in Timor Timur, but the teachers in some schools here didn't work very well.

When Fanggidae was asked about opportunities she had from her early career, she described that she learnt about responsibility, working-hard, and loyalty. Other leadership traits she mentioned were to love, to protect, to be independent, to show courage, to love her job, and never give up. Leadership capacities she learnt when she was young included tolerance, familial values and commitment. Therefore, Fanggidae was fully aware of her responsibilities and her commitment, as explained below:

I was 'called' to work whole-heartedly. If we teach the students without commitment, they will run away from the classroom. In Timor Timur, sometimes, we experienced some gunfire near our school. If we couldn't manage the classroom and some of the students ran away from school to the school-yard, I worried that my students would be accidentally shot by extremists, who would responsible if it did happen in my school?

Another opportunity was when Fanggidae was working with her school principal (as a teacher), who had strong leadership skills. She learnt how to manage a school and how to lead the teachers.

The opportunity when I was a teacher I learnt from my school principal. He was a very good as a leader and as a 'father', he was a tough man, even though his temperament was like that, but we (as teachers) learnt a lot from him. We respected him so much, for example, I wanted to get to school earlier than him, but when he got to school earlier than me, I couldn't even face him, I was so embarrassed. Working with people like him, we respected him, he had a charm and we worked whole-heartedly, naturally, without coercion. 
When Fanggidae was asked who influenced her, she mentioned several figures who were important in shaping her leadership. First, it was her father who taught her responsibility, loyalty, discipline and working without complaint. Other people she mentioned were her husband, her school principal when she was a teacher, the school supervisor coordinator and the head of the provincial education office. She learnt from them about how to appreciate other people's work and how to forgive others' mistakes.

Fanggidae held strong religious values. When she was asked about her values, she mentioned that religious values were most important. Other than that, she mentioned honesty, openness, tolerance, and discipline as her values. Other values also she discussed were responsibility, creativity, independence, democracy, curiousness, appreciation of other people's work, friendliness, familial, love of peace, respecting the environment, patriotism and faithfulness.

\subsubsection{Leadership practices}

Fanggidae's main leadership goal was to improve students' results at her school. She expected her students to be able to win some academic competitions; pass the tests to enrol at University level; develop themselves based on their talent and skills, and solves their life problems (for example, job issues, financial problems). She gave an example, some parents expected their students to continue studying at University, however other parents, expected their children to look for a job straight away. Based on these expectations, Fanggidae though that it was good to provide a vocational curriculum for the students, she explained:

I had some alumni from this school now doing business, journalism, or working for the government, and so on. I like to encourage my students to participate in competitions, any competitions, in order to know at which level their knowledge and skills are, as compared to other students from different schools. This is also to encourage the student to be more independent, and to be creative.

When Fanggidae was asked about her strategies to achieve these goals, she firstly explained about spiritual values. Although Timor Island is 
mostly Christian, she assured that all five religions were taught at her school, as follows,

Firstly, we had to remember God, we had to pray in our religions' ways, here, we taught religion based on the students' religions. Five religions have been taught in this school. We have religion teachers for every religion (Muslims, Catholicism, Protestants, Hinduism and Buddhism).

Fanggidae described other strategies that were related to academic and non-academic approaches. For example, for the academic approaches, she conducted additional lessons for students, analysed test results, evaluated academic challenges with the teachers, sent some students to participate in academic competitions, and managed the teaching-learning process to be effectively conducted into all classrooms. Non-academic strategies included increasing discipline for a school community members and improving the quality of extracurricular activities at the school.

We have additional lessons once a week. Our planning for this year depends on the students' interest, for example mathematics and science for those who are interested in participating in the competition Mathematic and Sciences Olympics competition.

To ensure the quality of teaching at her school, Fanggidae had two strategies: completing all learning plans in the beginning of each semester and doing classroom supervision. To prepare the learning plans, she worked closely with all subject teachers at her school. The learning plans consisted of syllabus, daily learning plans, learning material, teaching aids and student evaluation/tests. For classroom supervision, Fanggidae worked with school supervisors and teacher instructors. After supervision in each classroom regularly, they were evaluated based on the observation process to give input to the teachers:

Supervision is aimed to analyse some problems from the teachers and from the students. For example, the problem with the teachers was when they couldn't manage the classroom smoothly, while from the students sometimes they weren't ready with the subject taught because they didn't have the text book required in the subject. 
Fanggidae participated in the principals' working group in the Kupang City of NTT Province, and was the treasurer of this group. At her school, she organized training for the subject teachers' working group called MGMP. She also supported another government body called LPMP (quality assurance to improve the quality of education) to train her teachers and also developed an IT pilot project at her school for the teachers, explaining:

After training, they will disseminate the training results to other teachers. I also tried to optimize the subject teachers' working group because their work is important to improve students' results. I believe if this group works well, we would get a better student result

The school where Fanggidae works is located in the main road of the Kupang city. She explained that to manage students' safety and security, her school had a proper school gate and school guards. She also maintained the relationship between her school and the community near the school building. In addition, she created familial values within the school community. She described how she encouraged all school members to be 'the police' for themselves. She tried to improve other people's awareness of always being prepared and avoiding all unnecessary physical and mental problems. Further she explained:

The police's responsibilities are to serve, to discipline and to secure the community. If you could apply the police responsibilities to yourself and your family, everybody will be safe and you will find a sense of safety around you...it means they you need to create a safe environment for yourself, which will lead to safety in the bigger environment. On the contrary, if you create a conflict, you will deal with a conflict everywhere you go.

Inside the school building, she had a school canteen for all school community members to access healthy foods during school hours. Furthermore, she explained that there was a school health unit called Usaha Kesehatan Sekolah placed at her school. This was to give first aid to all students, teachers and staff if there was an accident at her school.

When Fanggidae was asked about her critical friends, she explained that her teachers were her critical friends, and gave her monthly feedback through teachers' forum at her school. Sometimes there were challenges in leadership role, as stated below: 
One day, one teacher hit the table when he had an argument, but for me it was like 'learning from the experience' moment, this teacher wasn't my enemy, because he gave me correction then I could learn something from his argument

Fanggidae was open to feedback from her teachers, and she knew how to handle disagreements within her school members.

\subsubsection{School documents}

Fanggidae explained that her school conducted an IT project to improve teaching and learning. Besides that, she mentioned that her most important value was being religious. The school document, which related to the experience was sought to check how these strategies and values were reflected. It can be seen in figure 6.1.

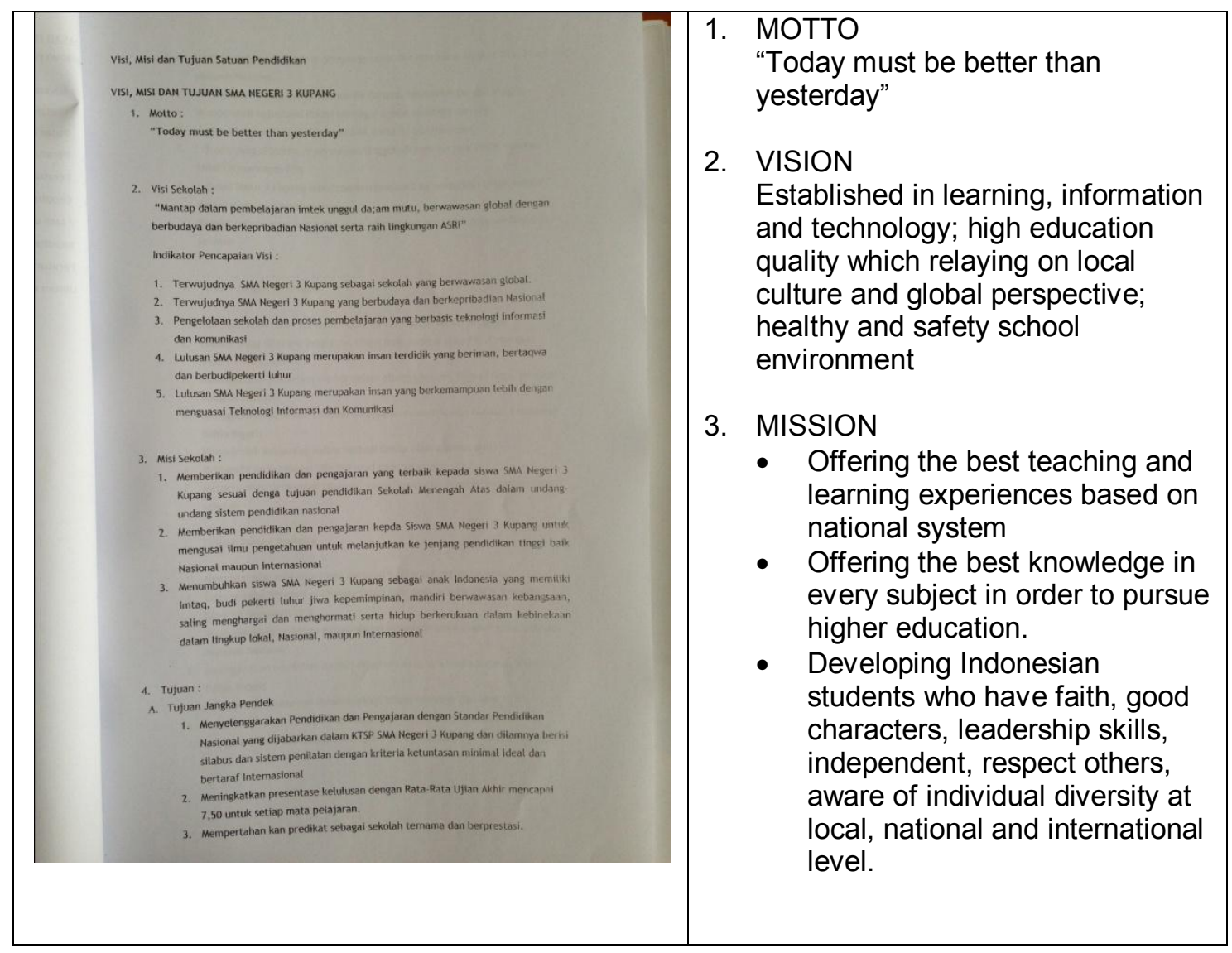

Figure 6.1: School vision and mission (Case: Fanggidae)

The school where Fanggidae worked had a motto, which was 'today must be better than yesterday'. The school vision includes learning through IT, establishing a high quality of education that relies on local culture; and creating healthy and safe school environment. It also stated in the mission that this school will develop students who have faith, good character, as well 
as leadership skills. This document analysis identified that Fanggidae's personal values were relevant to the school document.

\subsection{Case: Ndoen}

Ndoen is a male school principal who led one of the highest achieving schools (senior high school) in this province. He 53 years old, and is leading 1735 students and 100 teachers at his school.

\subsubsection{Life experience}

In his reflection Ndoen described his leadership roles since he was at elementary school. He had a leadership role as a classroom representative when he was at elementary school, junior high school, and senior high school. He recalled that some teachers at his school treated him differently, for example when he acted badly at school, he was not punished, as the teacher said: "he doesn't need to be punished because he's the smartest student in our school'. He was also one of the committee members in the students' association when he was at junior high school.

When Ndoen graduated from teaching school/college (equal to senior high school level), he intended to take a major in mathematics at University, however, his teaching qualification did not allow him to enrol in the mathematics department. To take a major in mathematics, students must graduate from regular high school, rather than teaching school/college. Thus, Ndoen only had two options: to enrol in the English department or to enrol in the Bahasa/Indonesian department. He decided to take English as his major at University. Ndoen explained that:

I was entering a 'wrong room' when I was at teaching college, when I graduated from junior high school, my score in mathematics was 99 of 100, however I had no guidance, no one told me to study at senior high school, thus I went to teaching college without knowing I wouldn't be able to take mathematics at University.

Even though mathematics was still an interest, he believed taking English was the best decision he made as it was valuable for his future career and livelihood. He struggled to learn English in the beginning, but with his motivation and as he explained his 'smart-brain', he could learn English conversation and grammar easily within 3 months. 
There was a time when Ndoen did not feel confident to take the role of a school principal, because he felt inexperienced. Based on his explanation, he had never been a vice principal, thus he was unsure of his leadership skills and abilities. He said that he depended on his brain and intuition to lead. Surprisingly, his first principalship was in an SMA 1 high school. This high school based on Ndoen explanation was one of the best high schools in this city. During the interview, Ndoen mentioned several times, that he was a person that always obeys the rules, and this could be one of his good leadership qualities.

When Ndoen was asked about his opportunities and challenges, he described how challenges and opportunities were equal in building his talents and creativity. For example, he explained how his experience living with his uncle when he was young provided the opportunity to learn the same skills as his uncle had, which were the ability to repair electronic devices such as TVs, and radios, as well as to repair watches. However, at the same time, this was his challenge as well. Living with his uncle meant he has to support his uncle to repair those devices until late at night, and also there was a time, when his uncle hit him with an iron stick if something went wrong. The reason Ndoen had to live with his uncle was because he came from a low economic background, which meant his parents were not able to fully pay his school fees or the cost of his accommodation in the capital city of NTT province. Luckily, Ndoen received a scholarship for two years when he was at teaching school. Later on in his life, he was able to make money with his skills in repairing electronics devices as well as automotive skills, and his ability to provide English translations. When Ndoen was asked whether he got the repairing skills from his uncle, he did not admit that clearly, instead he said that he hated his uncle and the skills he got were self-taught, it was just his hobby.

Could be...maybe I was influenced by my uncle, but when I was living with his family, I hated him, because, usually I helped him until 1am$2 a m$ in the morning. But soon after I moved from his house, I did remember some repairing skills I learnt from my uncle... When I was young I often took a walk passing a motorbike workshop where I stopped by and saw them repairing the motorbikes, that was where I got my skills, not because of my uncle but I think it because I have a smart-brain. 
Another opportunity Ndoen had was entering the University without a test, because he was one of the top five ranking students from the teaching school/college. This was a privilege for the top ranking students to enrol at the University without a test. Despite that fact that he could not take mathematics courses, he met some friends who were happy to help him improve his English abilities. Ndoen said that he could easily learn something new because of his smart-brain. He recalled his experience when he was at school level, when other friends were struggling and stressed with algebra, physics and mathematics, he could do all those subject very well.

When Ndoen was asked who his role model were, he mentioned that his principals and teachers. There were two principals who inspired him, his elementary school principal when he was a student and another high school principal when he was a teacher. This principal influenced him a lot, in terms of punctuality and the ability to remember all of the students' names:

When I was in a high school as a teacher, my school principal is a diligent man. He came to school at 6am, and I usually came at 6.30. I tried to come earlier than him to show my respect, I came five minutes before 6am. He hasn't come yet, I was so proud of myself, but the following day when I came 5 minutes before 6am, he was there already. Hahahaha... He was a great principal; he could remember all the names of students, something that I can't do!

He explained that his algebra and mathematics teachers also influenced him in some ways. Those teachers were his favourites because when they came to classroom, they did not bring anything except chalks, ruler, and compass. They never brought any notes or textbooks when they were teaching. They came to the classroom and wrote mathematic formulas in the whole blackboard. Ndoen seemed to admire them very much for their abilities to memorize mathematic formulas.

In his early principalship, Ndoen faced a student sdemonstration, even though he was not the target. This was a result of the previous school principal's decision to move one of the teachers to another school. The students really liked this teacher and were angry because of this issue. As the new principal, Mr Ndoen had to deal with this situation: not only he was responsible in front of the government, but also with parliament. This was a massive issue in Kupang city and all over the local newspapers. He was responsible for what the previous principal did. After a long debate at 
parliament, he solved the problem because he was fully responsible for what happened at his school.

During the interview Ndoen articulated several values he held. The most important value mentioned was intelligence, followed by patience. However, he said that humility and humour were also important in leading a school where teachers and students around him would feel relaxed. Other values explained including competition, respect, self-discipline, openmindedness and honesty. He explained how he measured intelligence:

In my opinion, intelligence is the most important value; sometimes we met people who aren't smart but intelligent. I can tell which one of my teachers who aren't intelligent. I just need to make a joke, when everybody was laughing, and I found teacher who was laughing too late towards the joke. I can tell that this person isn't intelligent. I usually made a further encouraging discussion with this teacher.

The most important value held by Ndoen was in line with characteristics of influential people such as his principals and his teachers. This indicated that his role models had shaped his values in his future career.

\subsubsection{Leadership practices.}

Ndoen's leadership principles were leading with affection, and teaching students with care. Ndoen explained that he had to understand his teacher and students' characteristics and capacities. He also built informal relationships with teachers. He had around 100 teachers, who regularly coordinated with him; he made himself available anywhere around the school:

I use less bureaucracy with all teachers, if the teachers wanted to see me, they didn't have to come here (at his office) formally, if they met me in front of the toilet or at the school-yard, we could discuss.

The above statements reflected that he was trying to be close to his teachers and breakdown boundaries. This was in line with his principle of leading with affection. Thus his first managerial strategy in leading this school was "holding all school's member as one unit of strength". For example, he worked with the vice principal and the teachers as he fully understood if he was alone in front line, he would not be successful. Another managerial 
strategy explained by Ndoen was weekly regular meetings with all teachers and staff. In the meetings, they discussed the school's challenges and how to solve problems. For example, financial issues, low commitment teachers, and school rules.

Ndoen realized that his approach to the teachers had both positive and negative aspects. The way Ndoen treated his teachers made the teachers loyal to him and encouraged them to work closely with him to solve problems, however, as a result Ndoen admitted that he had difficulty in challenging his teachers when they made mistakes. He said that one of his weaknesses was not being able to be straight forward, explaining:

We solved some problems within this school with a familial approach, some teachers who made mistakes or indiscipline usually they knew that they didn't obey the school's rule without me needing to explain their mistakes. However, some teachers were reluctant to receive some feedback. I know I had to do something with those teachers, I just I didn't know the best way to talk to them without hurting their feelings.

When Ndoen was asked what kind of school rules teachers had to obey in the above case, he gave an example of punctuality; it was expected that all teachers arrived on time at school. However, he gave some exceptions if the weather was not so good or transportation problems that delayed teachers coming to school.

Ndoen explained managing 100 teachers was definitely not a simple task, especially for a high achieving school. Throughout the interview, he explained that to ensure teachers' quality of teaching; he conducted regular supervisions and unscheduled supervisions, as well as classroom observations. When he was asked whether he gave feedback after his supervisions and observations, he said that:

I always gave input toward the subject taught. I matched between what was in the daily learning plans with the real teaching process in the classrooms. Even though, I wasn't mastered in the subject taught, but my principle is I have to learn all the subjects taught in my school, I could learn from books, magazines, even from children's magazines, there were a lot we could learn these resources. I also encouraged my teachers to learn from the internet. 
Ndoen discussed how he supported his teachers to engage in teacher professional development. He asked his teachers to join the teachers' working group. He believed the teachers could get help from this group and get to know their weaknesses. In the teachers' working group, teachers' capacities in teaching would be upgraded through a series of workshops and discussions. In addition, he encouraged his teachers to learn new information from resources, because he believed that the students were learning faster than the teachers did. Based on Ndoen observation, students learnt faster than teachers in terms of learning new technologies, this to minimise the gap between teachers and students capacities about new technology, Ndoen encouraged his teachers to learn how to use the internet.

However, when Ndoen was asked whether he joined principals' working groups, he said he had not. Instead, he showed his book collections on his office table. Some of the books were about leadership for principals, and other books about motivation. He pointed one particular book he seemed very proud because the author graduated from his school, he explained:

This book was written by a Timorese that only graduated from high school, this school, but he had written several books. I liked the author's writing style, who had really nice perspective about Timorese culture, he never studied at University but he is a great author.

Ndoen's school had a big building and a very large school yard, and was located in the main busy street in Kupang City. Ndoen explained how he maintained his school's safety and environment. His school had a proper school gate and security guards. He explained that he also had good coordination with the school community; otherwise, the school community would damage the school's facilities. In general, Ndoen stated that the relationship between his school and the community had always been positive. There was no regular student health check in this school by the community health unit, but this school had first aid in case of an accident.

The last question Ndoen was asked was about critical friends, he mentioned that to know about his leadership achievement, he went to the school's cleaners. Ndoen believed that all the school cleaners were always honest to him and they did not make up stories or giving false impressions, 
they were the first people to be asked. However, he always asked the teachers to speak up about anything when they had school meetings.

\subsubsection{School documents}

Ndoen's life story indicates that he is very good at mathematics and also

English. School document that may support and clarify what has been said by Ndoen were accessed.

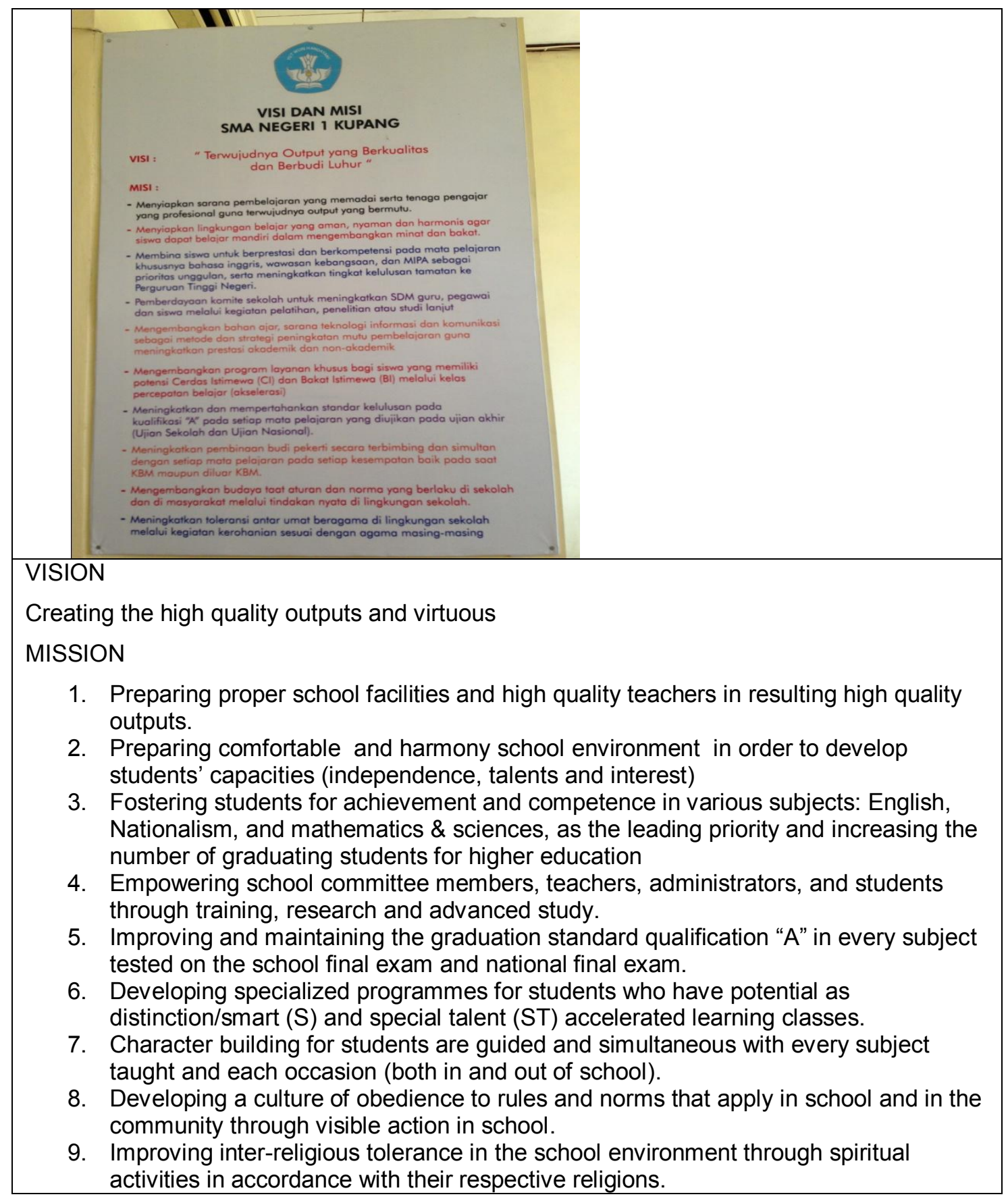

Figure 6.2: School vision and mission (Case: Ndoen) 
The school vision stated in figure 6.2 was to create good quality and virtuous students. The school mission states that this school would provide good facilities and qualified teachers to support teaching and learning. It also stated that this school will focus on three main subjects, English, citizenship and mathematics. There is a connection between Ndoen personal experience and his leadership practices.

\subsection{Chapter summary}

This chapter presents findings from two principals at the high school level. There were similarities between the two participants, such as both of them coming from a low socio-economic background, and having to live with people other than their parents, and received a scholarship. There were also some critical events that differed including loss of a mother in early young age (Fanggidae) and being hit by an uncle when a teenager (Ndoen). The most important value they held was also different, religious values were chosen by Fanggidae, and self-discipline by Ndoen. Leadership practices of the participants showed that both of them had their own different strategies. Moreover, Ndoen did not join principals' working group, while Fanggidae joined a principals' working group as secretary. The summary of the findings can be seen in appendices $\mathrm{P}$ (Fanggidae) and Q (Ndoen) 


\section{CHAPTER SEVEN}

\section{Discussion}

\subsection{Chapter overview}

The purpose of this study was to explore how principals' life experiences influenced their authentic leadership practices. The research methodology chosen was an embedded case study design. The first section will discuss the themes that emerged through the data analysis process, including childhood experiences, role models, and previous leadership experiences and values. This will be followed by discussion on the leadership practices based on the five leadership dimension proposed by Robinson (2011). Section two will respond to the main research question: in what ways do life experiences influence the development of authentic leadership practices of school principals.

\subsection{Childhood experiences}

Childhood experiences of all principals in this study appeared to have impacted on their leadership capabilities. Thus the challenges faced by the participants will be summarised. This will be followed by a discussion of the impact of the challenges on their leadership practices.

\subsubsection{Childhood challenges}

A commonality identified from the findings was that four out of six principals faced significant challenges in their childhood. These challenges varied from financial problems, having to live with people other than parents and the loss of a parent. The participants' life stories confirmed that leadership could be built out of challenges as suggested by Shamir and Eilam (2005). Previous research has suggested that certain life events may be critical to develop authentic leaders (Bennis \& Thomas, 2002; Gardner et al., 2005; Northouse, 2013). Table 7.1 presents the challenges faced by the participants in their childhood and the impact on their leadership development. 
Table 7.1: Childhood experiences

\begin{tabular}{|l|l|l|}
\hline \multicolumn{1}{|c|}{ Participant } & \multicolumn{1}{|c|}{ Childhood experience } & \multicolumn{1}{c|}{ Impact on leadership capabilities } \\
\hline $\begin{array}{l}\text { Gerson } \\
\text { Ndoen } \\
\text { Fanggidae }\end{array}$ & $\begin{array}{l}\text { Financial problems: paying } \\
\text { school fees, had no } \\
\text { transportation to go to school. }\end{array}$ & $\begin{array}{l}\text { Managed to get a scholarship: } \\
\text { intelligence, independence, and } \\
\text { toughness. }\end{array}$ \\
\hline $\begin{array}{l}\text { Seran } \\
\text { Fdoen }\end{array}$ & $\begin{array}{l}\text { Living separately from their } \\
\text { parents at a young age. }\end{array}$ & $\begin{array}{l}\text { Helped their relatives doing house } \\
\text { work and jobs: patience, hard work, } \\
\text { ability to cope with difficulty, } \\
\text { vocational skills, toughness, } \\
\text { creativity, and resilience. }\end{array}$ \\
\hline Fanggidae & $\begin{array}{l}\text { Difficult family circumstances: } \\
\text { lost her mother when she was } \\
12 .\end{array}$ & $\begin{array}{l}\text { Took leadership role within her } \\
\text { family: independence, courage, and } \\
\text { strength. }\end{array}$ \\
\hline
\end{tabular}

Gerson, Seran, Ndoen and Fanggidae all had financial problems impacting on their ability to pay school fees and travel to school. Paying school fees can be difficult for large families and may affect whether a parent can send their children to school. Three of the participants managed to get a scholarship, so that their parents did not need to pay the school fees. This required academic results above the average and needed hard work and commitment. In another experience related to transportation, the participants mentioned that they needed to walk long distances to school, while other students may travel by other modes of transport or the parents dropped them off. The experience of walking a long distance alone may have developed participants' capacities for being tough and independent, because they relied on themselves not their parents, to get to school.

Three of the principals had accommodation difficulties, and had to live separately from their parents at a young age. Most of these experiences were reportedly unpleasant, including having to help their relatives with the housework and jobs as a substitute to avoid paying for their accommodation. In the specific case of Ndoen, he was hit as punishment when he failed to help his uncle in repairing electronic devices. Later in life, not only can Ndoen repair electronic devices, but also he has the automotive skills to repair a broken car or motorcycle because he often stopped by a car workshop on the way home from school. Ndoen did not suggest that these vocational skills were influenced by his uncle; instead he stated that he was self-taught. This showed how Ndoen learned and adapted vocational skills which made him more independent and enabled him pay his school fees. These findings 
agree with the previous research by Shamir and Eilam (2005); that leadership can be developed out of challenges.

Fanggidae whose mother died when she was 12 years old, explained that this was one of her negative events. Losing a parent at a young age resulted in many challenges. Fanggidae's elder siblings lived away from home in order to study, so she had to take care of her younger siblings, as well as being a 'leader' within her family in terms of domestic-work. This experience may have influenced the development of qualities such as courage, strength and independence.

The events and experiences chosen by authentic leaders to appear in their life-stories reflect the leaders' self-concepts and their concept of leadership (Shamir \& Eilam, 2005). Previous research confirms that certain trigger events from life-stories can benefit authentic leadership development, especially in stimulating positive growth and development (Avolio, 2005; Luthans \& Avolio, 2003). Trigger events in a previous study have been viewed as involving crises and negative events (e.g.: loss of a loved one, health problems, financial hardships), and have served as important forces in the authentic leadership development (Gardner et al., 2005). The current research agrees that financial problems and loss of a significant person may influence the development of authentic leadership.

Although both positive and negative events can trigger the development of leadership capabilities, in this research negative events are more obvious in participants' childhood stories. Toor and Ofori's (2008) research revealed that experiences during childhood both within family and outside family significantly influenced the leadership development at later stages. In this study, the participants who had to live with people other than parents (Seran, Ndoen and Fanggidae), and the participants who lived with their family (Vama, Louisa and Gerson) may have had the same opportunity to develop leadership capabilities. However, other researchers argue that childhood events shape charismatic leaders (O'Connor, Mumford, Clifton, Gessner \& Connelly, 1995), without mentioning other types of leadership, such as authentic leadership. Findings in the current study seem to disagree with this research conducted by O'Connor et al. (1995). These interviews reveal found that receiving a scholarship can be seen as a positive trigger 
event, while other experience such as financial problems, living separately from parents and loss of a parent are negative trigger events in the development of authentic leadership.

\subsubsection{Childhood experiences: impact on leadership practices}

There are two main focuses for findings related to the participants' goals as school principals. First, half of the participants set goals related to students' academic achievement (Seran, Gerson, Fanggidae) and the second, the other half focused on the quality of teaching and learning (Vama, Louisa, Ndoen). It was found that principals' life stories were congruent with some of the school documents, such as school vision, missions and rules. For example, the mission of Fanggidae's school including offering the best teaching and learning experiences, while the vision of Ndoen's school was creating high quality outputs and virtuous students. Moreover, Seran provided a school document which aimed to improve the standard competence of teachers by establishing a subject teachers' working group. An explanation for these school mission statements could be that highperforming school leaders focus on improving teaching and learning, establishing clear educational goals, planning the curriculum, and evaluating teachers and teaching (Robinson et al., 2009). However, most research in the western context on leadership that connects school leadership to student learning was based in elementary schools rather than the high school level (Sebastian \& Allensworth, 2012). The present study found that principals focused on student learning not only in elementary schools, but also in junior and senior high schools.

There were some links between participants' childhood experiences and their leadership goals. Authentic leaders have a highly developed sense of how their roles as leaders involve a responsibility to act morally and in the best interests of others such as students and teachers (May et al., 2003). For example, Fanggidae's goal was to improve students' results, in particular to win academic competitions. Based on Fanggidae's life story, getting a scholarship meant to be best and have the highest academic results among her scholars. There was a link between Fanggidae's personal experience of receiving a scholarship and her current leadership practice which was "to improve students' results", in particular to win academic competitions. 
In another example, Ndoen articulated his goal as "leading with affection and teaching students with care"; the terms of "affection" and "care" appeared in his leadership goals which were somehow different from other goals. Ndoen's had the unpleasant experience of living with his uncle who sometimes hit him. Based on his childhood experience, Ndoen expects other people to treat students with "affection" and "care" possibly to avoid any students having the same experience as him. Starratt (1991) offers a theory for practices in educational leadership where ethics of caring are one of the pillars in addition to ethics of critique and justice. Further, Starratt argues that an ethic of caring would ideally be grounded in the belief that the integrity of human relationships is of significance, and the school as an organization should hold the good of human beings within it as important. Thus, it could be argued that life experience may influence the leader to set their leadership goals.

There is a link between childhood experience and leadership strategies related to financial support for students. This relates to the second dimension of leadership: resourcing strategically. For example, Gerson had a strategy in terms of financial management support for students from low economic backgrounds, he asked school alumni to donate money. As Gerson had transportation problem when he was at school, this may have influenced his current leadership practice of prioritising payment of students' transport costs.

Seran's leadership practice indicated that he led by example; meaning that he acted as a good example for his teachers and children with regard to self-discipline. In addition, Seran mentioned that leading by example included obeying the school rules. Based on his childhood experience, Seran was an obedient child who followed his family rules. Leadership practices in Indonesia may not similar to those in neighbouring countries. Leading Indonesian people is not the same as leading Westerners nor is it the same as leading other Asian people (Irawanto, 2009). From the roots of Indonesian history, the Javanese culture, a collectivist, obedience and group harmony focused culture, has had a strong influence over a long period of time (Irawanto, Ramsey \& Ryan, 2011). Thus, Seran's childhood experience and 
practice might be influenced not only by his culture on Timor island but also by Indonesian culture more generally, such as valuing obedience.

\section{Table 7.2: Leadership practices and childhood experiences}

\begin{tabular}{|l|l|l|}
\hline \multicolumn{1}{|c|}{ Participants } & Childhood experiences & $\begin{array}{l}\text { Leadership practices in setting } \\
\text { goals and expectations }\end{array}$ \\
\hline Fanggidae & Receiving a scholarship & $\begin{array}{l}\text { To improve students' results, win } \\
\text { in academic competitions (goals) }\end{array}$ \\
\hline Ndoen & $\begin{array}{l}\text { Had to live other than his } \\
\text { parents, often hit by his uncle }\end{array}$ & $\begin{array}{l}\text { As a school principal, his goal is } \\
\text { 'leading with affection and } \\
\text { teaching students with care' } \\
\text { (goals) }\end{array}$ \\
\hline Participants & Childhood experiences & \multicolumn{1}{|c|}{$\begin{array}{l}\text { Leadership practice in } \\
\text { resourcing strategically }\end{array}$} \\
\hline Gerson & $\begin{array}{l}\text { Had difficulty to travel from } \\
\text { home to school (had to walk } \\
\text { to school) }\end{array}$ & $\begin{array}{l}\text { As a school principal, he agreed } \\
\text { to allocate some funds for } \\
\text { students' transportation (strategy) }\end{array}$ \\
\hline Seran & $\begin{array}{l}\text { Parents and grandparents } \\
\text { taught him about self- } \\
\text { discipline }\end{array}$ & $\begin{array}{l}\text { Leading by example, applying } \\
\text { self-discipline and obeying the } \\
\text { school rules }\end{array}$ \\
\hline
\end{tabular}

Table 7.2 summarises how the childhood experiences of four principals may relate to their leadership practices. These findings echo Northouse's (2013) study on authentic leadership development; that found particular life events might be critical factors in encouraging future leadership. In addition, an individual's life stories may inform authentic leadership development (Northouse). This current study suggests that principals' life experience may impact on their leadership practices such in setting goals and resourcing strategically to achieve these goals.

\subsection{Role models}

The section will discuss the role models of the principals and how they appeared to influence the principal's leadership capabilities and practices.

\subsubsection{Significant role models}

Various role models appeared in principals' life-stories: parents; spouses; teachers; school principals; and government officials. One participant had one role model, while other participants mentioned two to five figures. The participants' role models are presented in table 7.3. 
Table 7.3: Participants' role models

\begin{tabular}{|c|c|c|}
\hline Participant & Role Models & Impact on leadership capabilities \\
\hline $\begin{array}{l}\text { Gerson } \\
\text { Seran } \\
\text { Ndoen } \\
\text { Fanggidae }\end{array}$ & $\begin{array}{l}\text { School: } \\
\text { Principals, teachers, } \\
\text { vice chancellor. }\end{array}$ & $\begin{array}{l}\text { Intelligent, good interpersonal skills, diligent, } \\
\text { punctual, good-teacher, concerned with } \\
\text { student learning, good-principal, respect the } \\
\text { school environment. }\end{array}$ \\
\hline $\begin{array}{l}\text { Vama } \\
\text { Louisa } \\
\text { Gerson } \\
\text { Seran } \\
\text { Fanggidae }\end{array}$ & $\begin{array}{l}\text { Family: } \\
\text { Husband, parents. }\end{array}$ & $\begin{array}{l}\text { Calm, focused, patient, positive thinker, open } \\
\text { to suggestion, self-disciplined, talented } \\
\text { leaders, responsible, loyal, self-disciplined, } \\
\text { humble, appreciative of other people's work, } \\
\text { forgiving, independent, honest. }\end{array}$ \\
\hline Louisa & $\begin{array}{l}\text { Colleagues: } \\
\text { School supervisor, other } \\
\text { colleagues. }\end{array}$ & Good-teacher, loyal, open to suggestion. \\
\hline $\begin{array}{l}\text { Fanggidae } \\
\text { Ndoen }\end{array}$ & Government officials. & $\begin{array}{l}\text { Responsible, loyal, disciplined, working } \\
\text { without complaining. }\end{array}$ \\
\hline
\end{tabular}

Four out of six participants explained that their school principals were their role models, two mentioned teachers, while one participant explained that his vice chancellor was his role model. It is interesting to note the participants who were school principals from the highest achieving schools chose their school principals as role models. Leadership characteristics such as intelligence, good interpersonal skills, diligence, punctuality, how to be a good-teacher, concern with student learning, inspiration to become a principal, and respect for the school environment may have been learnt from these role models. According to Shamir et al. (2005) authentic leaders do not imitate role models, but use them as the reference to construct self-concept. Thus, in this current research, the role model's qualities may have influenced the development of participants' self-concepts.

All the female participants (Vama, Louisa, and Fanggidae) mentioned their husbands as their role models and their sources of influence. For example, Vama explained her husband was patient, calm, and a positive thinker. Furthermore, these characteristics have influenced her leadership practices. She tried to behave wisely in front of her teachers and the parents, and drew on her husband's characteristics to influence her leadership qualities.

Louisa took many years to apply for principalship because her husband did not encourage her. Even though other people realized her leadership potential, because of her husband she decided not to apply. She finally decided to apply after her husband passed away. Furthermore, there was a tension between Vama and her husband because of the time she 
spent at work. According to Shamir et al. (2005) many leaders' life-stories emphasize learning from role models of various types. A previous study by Toor and Ofori (2008) points out that teachers, parents, and mentors are significant in the development of leadership among the emergent leaders, and educational and occupational experiences were significant in leadership development. However, spouses are not mentioned in any other research as role models of the leaders. This current research points out that spouses can be one of the sources of influence on leadership as well as a barrier.

Besides spouses, parents were also prominent role models for Louisa, Gerson, Seran, and Fanggidae. When people name the greatest influences on their lives, parents are usually at the top of the list; therefore, it seems reasonable to argue that family life can affect the development of leadership (Smith \& Piele, 2006). For example, Seran explained that his parents taught him how to be independent, responsible, disciplined and honest; while Fanggidae mentioned that her father also taught her about responsibility, loyalty, discipline and working without complaint.

The participants learnt some of the leadership capabilities and skills listed in table 7.3, from their role models including being calm, disciplined, and thinking positively. Leadership competences found in the present study include intelligence, responsibility, diligence, and independence. Leadership skills indicated in this study include technical knowledge and skills, and interpersonal skills. This finding supports previous research by Northouse (2012), that leadership skills consist of interpersonal skills, even though administrative skills and conceptual skills as proposed by Northouse did not appear in this research. The leadership capacities that appeared in this current study were similar to leadership characteristics proposed by Yukl (2013) and Smith and Piele (2006). Thus the current research identified a lack of awareness of both administrative skills and conceptual skills.

Role models are seen as part of personal history within leadership experiences (Gardner et al., 2005). The school principals in this current research may have gained self-awareness from reflection on their role models. Shamir et al. (2005) found out that many leaders put an emphasis on role models in their life-stories. This current study used similar procedures proposed by Shamir and Eilam (2005), where the participants were asked to list their role models and then reflect on the reasons for choosing these 
models. One or more positive role models who demonstrated high levels of integrity, transparency, and trustworthiness were significant forces in the leader's personal growth and resulting self-awareness (Gardner et al., 2005). Participants may have defined or re-defined themselves through their role models. Various studies (Shamir et al., 2005; Smith \& Piele, 2006; Toor \& Ofori, 2008) support the findings of the present study; various role models such as from family or school are important in influencing participants' authentic leadership development.

\subsubsection{Role models: impact on leadership practices}

Role model impact was found in the leadership practice in ensuring quality teaching (the third leadership dimension) and ensuring healthy and safe environment (the fifth leadership dimension) as indicated in Table 7.4.

\section{Table 7.4: Leadership practices: learning from role models}

\begin{tabular}{|c|c|c|}
\hline Participants & $\begin{array}{l}\text { Learning from the role } \\
\text { models }\end{array}$ & Ensuring the quality of teaching \\
\hline $\begin{array}{l}\text { Gerson } \\
\text { Ndoen }\end{array}$ & $\begin{array}{l}\text { Principal: taught him about } \\
\text { discipline and punctuality. } \\
\text { Teachers: were good teachers, } \\
\text { smart, intelligent and } \\
\text { concerned with their students. }\end{array}$ & $\begin{array}{l}\text { All teaching schedules have to be } \\
\text { fixed in the beginning of the } \\
\text { semester. } \\
\text { The teachers had to obey the school } \\
\text { rules. } \\
\text { Only qualified teachers are allowed } \\
\text { to teach the high graders for } \\
\text { additional lessons. } \\
\text { Conducted regular supervision, } \\
\text { classroom observations, and } \\
\text { feedbacks to the teachers. }\end{array}$ \\
\hline $\begin{array}{l}\text { Fanggidae } \\
\text { Lousia }\end{array}$ & $\begin{array}{l}\text { School supervisors: conducted } \\
\text { classroom observation, regular } \\
\text { monitoring and supervision, } \\
\text { classroom management. }\end{array}$ & $\begin{array}{l}\text { Conducting classroom observation, } \\
\text { Giving inputs and feedback to the } \\
\text { teachers; } \\
\text { Working collaboratively with school } \\
\text { supervisors and teachers coordinator } \\
\text { to develop syllabus, daily learning } \\
\text { plans, learning material, teaching } \\
\text { aids and students' evaluation tests. }\end{array}$ \\
\hline Participants & $\begin{array}{l}\text { Learning from the role } \\
\text { models }\end{array}$ & Healthy and safe environments \\
\hline Seran & $\begin{array}{l}\text { Had a role model who has a } \\
\text { rule to maintain the school's } \\
\text { environments (vice } \\
\text { chancellor). }\end{array}$ & $\begin{array}{l}\text { Applied the same rule as the role } \\
\text { model, for example: school building } \\
\text { must be clean from scratch. }\end{array}$ \\
\hline
\end{tabular}

Gerson's role models were his school principal, and algebra and geometry teachers. The reasons why he chose them as role models were because they were good teachers, smart, and cared about their students, and they also taught him about discipline. There is a link between the 
characteristics of Gerson's role models and his leadership practices. For example, Gerson explained that all teaching schedules were fixed at the beginning of the semester and only qualified teachers taught additional lessons for the ninth graders. This is in line with the third dimension of leadership as proposed by Robinson (2011) that is ensuring quality teaching. Fixing teaching schedules at the beginning of the semester may be a reflection of discipline that Gerson learnt from his role models, and his use of only qualified teachers may be a reflection of his role model characteristics of effectiveness and smartness. Similar to Gerson, Ndoen also had a school principal and teachers as his role models. The school principal influenced him to be disciplined and punctual, while teachers have influenced him to ensure that teachers had enough support such as feedback, and regular supervision.

Fanggidae and Louisa had role models who were school supervisors and used to monitor and supervise the schools regularly, as well as doing classroom observation. These activities influenced Fanggidae and Louisa on ensuring teaching quality in their schools such as conducting classroom observation, giving feedback to the teachers, and developing syllabus and daily learning plans. Fanggidae mentioned that she worked collaboratively with school supervisors and teacher coordinators in ensuring the quality of teaching.

Seran had an inspiring vice-chancellor as his role model when he was at university. This vice-chancellor had a strict rule about school environments; he did not allow the university buildings to get dirty. In terms of healthy and safe school environments, Seran applied the same rules and standards to maintain his school as his role model did in the past. This illustrates how a role model may be a source of influence for principal leadership practices and relates to the fifth dimension of leadership practice ensuring an orderly and safe environment proposed by Robinson (2011).

These findings reflected principals' practices in ensuring teaching quality by managing school curriculum, doing classroom observation, conducting regular monitoring and supervision of the teachers. This relates to the third leadership dimensions derived from the BES that leaders improve the quality of teaching and the curriculum (Robinson, 2011). The current research also echoes Alton-Lee's (2008) study, in that there were two direct 
links in the relationship between principal and teachers: and the first, direct involvement in the support and evaluation of teaching through regular classroom visits and provision of formative and summative feedback to teachers; and the second, direct oversight of curriculum through school-wide coordination across classes and year levels and alignment to school goals.

\subsection{Previous leadership experiences}

Previous experiences shaped the leadership capacities of the school principals in this study. The past leadership experiences including preparation for principalship roles and the impact on principal practices will be discussed in this section.

\subsubsection{Previous leadership experiences}

The positive leadership experiences found in the life stories varied from the leadership roles at school to the leadership experiences as identified in table 7.5 .

Table 7.5: Significant leadership experiences

\begin{tabular}{|l|l|l|}
\hline \multicolumn{1}{|c|}{ Participant } & \multicolumn{1}{|c|}{ Leadership experiences } & \multicolumn{1}{|c|}{$\begin{array}{c}\text { Impact on leadership } \\
\text { capacities }\end{array}$} \\
\hline $\begin{array}{l}\text { Seran } \\
\text { Ndoen }\end{array}$ & $\begin{array}{l}\text { At school: } \\
\text { classroom representative. }\end{array}$ & Self-confidence, intelligence. \\
\hline $\begin{array}{l}\text { Seran } \\
\text { Ndoen }\end{array}$ & $\begin{array}{l}\text { In organisations: } \\
\text { leader or member of students' } \\
\text { association. }\end{array}$ & $\begin{array}{l}\text { Increased self-confidence and } \\
\text { self-reliance. }\end{array}$ \\
\hline $\begin{array}{l}\text { Vama } \\
\text { Gerson }\end{array}$ & $\begin{array}{l}\text { In professional development: } \\
\text { involved in the teachers' } \\
\text { working group, in the } \\
\text { examination development } \\
\text { team, teacher instructor. }\end{array}$ & $\begin{array}{l}\text { Motivation and } \\
\text { encouragement to become } \\
\text { school principal, familiar with } \\
\text { principal work. }\end{array}$ \\
\hline Louisa & $\begin{array}{l}\text { In the community: } \\
\text { women organisations, church } \\
\text { services. }\end{array}$ & $\begin{array}{l}\text { Understanding other people's } \\
\text { characteristics, developed } \\
\text { leadership skills i.e. } \\
\text { interpersonal skills, spiritual } \\
\text { intelligence. }\end{array}$ \\
\hline
\end{tabular}

Leadership roles at school and at university shaped the leadership capacities of Seran and Ndoen. These participants mentioned that involvement in student organisations improved their self-confidence, intelligence, and self-reliance. Typical leadership roles within the students' association included organizing student events, conducting class-meetings, and taking part in the new students' orientation. 
Vama was involved in the teachers' working group as well as in the examination development team and Gerson was a mathematic instructor. Both participants mentioned that their experiences motivated and encouraged them to become school principals. Taking part in the examination development team was a prestigious role as it reflects academic ability and capacity. Similarly, being a mathematics instructor was also a valuable experience and shows that someone has academic distinction at mathematics. Being an instructor also gave Gerson the opportunity to train other mathematics teachers and share his knowledge.

Other findings revealed in this current study include the fact that four out of six participants took the principal's role when they were teachers and two out of four used to be vice-principals. The other two participants mentioned that they felt inexperienced and were also unsure that they would become a good principal. They did not take any principal roles and had never been a vice principal. The experience of taking principalship roles familiarised the participants with the role and responsibilities. When the participants attended principal meetings on their principals' behalf; they discussed both academic and non-academic issues and decided to take action at their schools. Through this process, some participants explained that other school principals recognized they had leadership capacities and abilities. As a result, once they became school principals, they knew how to tackle academic and non-academic issues. This finding is consistent with the theory presented by Shamir et al. (2005) that leadership development may be built through learning from experience. Those experiences helped the participants developed greater self-concept and define themselves as leaders.

Vama explained that she was unsure whether she would become a good school principal and never imagined becoming a school leader. Ndoen was asked by his school principal when he was a teacher to be a school principal but was not confident to be a school principal when he was a teacher. These views are in line with Shamir and Eilam's (2005) description about a gradual process of self-clarification, starting from a vague selfidentity and progressing through encounters with various real characters.

Louisa had the courage to take a principal's role as a result of the skills she had developed through participation in women's organizations in 
her community and through religious services in church. Through social activities with community members, Louisa developed leadership skills such as interpersonal skills, and spiritual intelligence. Louisa's experience reflected that leadership is considered a social construction (Southworth, 2002; Dimmock \& Walker, 2000). This current research supports the idea of building leadership skills through involvement in community social services.

\subsubsection{Previous leadership experiences: impact on leadership practices.}

Previous leadership experiences may impact on ensuring quality teaching, the fourth leadership dimension; and ensuring healthy and safe environment, the fifth leadership dimension as proposed by Robinson (2011). Table 7.6 shows those leadership practices.

Table 7.6: Leadership practices learning from previous experiences

\begin{tabular}{|c|c|c|}
\hline Participants & Leadership experiences & $\begin{array}{l}\text { Leading teacher learning } \\
\text { and development }\end{array}$ \\
\hline $\begin{array}{l}\text { Seran } \\
\text { Ndoen }\end{array}$ & $\begin{array}{l}\text { Leadership at school and at } \\
\text { University. }\end{array}$ & $\begin{array}{l}\text { Involved in principals' working } \\
\text { group (as the leader) and led } \\
\text { teachers' working group. } \\
\text { Supported teachers to join } \\
\text { subject teachers' working } \\
\text { group. }\end{array}$ \\
\hline $\begin{array}{l}\text { Seran } \\
\text { Ndoen } \\
\text { Vama } \\
\text { Gerson } \\
\text { Fanggidae } \\
\text { Louisa }\end{array}$ & $\begin{array}{l}\text { Leadership in organisations } \\
\text { and in the professional } \\
\text { development. }\end{array}$ & $\begin{array}{l}\text { Involved in principals' working } \\
\text { groups (three of them were the } \\
\text { committees at this group). } \\
\text { Enables teachers to involve in } \\
\text { professional development } \\
\text { (teachers' working group, } \\
\text { subject teachers' working } \\
\text { group). }\end{array}$ \\
\hline Participants & Leadership experiences & $\begin{array}{c}\text { Ensuring healthy and safe } \\
\text { environment }\end{array}$ \\
\hline Fanggidae & Working in the conflict area. & $\begin{array}{l}\text { Created a motto for all school } \\
\text { communities as "being a } \\
\text { police for myself". } \\
\text { Ensured that all community } \\
\text { members keep away from } \\
\text { some trouble that damaging } \\
\text { school facilities. }\end{array}$ \\
\hline Louisa & Leadership in the community. & $\begin{array}{l}\text { Shared responsibility with } \\
\text { parents and school } \\
\text { committees regarding school } \\
\text { facilities. }\end{array}$ \\
\hline
\end{tabular}

Based on the findings, all participants encouraged their teachers to join at least one professional development group available in their district, such as KKG, MGMP, and LPMP. It has been suggested by Young and King 
(2002) that principals play a significant role in developing and sustaining effective professional development and in ensuring coherence among various teachers' development programs. According to Bryk, Sebring, Allensworth, Luppescu, and Easton (2010, as cited in Sebastian \& Allensworth, 2012), strong leadership practices may impact on school processes that affect student achievement. Some of those processes were developing the professional capacity of staff, the learning climate of the school, family and community involvement, and ambitious instruction. Further, from the study by Bryk et al. school principals might be expected to develop school capacity in each of these four areas in order to improve student achievement. Thus, the findings from this study agree with previous studies that stress the importance of school principals encouraging their teachers to take a part in any form of teacher professional development, and this may positively impact on student achievement.

All participants, other than Ndoen, joined the available professional development communities, MKKS (principals' working groups). Professional development supports teachers and principals to learn, enhance and use appropriate knowledge, skills and values (Bolam, 2000). Within MKKS, all school principals in every sub-district have regular meetings to discuss school policies and activities in general, write principals' joint reports, as well as to organize any plans on academic, non-academic and social events. For example, Seran was the leader of the principals' working group and Gerson was the secretary of this group at junior high school level, while Fanggidae was the treasurer of the principals' working group at senior high school level. It can be seen that half of the participants held a significant position among their colleagues in terms of being involved in their professional development communities. It could be relevant to note that joining professional development communities may broaden principal leadership capabilities in applying relevant knowledge as proposed by Robinson (2011).

Continuing professional development was widely accepted as fundamental to the improvement of organisational performance and as a core task of management and leadership (Bell \& Bolam, 2010). Research has shown that effective professional development concentrates on instruction and student learning outcomes, promotes collaboration among peers, 
provides opportunities for reflection, feedback, and critical thinking, and these are sustained and continuous (Corcoran \& Goertz, 1995; Little, 2003). Leadership practices such as promoting or participating in effective teacher professional learning and development have been shown to have a greater impact on student achievement than any other leadership activity (Robinson et al., 2009). Thus, the current research argues that when principals in the highest achieving schools are involved in professional development groups aiming to improve academic and non-academic results, this may positively impact on student learning outcomes, promote collaboration among principals, and offer reflection and feedback.

This research found that principal's previous leadership experiences impacted on their practices in ensuring healthy and safe school environments. It was found that the school principals did not work alone; they shared responsibilities with parents and community members to create school safety and security. Previous studies have suggested that basic needs such as order and safety at school may have strong effects on the motivation and learning for teachers and students (Cornell \& Mayer, 2010; Ripski \& Gregory, 2009). For example, Fanggidae had experience working in the conflict area between Indonesian police/army and the militia (pro Independence for Timor Timur). She created familial values for everyone at school and in the local community to improve quality relationships between school and the community, and it was no surprise when she raised the issue about being "being a police for myself" to keep everyone out of trouble because safety issues may become one of the significant issues affecting her leadership practices. Similarly, Louisa's experience of working in her community impacted on her leadership practices, such as shared responsibilities with parents and local community in regard to school environment and school facilities. Louisa explained that the community members near their schools used school facilities. She reported that community members used school facilities without the responsibility of maintaining those facilities. She came to the community leaders and explained the problems, as a result both parties agreed to improve a safe school environment by enhancing collaboration between school and the local community. 


\subsection{Values}

This section focuses on the values espoused by the principals and how values appeared to influence the principal's leadership practices. The most important values were also discussed.

\subsubsection{Key values}

Key values espoused by participants in this study included self-discipline, honesty, intelligence, patience and religious observance. All participants indicated that they held self-discipline as an important value and four out of six principals indicated that self-discipline was the most important value. Four participants chose honesty as their value; other significant values found in half of the participants were intelligence and patience. One participant listed being religious as the most important value she held. Other values mentioned included humility, humour, trust, and service, challenge, achievement, productivity, openness, tolerance, responsibility, competition, respect, openmindedness, loyalty and integrity. Shamir and Eilam (2005) suggest that leaders' feelings about their role models were associated with their motives and values. Table 7.7 shows what values research participants held, and the possible impacts on authentic leadership practices.

\section{Table 7.7: Values}

\begin{tabular}{|c|c|c|}
\hline Participants & Values & Impact on authentic leadership practices \\
\hline $\begin{array}{l}\text { Vama }\left(1^{\text {st }}\right) \\
\text { Louisa }\left(1^{\text {st }}\right) \\
\text { Gerson }\left(1^{\text {st }}\right) \\
\text { Seran }\left(1^{\text {st }}\right) \\
\text { Fanggidae }\left(5^{\text {th }}\right) \\
\text { Ndoen }\left(7^{\text {th }}\right)\end{array}$ & $\begin{array}{l}\text { Self- } \\
\text { discipline }\end{array}$ & $\begin{array}{l}\text { A principal has to obey any rules (school rules and } \\
\text { administrative rules). } \\
\text { Expect the teachers and the students to obey the } \\
\text { school rule. } \\
\text { Syllabus and daily learning plans have to be } \\
\text { developed in the beginning of the semesters. }\end{array}$ \\
\hline $\begin{array}{l}\text { Fanggidae }\left(2^{\text {nd }}\right) \\
\text { Louisa }\left(3^{\text {rd }}\right) \\
\text { Seran }\left(3^{\text {rd }}\right) \\
\text { Ndoen }\left(9^{\text {th }}\right)\end{array}$ & Honesty & $\begin{array}{l}\text { Creating a culture of trust with parents and school } \\
\text { community. } \\
\text { Creating familial values and maintains a good } \\
\text { relationship with teachers. } \\
\text { Giving feedback regularly to the teachers toward } \\
\text { teachers' quality of teaching. } \\
\text { Creating healthy and safe school environment. }\end{array}$ \\
\hline $\begin{array}{l}\text { Ndoen }\left(1^{\text {st }}\right) \\
\text { Louisa }\left(2^{\text {nd }}\right) \\
\text { Gerson }\left(2^{\text {nd }}\right)\end{array}$ & Intelligence & $\begin{array}{l}\text { Setting a leadership goal that focuses on students } \\
\text { academic results (win in each academic competition, } \\
\text { be the best in academic achievement). } \\
\text { Information and technology (IT) based leadership. }\end{array}$ \\
\hline $\begin{array}{l}\text { Vama }\left(2^{\text {nd }}\right) \\
\text { Ndoen }\left(2^{\text {nd }}\right) \\
\text { Gerson }\left(3^{\text {rd }}\right)\end{array}$ & Patience & $\begin{array}{l}\text { Dealing with the dilemmas or conflicts with teachers, } \\
\text { spouse and local communities. }\end{array}$ \\
\hline Fanggidae $\left(1^{\text {st }}\right)$ & $\begin{array}{l}\text { Religious } \\
\text { values }\end{array}$ & $\begin{array}{l}\text { Shaping faith to God, having spiritual capacities to } \\
\text { support making ethical decision. }\end{array}$ \\
\hline
\end{tabular}


Participants in this study mentioned that they learnt self-discipline from their family members or other significant role models such as teachers and school principals. This echoes one of the characteristics of authentic leaders proposed by George (2003), demonstrating self-discipline. A study conducted in South Sulawesi Province (one of eastern parts of Indonesia) in Indonesia indicated that discipline was also a principal characteristic that could be developed in the school environment (Lolowang, 2009). However, another Indonesian study by Raihani (2008) conducted in Java Island exploring principals values, did not find self-discipline as one of the school principals' values. Thus, this research indicated that in eastern parts of Indonesia, selfdiscipline is an important value for school principals and this finding fits with authentic leadership characteristics proposed by George (2003)

Essential values of good leaders proposed by Russell (2001) included honesty and integrity. However, McCain and Salter (2004, as cited in Avolio et al., 2004) identified that in being an authentic leader it was not enough to be honest, but one also must learn to love honesty and justice for themselves. The current research found that honesty was a shared value among the participants, but other values or moral perspective that significantly contributed to authentic leadership development such as integrity and justice were not as highly valued.

Intelligence was a value indicated by half of the participants, and one of them (Ndoen) put intelligence as the most important value. Teachers who were smart and intelligent were significant role models for Ndoen. These teachers might be the source influencing his choice of value. This is relevant to previous research conducted by House et al. (2004) about positive leader attributes. Intelligence is such a fundamental (and difficult to define) human trait that researchers have often looked for a connection between intelligence and leadership (Lashway, Mazzarella \& Grundy, 2006). Lashway et al. (2006) argue that intelligence is undeniably important for school leaders. A number of earlier studies cited by Bass (1990) point out a fairly high correlation between intelligence and the likelihood of being perceived as a leader, but found low positive correlations between intelligence and leadership. The reason for this could be that another specific type of intelligence, which is emotional intelligence, the ability to understand and manage moods and 
emotions within the self and others, contributes to effective leadership (George, 2000). Emotional intelligence is seen as a foundation of leadership success beginning with self-awareness (Goleman, Boyatzis \& McKee, 2002), and self-awareness is important for authentic leadership (Gardner et al., 2005). Although during the interview the participants did not explain specifically that they possessed or valued emotional intelligence, some of the participants' life experiences reflected that they practiced this value.

The value of patience was chosen by half of the participants. Patience has been described as a virtue needed by any leader (Boylston \& Peters, 2004). The value of patience was found in the "altruistic love" values proposed by Fry (2003) under the framework of spiritual leadership. Altruistic love defines the set of values, assumptions, and ways of thinking considered to be morally right that are shared by group members and taught to new members in the organizational culture (Klimoski \& Mohammad, 1994; Schein, 2004, as cited in Fry, Hannah, Noel \& Walumbwa, 2011). Fry's theory indicated patience as one of spiritual leadership qualities together with other qualities such as trust, honesty, forgiveness and kindness (Fry). In this research, it was apparent taking time to listen and meet with teachers, students and communities may not be the leader's top priority, but could be a very important aspect of the role as a school leader.

One value, religion, was not shared among the principals. Fanggidae, who had life experience in Timor Leste (then East Timor) chose being religious as her most important value. An Indonesian model of successful school leadership research conducted in the three secondary schools' in Yogyakarta, Java Island (Raihani, 2008) found out that the religious beliefs and values of the principals in these schools were very strong and exerted a strong influence on their leadership practices. Thus, this belief may influence Fanggidae who had worked in Timor Timur, and chose religious values as her most important value. Vama shared her life experience when she was in Timor Timur as follows:

Some of my colleagues asked me whether I was scared or not. Believe it or not, I told them that in that place God was shaping my faith, I wasn't scared; I put my life in God's will, in God's hand. 
To summarise the analysis of values, the findings indicated that the values chosen by the principals were driven by their life experiences, including childhood experiences, and also from their role models. It echoes Gardner et al's. (2005) study that values are learned through the socialization process with other people (i.e role models). Values reflect underlying human motivations and shape subsequent attitudes, speech, and actions (Begley, 2006). Furthermore, Begley argues that the ways leaders perceive their personal values lead to authentic leadership practices such as supporting decision making and resolving ethical dilemmas. The current study revealed that values held by school principals in the highest achieving school in NTT Province, are different from the values held by principals in Australia studied by Branson (2007) such as dignity, respect, courage, accepting others, pride, and success. The reason for this could be that cultural contexts in Australia and Indonesia are different, resulting in differing developmental processes for personal values (Branson). The following section will discuss how values influence authentic leadership practices for school principals

\subsubsection{Values: impact on leadership practices}

The value of self-discipline may influence leadership practices in resourcing strategically and ensuring teaching quality, while the value of intelligence may influence setting goals and resourcing strategically. Honesty may influence the way principals work with teachers in ensuring teaching quality. Honesty and patience may also impact on the way principal works with local community in ensuring a healthy and safe environment, and this include dealing with dilemma. This impact is shown in table 7.8. 
Table 7.8: Values impact on leadership practices

\begin{tabular}{|c|c|c|}
\hline Participants & Values & $\begin{array}{l}\text { Impact on academic and non-academic } \\
\text { resourcing strategies }\end{array}$ \\
\hline \multirow{3}{*}{$\begin{array}{l}\text { Vama } \\
\text { Louisa } \\
\text { Gerson } \\
\text { Seran } \\
\text { Fanggidae } \\
\text { Ndoen }\end{array}$} & \multirow[t]{3}{*}{ Self-discipline } & $\begin{array}{l}\text { A principal has to obey any rules (school rules and } \\
\text { administrative rules). } \\
\text { Expect the teachers and the students to obey the } \\
\text { school rule also. }\end{array}$ \\
\hline & & Value impact on ensuring teaching quality \\
\hline & & $\begin{array}{l}\text { Syllabus and daily learning plans have to be } \\
\text { developed in the beginning of the semesters. }\end{array}$ \\
\hline \multicolumn{2}{|l|}{ 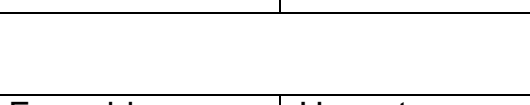 } & $\begin{array}{l}\text { Value impact on ensuring teaching quality and } \\
\text { ensuring healthy and safe environments }\end{array}$ \\
\hline $\begin{array}{l}\text { Fanggidae } \\
\text { Louisa } \\
\text { Seran } \\
\text { Ndoen }\end{array}$ & \multirow[t]{2}{*}{ Honesty } & $\begin{array}{l}\text { Creating a culture of trust with parents and school } \\
\text { community. } \\
\text { Creating familial values and maintains a good } \\
\text { relationship with teachers. } \\
\text { Giving feedback regularly to the teachers toward } \\
\text { teachers' quality of teaching. } \\
\text { Creating healthy and safe school environment. }\end{array}$ \\
\hline & & $\begin{array}{l}\text { Value impact on setting goals and resourcing } \\
\text { strategically }\end{array}$ \\
\hline \multirow[t]{2}{*}{$\begin{array}{l}\text { Ndoen } \\
\text { Louisa } \\
\text { Gerson }\end{array}$} & \multirow[t]{2}{*}{ Intelligence } & $\begin{array}{l}\text { Setting a leadership goal that focuses on students } \\
\text { academic results (win in each academic competition, } \\
\text { be the best in academic achievement). } \\
\text { Information and technology (IT) based leadership. }\end{array}$ \\
\hline & & $\begin{array}{c}\text { Value impact on ensuring healthy and safe } \\
\text { environments }\end{array}$ \\
\hline $\begin{array}{l}\text { Vama } \\
\text { Ndoen } \\
\text { Gerson }\end{array}$ & Patience & $\begin{array}{l}\text { Dealing with the dilemmas or conflicts with teachers, } \\
\text { spouse and local communities. }\end{array}$ \\
\hline
\end{tabular}

Self-discipline was a value held by all participants. The value of selfdiscipline may influence both academic and non-academic strategies. In nonacademic strategies, the value of self-discipline impacts on school principals' personal qualities, such as beliefs that as a principal, they have to obey any rules (school rules and administrative rules from the government). On the other hand as a leader in the school, the school principal also expects teachers and students to obey the rules. This is an example of how principals applied this value both to themselves and to the others. The school documents such as obeying the 'shamed culture' (Gerson's school, figure 5.1) and school missions (Ndoen, figure 6.2); stated that developing a culture of obedience to school rules and norms are expected of all school members. Supporting an academic strategy, principals had a rule that syllabus and daily learning plans have to be developed at the beginning of the semester.

The values of self-discipline helped the principals handle some problems at school including undisciplined teachers, high student truancy and difficulty in adhering to the school curriculum. For example, Ndoen stated 
that he is a person who always obeys the rules, and this contradicts with some of his teachers who disobeyed the school rules. Ndoen understood that he needed to discipline the teachers, when they disobeyed the rules.

The value of honesty may impact on authentic leadership practices in creating healthy and safe environments. Creating familial values and maintaining good relationships with teachers, creating a culture of trust with parents and school community, and giving regular feedback to the teachers toward teachers' quality of teaching, creating a culture of trust with parents and school community may all reflect the value of honesty. For example, Seran invited parents and community members to be involved in the registration weeks; this is to show how he trusts the community members to be involved at school and make a contribution in helping the registration process. Moreover, Ndoen mentioned that school principals have to work collaboratively with community members near the school; otherwise they would damage school facilities. Though community members may indeed share norms, they may also have diverse norms (Shields \& Seltzer, 1997); these diverse expressions of community have implications on how school leadership most effectively operates in urban areas. Previous research suggests that school leaders should play an active role in community settings (Khalifa, 2012). In this current study, it appeared that some practices based on cultural trust had been commonly taken on board, such as coordinating with community leaders, and government officials.

Creating a healthy and safe school environment can be seen as authentic leadership practice that is influenced by the value of honesty because it involved creating a relational trust between school members (the principals, the teachers) and the community member including parents. Most of the participants described how they provided for and maintained the school building facilities and environment as safe and healthy for students and teachers. More importantly, in their authentic leadership practices, most of the school principals described the involvement of various parties in managing order and safety and providing a healthy environment, including parents, community and relevant stakeholders (i.e.: government staff, police officers, and doctors and paramedics from the community health centres).

The value of patience may also impact authentic leadership practices in terms of creating healthy and safe environments. Principals' life 
experiences indicate that they faced some problems and dilemmas in their early principalships, both inside and outside schools, and at home. These findings revealed that the value of patience influenced the ways the principals tackled the problems and dilemmas. This suggests that the value of patience held by the participants (Vama, Ndoen, Gerson) may influence the authentic leadership practices for the school principals. For example, Vama explained that it took almost a year to change the school environment. Taking a year to make a personal approach to the teachers needed a lot of patience, until the teachers were aware that they needed to change, to be more effective and focused on students' results. As she put it:

It had been too long that the 'rhythms' of the school was too slow...It's like they had been 'sleeping' for a long time, and then when I came, I woke them up.

Blumberg and Greenfield (1986, as cited in Lashway et al., 2006) observed the eight outstanding principals they studied had very well-developed interpersonal skills and were able to communicate effectively in face-to-face interaction with a diverse range of individuals and groups. Vama's case reflects how authentic leader has strong values to assist them to do the right thing as proposed by George (2003). It is important to note that leadership skills (i.e. interpersonal skills, communication skills) could support valuebased leadership.

\subsection{The influence of life experiences on the development of authentic leadership practices}

This study suggests that life experiences and both positive and negative childhood experiences may impact on leadership capabilities such as intelligence, independence, toughness, patience, creativity, resilience, courage and strength. Challenging childhood experiences considered as negative events have been shown to support the development of authentic leadership (Gardner et al., 2005). Based on the findings, childhood experiences appeared to influence the ways in which principals practice the first dimension of leadership proposed by Robinson (2011): setting goals and expectations. These goals related to students' academic achievement and the quality of teaching and learning. Authentic leaders developed capabilities to support their practices in the best interest of students and teachers. Thus, 
it is evident that childhood experiences may influence authentic leadership practices in establishing goals and expectations, and it can be seen in figure 7.1.

\section{Childhood experiences, i.e challenging experiences}

\section{Leadership} capabilities, i.e intelligence, independence, patience, toughness, courage and strength
Setting goals and expectations focus on students academic achievement \& quality of teaching and learning - Resourcing strategically focus on financial resource

\section{Figure 7.1: An example in what ways childhood experiences influence the development of authentic leadership practices}

Childhood experiences may also influence leadership strategies that help achieve these goals. These relate to the second leadership dimension: resourcing strategically (Robinson, 2011). This study also found that childhood experience was influenced by Indonesian culture, such as an obedience culture. Thus, leadership practices in resourcing strategically reflect how difficult circumstances and culture impact on leadership practices. For example, a child who was raised by his family under the culture of obedience and discipline may develop into a person who tries to obey the rules and practice self-discipline. This process may encourage the development of authentic leaders with strong personal values.

Significant role models revealed in this study include school principals, teachers, parents, and spouses. Role models were crucial in influencing the development of leadership capabilities such as intelligence, respect for the school environment, calmness, patience, self-discipline, honesty, responsibility, humility, and openness to suggestion. Principals and teachers may have significantly influenced the participants, as most explained they 
wanted to be a good principals and good teachers who were concerned with student learning. Role models were used as references to develop selfconcepts. This echoes Gardner at al.'s (2005) study on authentic leadership which found that role models who demonstrated leadership qualities and capacities may significantly impact on leaders' self-awareness. Learning from role models may also impact on leadership practices on ensuring quality teaching and healthy and safe environments. In this study there is a similarity between principals' current leadership practices and the action of their role models.

Previous leadership experience may impact on leadership capacities. Prior leadership experience, such as committee membership, teacher instructors, vice-principal role may have influenced the way principals practiced authentic leadership. Through previous leadership experiences, the participants developed their leadership capacities such as self-confidence, intelligence, and interpersonal skills.

The way participants developed their values may be influenced by many factors, including childhood experiences, learning from role models and previous leadership practices. Self-discipline was the most significant value and was relevant to the authentic leadership characteristics proposed by George (2003). The impact of values can be linked to several of the leadership dimensions (Robinson, 2011). The value of self-discipline may relate to resourcing strategically. The value of honesty and patience may impact on authentic leadership practices in creating healthy and safe environments, including building trust with the teachers and local community.

Figure 7.2 provides a summary of the findings that help answer the main research question: in what ways do life experiences influence the development of authentic leadership practices of school principals. 


\section{of authentic leadership}

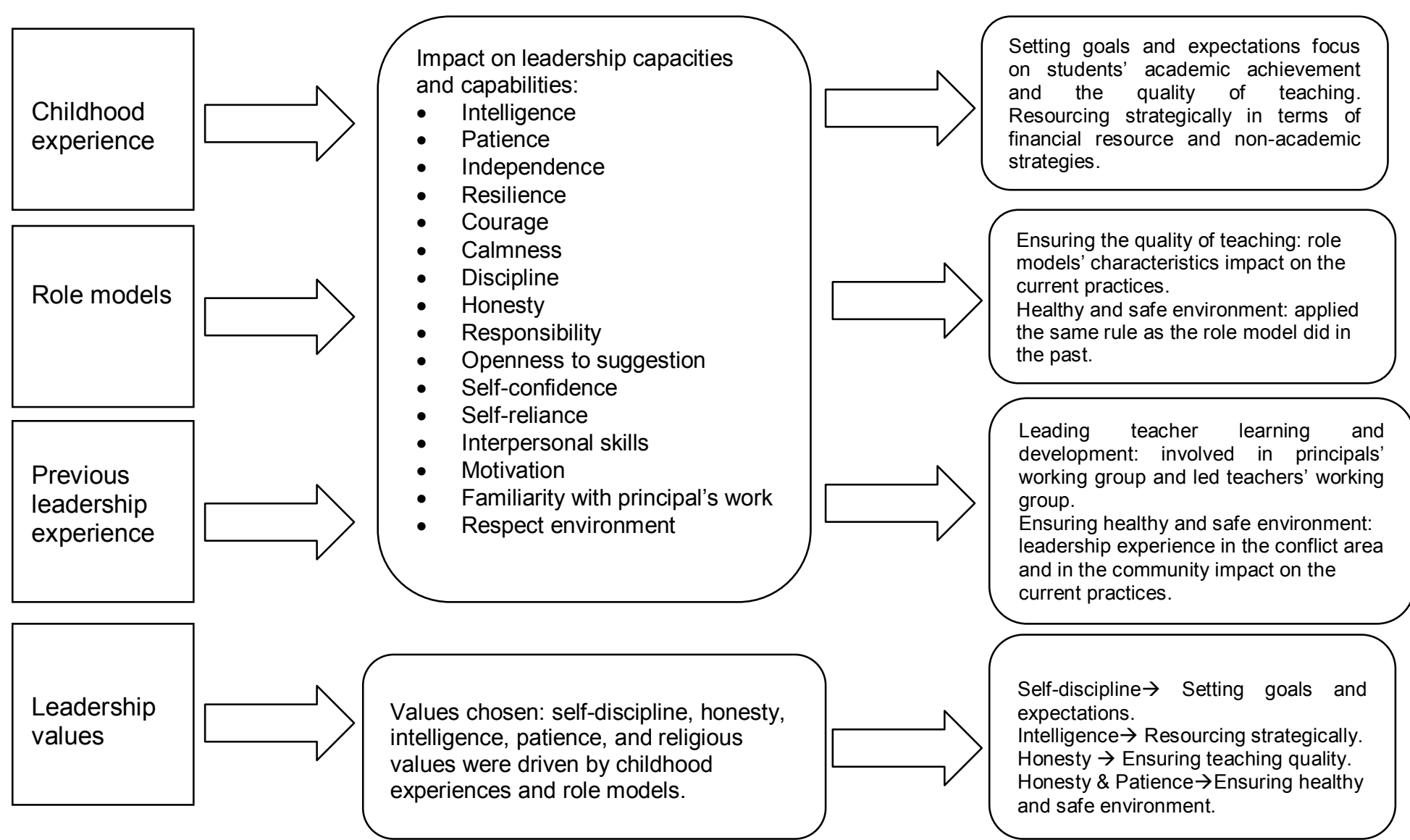

Highest achieving schools, in terms of academic results. Good relationships with teachers and local community.

Figure 7.2: How life experience impacts on the development of authentic leadership and practices 
It can be seen through the figure that themes such as childhood experiences, role models, and previous leadership practices all contribute to the development of authentic leadership capabilities, capacities and values. Authentic leadership practices can be linked to the five dimensions of leadership proposed by Robinson (2011).

\subsection{Chapter Summary}

This chapter presented a thematic analysis and discussion of the findings of this research. The thematic analysis focusing on the life experiences and leadership practices of the principals helped answer the research questions. Childhood challenges, role models, previous leadership experiences, and leadership values identified by the participants have the potential to influence authentic leadership capacities, capabilities and values. These life experiences may influence leadership practices which were discussed in relation to the five dimensions of leadership (Robinson, 2011). 


\section{CHAPTER EIGHT}

\section{Conclusion}

\subsection{Chapter overview}

This concluding chapter begins with a review of the research question: in what ways do life experiences influence the development of authentic leadership and practices? Research implications for education policy in principal preparations are then provided, followed by research implications for principals' leadership practices. In the fourth section, research limitations will be articulated. Finally, future possible research will be discussed.

\subsection{The influence of life experiences on the development of authentic leadership and practices}

This research aimed to explore the question: in what ways do life experiences influence the development of authentic leadership practices of school principals in the highest achieving schools. Two sub-questions were what aspects of leaders' life-stories have the greatest impact on their authentic leadership practices; and in what ways do these principals practice authentic leadership.

Significant challenges during childhood were trigger events that appeared to strengthen the development of authentic leadership. Financial problems, living separately from their parents and loss of a parent were considered as negative trigger events, while getting a scholarship was a positive trigger event in the development of authentic leadership. These experiences appeared to positively impact on the development of leadership capabilities such as intelligence, independence, toughness, patience, creativity, resilience, courage and strength. Childhood experiences may influence leadership practices in setting goals and expectations, and resourcing strategically. Some of the participants' goals were related to students' academic achievement and the rest focused on the quality of teaching. Challenging childhood experiences may also influence school principals to set their leadership goals, such as an unpleasant experience of living with uncle resulting in a goal as "leading with affection and teaching 
students with care". Another finding was that negative childhood events impacted on resourcing strategically, for instance financial resources and non-academic leadership practices (obeying school rules, shamed rule and obedience culture). Therefore, there is a link between life experience and leadership practices in setting goals and expectations; and resourcing strategically.

Learning from role models resulted in the development of leadership capabilities such as intelligence, interpersonal skills, diligence, punctuality, self-discipline, patience, honesty, and inspiration to become a school principal, as well as respect for school environment. Various role models appeared through principals' life-stories, such as parents, spouses, school principals, teachers, colleagues and government officials. These findings were consistent with previous research by Shamir et al. (2005), Toor and Ofori (2008), and Smith and Piele (2006) about various role models. All the female participants chose their husbands as their role model, although the husbands were also sometimes the source of dilemma.

Previous leadership experiences had a positive impact on leadership capacities of principals in this study leading to self-confidence, self-reliance, motivation, familiarity with principal work, encouragement to take bigger leadership roles, interpersonal skills and spiritual intelligence. These capacities were developed by taking leadership roles at schools, in organisations, in professional development and in the community.

Important values held by participants included self-discipline, honesty, intelligence, patience and being religious. These key values appear to significantly contribute to authentic leadership development. Self-discipline was listed as the most important value for the most of the participants. There is an indication that self-discipline could be seen as one of principals' assumed characteristics in the eastern part of Indonesia. Findings indicated that the values chosen by the principals were driven by their life experience, including childhood experience and their role models.

There is a link between participants' life experience and their practices in establishing goals and resourcing strategically. Establishing goals was influenced by childhood experiences, while the strategies in achieving the goals were influenced by previous leadership experience and values. 
Leadership capacities in applying relevant knowledge influenced the way principals ensured the quality of teaching, which included developing school curriculum, classroom observation and regular monitoring and supervision.

\subsection{Implications for the NTT provincial education office}

This research may make a useful contribution to principal selection processes in the NTT province. It is evident in this research that principals in the highest achieving school practiced authentic leadership by understanding their values and reflecting them in their practices. This research supports the view that authentic leaders are able to articulate their leadership goals and strategies. Thus, the NTT government may select school principals from potential candidates who have strong understandings of their values, goals and strategies.

The NTT provincial education office could consider developing a preparation programme for new school principals, where the new principals could reflect their leadership journey. Asking the new principal to draw a lifeline may help them to identify events (both positive and negative trigger events) and role models. This could be followed by a reflection process, where the new principals are asked to share their leadership journey. This process may help the principal to increase their self-knowledge reflecting on their role models, values and their previous leadership experiences.

\subsection{Implications for school principals' leadership practices}

The purpose of this study is to explore how principals' life experiences influence the development of authentic leadership practices. Shamir and Eilam (2005) propose that the development of authentic leadership can be planned and guided by assisting leaders to draw personal meanings from their experiences to achieve greater self-knowledge and clarity. It is suggested that school leaders could draw their life experiences as part of leadership reflections.

This study found that challenging experiences, especially hardship in the family setting, created trigger events which supported the development of authentic leadership. School principals may choose to emphasize positive experiences for all students, i.e.: supporting students' association as an organization in order to support the development of future leaders. Previous 
school principals were identified as significant role models, therefore, it may be worth for the school principals in this study being aware of how they will be viewed as role models not only for their teachers but also for their students.

The participants in this study indicated that their leadership practices in setting goals focused on students' academic achievement and the quality of teaching and learning. As the leaders at school level, all participants should support teachers' professional development in order to improve the quality of teaching. In addition, it is suggested that school principals articulate and reflect on their values to improve authentic leadership practices. Most of the participants held self-discipline as the most important value, even though other values, such as intelligence, honesty, patience, and religious values were revealed in the findings. Those values were significant in guiding the school principals' practice.

This research might benefit not only the participants who are involved in this study, but also other school principals in the NTT province. Other school principals may draw their life story to reflect on their life experience, behave positively as role models for teachers and students, practice coherence between values and practices, support teachers' professional development and seek regular feedback from the school community.

\subsection{Research Limitations}

This current study is a small-scale research study located in NTT, one of the eastern provinces in Indonesia, with only six school principals. All school principals were selected from the highest achieving schools in this province. This research did not look at school principals of schools from low academically achieving schools. The research method was the life-story approach, which only collected data based on principals' self-report. It did not use other research methods, such as focus group discussions or observations. Thus, these current research findings do not provide a broader perspective on authentic leadership practices. However, the study has the advantage of providing a better understanding of how school principals in the highest achieving schools may have developed authentic leadership and how their life experiences influences their leadership practices. 


\subsection{Future Research}

Research could be carried out in field studies that explore leaders' lifeexperience and authentic leadership practices in schools setting using observation or experimental studies. In addition, there is a need for research on the impact of authentic leadership practices on the followers. In the eastern part of Indonesia, provinces such as NTT where the educational statistics are very low, research in exploring why educational results in this province are very low and what leadership practices might improve academic achievement could be useful.

\subsection{Chapter summary}

This chapter began with a chapter overview. The next section provided a summary of the findings on the influence of life experience on authentic leadership practices. The research implications for the provincial government in NTT and for the school principals were considered and discussed. The research limitations were reviewed and the future research discussed in the last section. 


\section{REFERENCES}

Ado. (2013, May 24 ${ }^{\text {th }}$ ). Hasil UN, NTT peringkat 29 dari 33 Provinsi. NTT terkini. Retrieved from http://www.nttterkini.com/hasil-un-ntt-peringkat29-dari-33-provinsi/

Alton-Lee, A. (2008). Making a bigger difference for diverse learners: The iterative best evidence synthesis programme in New Zealand. In The Education of Diverse Student Populations (pp. 253-271). Netherlands: Springer.

Alwasilah, A. C. \& Furqon, (2010). Indonesian statistics. International Encyclopedia of Education (Third Edition) ( $p p$ 611-617). Elsevier Ltd. Retrieved from http://www.sciencedirect.com/science/article/pii/B97800804489470156 $\underline{82}$

Antonakis, J. (2012). Transformational and charismatic leadership. In D.V. Day \& J. Antonakis (Eds.), The nature of leadership ( $2^{\text {nd }}$ ed., pp. 256288). Thousand Oaks, CA: Sage.

Atwell, A. (2006). The impact of a leadership training program on school based management and school community action in Praya Barat Daya, Lombok, Indonesia (Doctoral dissertation, University of Southern Queensland). Retrieved from http://eprints.usq.edu.au/3192/

Avolio, B. J. (1999). Full leadership development: Building the vital forces in organizations. Thousand Oaks, CA: Sage.

Avolio, B. J. (2005). Leadership development in balance: Made/born. Mahwah, NJ: Lawrence Earlbaum Associates.

Avolio, B. J., \& Gardner, W. L. (2005). Authentic leadership development: Getting to the root of positive forms of leadership. The Leadership Quarterly, 16(3), 315-338.

Avolio, B. J., Gardner, W. L., Walumbwa, F. O., Luthans, F., \& May, D. R. (2004). Unlocking the mask: A look at the process by which authentic leaders impact follower attitudes and behaviors. The Leadership Quarterly, 15(6), 801-823.

Avolio, B. J., Luthans, F., \& Walumba, F. O. (2004). Authentic leadership: Theory building for veritable sustained performance. Working paper: Gallup Leadership Institute, University of Nebraska-Lincoln.

Avolio, B.J., \& Luthans, F. (2005). The high impact leader: Moments matter for accelerating authentic leadership development. New York: McGraw-Hill.

Barker, C., Pistrang, N., \& Elliott, R. (2002). Research methods in clinical psychology: An introduction for students and practitioners (2nd ed.). Chichester: Wiley. 
Bass, B. M. (1990). Bass and Stogdill's handbook of leadership: Theory, research, and managerial applications (3rd ed.) New York: Free Press.

Bass, B.M., \& Riggio, R.E. (2006). Transformational Leadership. Marwah, NJ: Lawrence Erlbaum.

Bau, E. (2012, July $17^{\text {th }}$ ). Komisi X Pertanyakan Program Gong Belajar. Tribun News. Retrieved from http://www.tribunnews.com/2012/07/17/komisi-x-pertanyakanprogram-gong-belajar

Bedi, A. S., \& Garg, A. (2000). The effectiveness of private versus public schools: The case of Indonesia. Journal of Development Economics, 61(2), 463-494.

Begley, P. T. (2006). Self-knowledge, capacity and sensitivity prerequisites to authentic leadership by school principals. Journal of Educational Administration. 44(6), 570-589.

Begley, P. T. (2012). Leading with moral purpose: The place of ethics. In M. Preedy., N. Bennett \& C. Wise (Eds.), Educational leadership: Context, strategy and collaboration (pp. 38-51). London: Sage.

Begley, P.T. (2003). In pursuit of authentic school leadership practices. In P.T. Begley \& O. Johansson (Eds), The ethical dimensions of school leadership (pp. 1-12). Dordrecht: Kluwer Academic Press.

Bell, L. \& Bolam, R. (2010). Teacher professionalism and continuing professional development: Contested concepts and their implications for school leaders. In T. Bush, L. Bell \& D. Middlewood (Eds.), The principles of educational leadership and management (pp. 89-111). London: Sage.

Bennis, W., \& Thomas, R. (2002). Geeks and geezers: How era, values, and defining moments shape leaders. Boston: Harvard Business School Press.

Bolam, R. (2000). Emerging policy trends: Some implications for continuing professional development. Journal of In-Service Education, 26(2), 267-280.

Bouty, I. (2000). Interpersonal and interaction influences on informal resource exchanges between R\&D researchers across organizational boundaries. Academy of Management Journal, 43(1), 50-65.

Boylston, M. T., \& Peters, M. A. (2004). Interim leadership in an era of change. International Journal of Nursing Education Scholarship, 1(1), $1-12$. 
Branson, C. (2007). Effects of Structured Self-reflection on the development of authentic leadership practices among Queensland primary school principals. Educational Management Administration \& Leadership, 35(2) 225-246.

Braun, V., \& Clarke, V. (2006). Using thematic analysis in psychology. Qualitative Research in Psychology, 3(2), 77-101.

Bryk, A. S., \& Schneider, B (2003). Educational leadership, trust in schools: A core resource for school reform. Creating Caring School, 60(6), 40-45.

Chan, A., Hannah, S. T., \& Gardner, W. L. (2005). Veritable authentic leadership: Emergence, functioning, and impacts. In W.L. Gardner., B. J. Avolio \& F.O. Walumbwa (Eds.). Authentic leadership theory and practice: Origins, effects and development ( $\mathrm{pp} 3-41)$. Oxford, UK: Elsevier Ltd.

Chirban, J. T. (1996). Interviewing in depth: The interactive-relational approach. Thousand Oaks: Sage Publications.

Ciulla, J. (2004). Ethics, the heart of leadership ( $\left.2^{\text {nd }} E d\right)$. Westport, CT: Quorum Books.

Conger, J. A., \& Kanungo, R. N. (1998). Charismatic leadership in organizations. Thousand Oaks: Sage Publications.

Cooper, C., Scandura, T. A., \& Schriesheim, C. A. (2005). Looking forward but learning from our past: Potential challenges to developing authentic leadership theory and authentic leaders. The Leadership Quarterly, 16(3), 475-493.

Corcoran, T., \& Goertz, M. (1995). Instructional capacity and high performance schools. Educational Researcher, 24(9), 27-31.

Cornell, D. G., \& Mayer, M. J. (2010). Why do school order and safety matter? Educational Researcher, 39(7), 7-15.

Creswell, J. W., Hanson, W. E., Plano, V. L. C., \& Morales, A. (2007). Qualitative research designs selection and implementation. The Counseling Psychologist, 35(2), 236-264.

Creswell, J.W. (2009). Research design: Qualitative, quantitative, and mixed methods approaches (3rd ed.). Thousand Oaks, CA: Sage.

Creswell, J.W. (2012). Educational research: Planning, conducting, and evaluating quantitative and qualitative research (4rd ed.). Thousand Oaks, CA: Sage Publications, Incorporated.

Creswell, J.W., \& Miller, D. L. (2000). Determining validity in qualitative inquiry. Theory Into Practice, 39(3), 124-130. 
Dama. (2013, December $\left.20^{\text {th }}\right)$. Mantan walikota kupang Daniel Adoe digiring ke lapas penfui. Tribunnews. Retrived from http://kupang.tribunnews.com/2013/12/20/mantan-walikota-kupangdaniel-adoe-digiring-ke-lapas-penfui

Day, C. (2003). What successful leadership in schools looks like: Implications for policy and practice In W. Davies., \& J. West-Burnham (Eds.), Handbook of educational leadership (pp. 87-204). London: Pearson Education.

Day, C., Harris, A., \& Hadfield, M. (2001). Challenging the orthodoxy of effective school leadership. International Journal of Leadership in Education: Theory and Practice, 4(1), 39-56.

Day, D. V. (2000). Leadership development: A review in context. The Leadership Quarterly, 11(4), 581-613.

Day, D. V., Fleenor, J. W., Atwater, L. E., Sturm, R. E., \& McKee, R. A. (2014). Advances in leader and leadership development: A review of 25years of research and theory. The Leadership Quarterly, 25(1), 6382.

Decrop, A. (1999). Note: Triangulation in qualitative tourism research. Tourism Management, 20(1).157-161.

Densten, I. L., \& Gray, J. H. (2001). Leadership development and reflection: What is the connection?. International Journal of Educational Management, 15(3), 119-124.

Denzin, N., \& Lincoln, Y. (2005). Handbook of qualitative research (3rd ed.). Thousand Oaks, CA: Sage.

Departemen Pendidikan Nasional. (2003). Undang-undang sistim pendidikan nasional tahun 2003. Retrieved from www.depdiknas.go.id.

Dickson, G. (2008). Leadership as knowledge mobilization: Building coalitions for evidence-based change. Paper presented at the 9th European Conference on Knowledge Management, 4-5 September, Southampton.

Dimmock, C., \& Walker, A. (2000). Globalisation and societal culture: Redefining schooling and school leadership in the twenty-first century. Compare: A Journal of Comparative and International Education, 30(3), 303-312.

Duignan, P. (2003). SOLR project: Contemporary challenges and implications for leaders in frontline service organizations. Sydney: Flagship for Creative and Authentic Leadership, ACU National.

Duignan, P. (2006). Educational Leadership: Key Challenges and Ethical Tensions. Cambridge, New York, Melbourne: Cambridge University Press. 
Dunford, J., Fawcett, R., \& Bennett, D. (2000). School leadership: National and international perspectives. London: Koge Sage Limited.

Eagly, A. H. (2005). Achieving relational authenticity in leadership: Does gender matter? The Leadership Quarterly, 16 (3), 459-474.

Elmore, R.F. (2004), School reform from the inside out: Policy, practice, and performance. Cambridge, MA: Harvard Education Press.

Erickson, R. J. (1995). The importance of authenticity for self and society. Symbolic Interaction, 18(2), 121-144.

Fink, D. (2005). Developing leaders for their future not our past. In M. Coles., \& G. Southworth (Eds.), Developing leadership: Creating the schools of tomorrow (pp. 1-20). Maidenhead: Open University Press.

Floyd, A. (2012). Narrative and Life History. In A.R.J. Briggs., M. Morrison \& M. Colemen (Eds.), Research methods in educational leadership and management (pp. 223-234). Sage Publication.

Fry, L. W. (2003). Toward a theory of spiritual leadership. The Leadership Quarterly, 14(6), 693-727.

Fry, L. W., Hannah, S. T., Noel, M., \& Walumbwa, F.O. (2011). Impact of spiritual leadership on unit performance. The Leadership Quarterly, 22(2), 259-270.

Gardner, W. L., Avolio, B. J., \& Walumbwa, F. O. (2005). Authentic leadership theory and practice: Origins, effects and development (Vol. 3). Gulf Professional Publishing.

Gardner, W. L., Avolio, B. J., Luthans, F., May, D. R., \& Walumbwa, F. O. (2005). "Can you see the real me?" A self-based model of authentic leader and follower development. The Leadership Quarterly, 16(3), 343-372.

Gardner, W., Cogliser, C., Davis, K., \& Dickens, M. (2011). Authentic leadership: A review of the literature and research agenda. The Leadership Quarterly, 22(1), 1120-1145.

George, B. (2003). Authentic leadership: Rediscovering the secrets to creating lasting value. San Francisco, CA: Jossey-Bass.

George, J. M. (2000). Emotions and leadership: The role of emotional intelligence. Human Relations, 53, 1027-1055.

Goddard, R. D. (2003). The impact of schools on teacher beliefs, influence, and student achievement: The role of collective efficacy. In J. Raths \& A. McAninch (Eds.), Advances in teacher education (Vol. 6) (pp.183204). Westport, CT: Information Age Publishing. 
Goldman, B. M., \& Kernis, M. H. (2002). The role of authenticity in healthy psychological functioning and subjective well-being. Annals of the American Psychotherapy Association, 5(6), 18-20.

Goleman, D. (1995). Emotional intelligence. New York: Bantam Books.

Goleman, D., Boyatzis, R., \& McKee, A. (2002). Primal leadership: Realizing the power of emotional intelligence. Boston: Havard Business School Press.

Griffith, J. (2004). Relation of principal transformational leadership to school staff job satisfaction, staff turnover, and school performance. Journal of Educational Administration, (42)3, pp. 333-356.

Hallinger, P. (2001). The principal's role as instructional leader: A review of studies using the Principal Instructional Management Rating Scale. paper presented at the annual meeting of the American Educational Research Association, Seattle.

Hallinger, P. (2003). Reshaping the landscape of school leadership development: A global perspective. Lisse, The Netherlands: Swets and Zeitlinger.

Hallinger, P. (2005). Instructional leadership and the school principal: A passing fancy that refuses to fade away. Leadership and Policy in Schools, 4(3), 221-239.

Hallinger, P. (2011). Leadership for learning: Lessons from 40 years of empirical research. Journal of Educational Administration, 49(2),12542.

Hannah, S. T., Lester, P. B., \& Vogelgesang, G. R. (2005). Moral leadership: Explicating the moral component of authentic leadership. In W. L. Gardner., B. J. Avolio., \& F. Walumbwa (Eds.), Authentic leadership theory and practice: Origins, effects and development (Vol. 3, pp. 4381). Oxford, England: Elsevier.

Harris, A. (2008). Distributed leadership: According to the evidence. Journal of Educational Administration, 46(2), 172-188.

Harris, A. (2009). Distributed leadership: What we know. In A. Harris (ed.), Distributed Leadership: Different Perspectives (pp. 11-21). Dordrecht: Springer.

Harter, S. (2002). Authenticity. In C. R. Snyder., \& S. Lopez (Eds.), Handbook of positive psychology (pp. 382-394). Oxford, UK: Oxford University Press.

Heck, R., \& Hallinger, P. (2009). Assessing the Contribution of Distributed Leadership to School Improvement and Growth in Math Achievement. American Educational Research Journal September, 46 (3), pp. 659689. 
Higgins, J., \& Bonne, L. (2011). Configurations of instructional leadership enactments that promote the teaching and learning of mathematics in a New Zealand elementary school. Educational Administration Quarterly, 47(5), 794-825.

House, R.J., Hanges, P.J., Ruiz-Quintanilla, S.A., Dorfman, P.W., Javidan, M., Dickson, M., \& Associates (1999). Cultural influences on leadership and organizations: Prjocet GLOBE. In W. H. Mobley., M. J. Gessner \& V. Arnold (Eds), Advances in global leadership (pp. 131233). Stamford, CT: JAI Press.

Irawanto, D. W. (2009). An Analysis Of National Culture And Leadership Practices In Indonesia. Journal of Diversity Management, 4(2), 41-48.

Irawanto, D. W., Ramsey, P. L., \& Ryan, J. C. (2011). Challenge of leading in Javanese culture. Asian Ethnicity, 12(2), 125-139.

Jimenez, E., \& Lockheed, M. E. (1995). Public and private secondary education in developing countries: A comparative study (Vol. 309). World Bank Publications.

Johnson, B., \& Christensen, L. (2008). Educational research: Quantitative, qualitative, and mixed approaches. Thousand Oaks, California: Sage Publications, Inc

Jones, G. W., Nagib, N., Sumono., \& Handayani, T. (1998): The expansion of high school education in poor regions: The case of east Nusa Tenggara, Indonesia. Bulletin of Indonesian Economic studies, 34(3), 59-84.

Khalifa, M. (2012). A re-new-ed paradigm in successful urban school leadership: Principal as community leader. Educational Administration Quarterly, 48(3), 424-467.

Kythreotis, A., Pashiardis, P., \& Kyriakides, L. (2010). The influence of school leadership styles and culture on students' achievement in Cyprus primary schools. Journal of Educational Administration, 48(2), 218240.

Lashway, L., Mazzarella, J., \& Grundy, T. (2006). Portrait of a leader. In S.C. Smith \& P.K. Piele (Eds.), School leadership: Handbook for excellence in student learning (pp.52-76). Thousand Oaks, California: Corwin Press.

Leithwood, K. (2006). Teacher working conditions that matter: Evidence for change. Toronto: Elementary Teachers Federation of Ontario.

Leithwood, K. A., \& Jantzi, D. (2005) A review of transformational school leadership research 1996-2005. Leadership and Policy in Schools, 4(3), 177-199. 
Leithwood, K., \& Day, C. (2008). The impact of school leadership on pupil outcomes. School Leadership \& Management: Formerly School Organisation, 28(1), 1-4.

Leithwood, K., \& Jantzi, D. (1999). The relative effects of principal and teacher sources of leadership on student engagement with school. Educational Administration Quarterly, 35(5), 679-706.

Leithwood, K., \& Levin, B. (2005). Assessing school leader and leadership programme effects on pupil learning (Research Report 662). London, UK: Department for Education.

Leithwood, K., Anderson, S. E., Mascall, B., \& Strauss, T. (2012). School leaders' influences on student learning: The four paths. In M. Preedy., N. Bennett \& C. Wise (Eds.), Educational leadership: Context, strategy and collaboration (pp. 38-51). London: Sage.

Leithwood, K., Jantzi, D., \& Steinbach, R. (1999). Changing leadership for changing times. Buckingham, UK: Open University Press.

Little, J. W. (2003). Constructions of teacher leadership in three periods of policy and reform activism. School Leadership \& Management, 23(4), 401-419.

Lolowang, R. M. (2009). Implementasi Managemen Berbasis Sekolah. Jurnal IImu Pendidikan (JIP), Retrieved from jurnal.pdii.lipi.go.id.

Louis, K. S., Dretzke, B., \& Wahlstrom, K. (2010). How does leadership affect student achievement? Results from a national US survey, school effectiveness and school improvement: An international journal of research. Policy and Practice, 21(3), 315-336.

Luthans, F., \& Avolio, B. (2003). Authentic leadership: A positive development approach. In K. S. Cameron., J. E. Dutton \& R. E. Quinn (Eds.), Positive organizational scholarship (pp. 241-258). San Francisco, CA: Berrett-Koehler.

Luthans, F., \& Avolio, B. J. (2009). The "point" of positive organizational behavior. Journal of Organizational Behavior, 30(2), 291-307.

Lynch, M. (2012). A guide to effective school leadership theories. New York, USA. Routledge.

Mann, S.J. (1992). Telling A life story: Issues for research. Management Learning, 23(3), 271-280.

Marks, H. M., \& Printy, S. M. (2003). Principal leadership and school performance: An integration of transformational and instructional leadership. Educational Administration Quarterly, 39(3), 370-397. 
Marzano, R., Waters, T., \& McNulty, B. (2005). School leadership that works: From research to results. Alexandria, VA: Association for Supervision and Curriculum Development.

Masrafi. (2011, May $\left.18^{\text {th }}\right)$. Terendah peringkat UN SMA NTT. Media Indonesia. Retrieved from http://majalahanbi.blogspot.co.nz/2011/05/terendah-peringkat-un-smantt.htm|\#!/2011/05/terendah-peringkat-un-sma-ntt.html

Mauleti, Y. (2012, May $25^{\text {th }}$ ). Angka kelulusan UN NTT hanya meningkat 0.7 Persen. NTT Online. Retrieved from http://nttonlinenow.com/index.php/berita-ntt/daratan-timor/2207-gongbelajar-clemens-meba-gagal-total

May, D. R., Chan, A., Hodges, T., \& Avolio, B. J. (2003). Developing the moral component of authentic leadership. Organizational Dynamics, 32(1), 247-260.

McCauley, C. D. (2000). A systemic approach to leadership development. Paper presented at the 15th Annual Conference of the Society for Industrial and Organizational Psychology, New Orleans, LA, April.

Meba, K. (2011, September $\left.16^{\text {th }}\right)$. Gong belajar bangun karakter peserta didik. Antara news Sulawesi Tenggara. Retrieved from http://www.antarasultra.com/berita/261241/gong-belajar-bangunkarakter-peserta-didik.

Merriam, S. B. (1998). Case study research in education: a qualitative approach. San Francisco, California: Jossey-Bass.

Napitupulu, Y. (2011, November $\left.4^{\text {th }}\right)$. Staf militer dukung gerakan "Gong Pendidikan". U CAN Indonesia. Retrieved from http://indonesia.ucanews.com/2011/11/04/staf-militer-dukung-gerakan\%E2\%80\%98gong-pendidikan\%E2\%80\%99/

Neisser, U. (1994). Self narratives: True and false. In U. Neisser \& R. Fivush (Eds.), The remembered self: Construction and accuracy in the selfnarrative (pp. 1-18). Cambridge: Cambridge University Press.

Northouse, P. G. (2012). Leadership: Theory and Practice (6 $6^{\text {th }}$ Ed.). Sage Publications Inc. Thousand Oaks California

Northouse, P. G. (2013). Introduction to leadership: Concepts and Practice $\left(2^{\text {nd }} \mathrm{Ed}\right.$.). Thousand Oak, California: SAGE Publications Inc.

O'Connor, J., Mumford, M. D., Clifton, T. C., Gessner, T. L., \& Connelly, M. S. (1995). Charismatic leaders and destrctiveness: An historiometric study. Leadership Quarterly, 6(4), 529-555.

Padje, G.R. H. (2012, February 7). Menolak "Itu Suatu Solusi". Timor Express. Retrieved from http://www.timorexpress.com/index.php?actnews\&nid $=45207$ 
Peacock, J. L., \& Holland, D. C. (1993). The narrated life: Life stories in process. Ethos, 21(4), 367-383.

Raihani (2008). An Indonesian model of successful school leadership. Journal of Educational Administration, 46 (4), 481-496.

Reardon, R.M. (2011). Elementary school principals' learning-centered leadership and educational outcomes: Implications for principals' professional development. Leadership and Policy in Schools, 10(1), 63-83.

Report casts shadow. (2012, July $\left.12^{\text {th }}\right)$. Dunia pendidikan di NTT sangat memprihatinkan. DPR go id. Retrieved from http://www.dpr.go.id/id/berita/komisi10/2012/jul/18/4246/duniapendidikan-di-ntt-sangat-memprihatinkan

Report casts shadow. (2013, March $\left.7^{\text {th }}\right)$. Gubernur NTT korupsi dana bansos? Info Korupsi. Retrieved from http://infokorupsi.com/id/korupsi.php?ac=10520\&l=gubernur-nttkorupsi-dana-bansos.

Ripski, M. B., \& Gregory, A. (2009). Unfair, unsafe, and unwelcome: Do high school students' perceptions of unfairness, hostility, and victimization in school predict engagement and achievement?. Journal of School Violence, 8(4), 355-375.

Robinson, M.J. (2008). Forging the links between distributed leadership and educational outcomes. Journal of Educational Administration, 46(2), 2008 pp. $241-256$

Robinson, V. (2004). New understandings of educational leadership. Set 2004, 3(1), 39 - 43

Robinson, V. (2011). Student-centered leadership (1 $1^{\text {st }}$ ed.). Jossey-Bass Leadership library in education., San Fansisco: Jossey-Bass A Wiley Imprint.

Robinson, V., Hohepa, M., \& Lloyd, C. (2009). School leadership and student outcomes: Identifying what works and why (BES). Wellington: Ministry of Education.

Ross, J. A., \& Gray, P. (2006). School leadership and student achievement: The mediating effects of teacher beliefs. Canadian Journal of Education, 29(3), 798-822.

Rudin, K. (2012, October 1st). Dosa asal dan dosa publik pendidikan di NTT. Optimisme blogspot. Retrieved from http://optimisme4all.blogspot.co.nz/2012/09/dosa-asal-dan-dosa-publikpendidikan-di.htm|\#!/2012/09/dosa-asal-dan-dosa-publik-pendidikandi.html 
Russell, R. F. (2001). The role of values in servant leadership. Leadership and Organization Development Journal, 22(2), 76-83.

Scribner, J.P., Cockrell, K. S., Cockrell, D. H., \& Valentine, J. W. (1999). Creating professional communities in schools through organizational learning: An evaluation of a school improvement process. Educational Administration Quarterly, 35(1), 130-160.

Sebastian, J., \& Allensworth, E. (2012). The influence of principal leadership on classroom instruction and student learning: A study of mediated pathways to learning. Educational Administration Quarterly, 48(4), 626- 663.

Seo, Y. (2013, October $\left.31^{\text {st }}\right)$. Empat eks pejabat Kupang dituntut 3,5 tahun penjara. Tempo. Retrieved from http://www.tempo.co/read/news/2013/10/31/058526297/ Empat-EksPejabat-Kupang-Dituntut-3i5-Tahun-Penjara

Seo, Y. (Juni $2^{\text {nd }}$, 2012). Peringkat ujian nasional SMP NTT nomor buncit. Tempo. Retrieved from http://www.tempo.co/read/news/2013/06/02/058485104/PeringkatUjian-Nasional-SMP-NTT-Nomor-Buncit

Seo, Y. (September $\left.21^{\text {st }}, 2010\right)$. Pemerintah provinsi NTT canangkan siaga ujian nasional. Tempo. Retrieved from http://www.tempo.co/read/news /2010/09/21/ 179279370/Pemerintah-Provinsi-NTT-Canangkan-SiagaUjian-Nasional

Shamir, B., \& Eilam, G. (2005). What's your story?: A life-stories approach to authentic leadership development. The Leadership Quarterly, 16(3), 395-417.

Shamir, B., Dayan-Horesh., \& Adler, D. (2005). Leading by biography: Towards a life-story approach to the study of leadership. Leadership, 1(1), 13-29.

Shields, C. M., \& seltzer, P. A. (1997). Complexities and paradoxes of community: Towards a more useful conceptualization of community. Educational Administration Quarterly, 18(4), 413-439.

Smith, S. C., \& Piele, P. K. (2006). School leadership: handbook for excellence in student learning $\left(4^{\text {th }}\right.$ ed.). California: A Sage Publications Thousand Oaks

Southworth, G. (1995). Looking into primary headship: A research based interpretation. London: Falmer Press.

Southworth, G. (2002). Instructional leadership in schools: Reflections and empirical evidence. School Leadership \& Management: Formerly School Organisation, 22(1), 73-91. 
Sparrowe, R. T. (2005). Authentic leadership and the narrative self. The Leadership Quarterly, 16(3), 419-439

Spillane, J. P., Halverson, R., \& Diamond, J. B. (2004). Towards a theory of leadership practice: A distributed perspective. Journal of Curriculum Studies, 36(1), 3-34.

Starratt, R. J. (1991). Building an ethical school: A theory for practice in educational leadership. Educational Administration Quarterly, 27(2), 185-202.

Starratt, R. J. (2004). Ethical leadership. San Francisco: Jossey Bass.

Terry, R. W. (1993). Authentic leadership: Courage in action. San Fransisco: Jossey-Bass.

Titon, J. T. (1980). The life story. Journal of American Folklore, 93(369), 276292.

Toor, S. U., \& Ofori, G. (2008). Tipping points that inspire leadership: An exploratory study of emergent project I eaders. Engineering, Construction and Architectural Management, 15 (3), 212-229.

Tsai, W., \& Ghoshal, S. (1998). Social capital and value creation: The role of intrafirm networks. Academy of Management Journal, 41(4), 464-476.

Wahyuni, D. (2012). The research design maze: Understanding paradigms, cases, methods and methodologies. Journal of Applied Management Accounting Research, 10(1), 69-80.

Walumbwa, F.O., Avolio, B.J., Gardner, W.L., Wernsing, T. S., \& Peterson, S. J. (2008). Authentic leadership: Development and validation of a theory-based measure?. Journal of Management, 34(1), 89-126.

Wildy, H., \& Dimmock, C. (2002). Instructional leadership in primary and secondary schools in Western Australia. Journal of Educational Administration, 31(2),43-62.

Witzier, B., Bosker, R. J., \& Kruger, M. L. (2003). Educational leadership and student achievement: The elusive search for an association. Educational Administration Quarterly, 39(3), 398-425.

Yin, R. K. (2003). Case study research: Design and methods (3rd ed.). Thousand Oaks, CA: Sage Publications.

York-Barr, J., \& Duke, K. (2004). What do we know about teacher leadership? Findings from two decades of scholarship. Review of Educational Research Fall, 74(3), 255-316.

Young, P., \& King, M. B. (2002). Principal leadership for professional development to build school capacity. Educational Administration Quarterly, 38(5), 643-670. 
Yukl, G. (2013). Leadership in organizations $\left(8^{\text {th }}\right.$ ed). Upper Saddle Creek, New Jersey: Prentice-Hall 


\section{APPENDICES}

\section{Appendix A: Ethic approval}

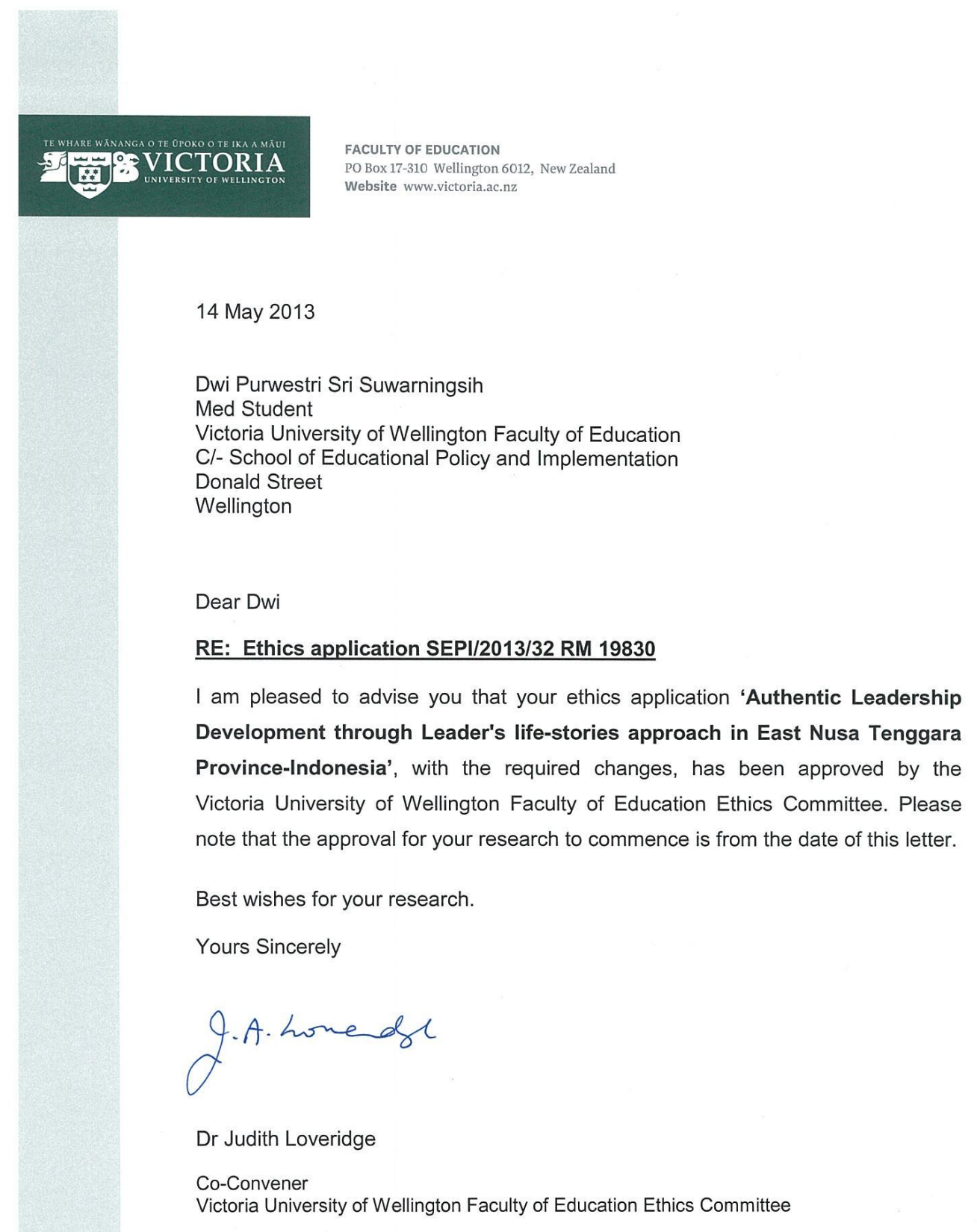




\section{Appendix B: Information sheet}

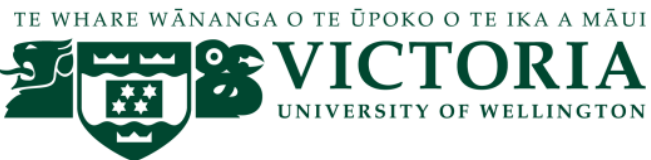

Faculty of Education

\section{The Influence of Life Experiences on Leadership Practices: A Case Study of Indonesian School Principals}

\section{Information Sheet for School Principal}

\section{Dear school principal}

My name is Dwi Purwestri Sri Suwarningsih. I am completing Masters of Education at Victoria University of Wellington, New Zealand. My research study aims to explore how individuals' life-stories impact on their leadership development and affect their leadership practices. I would like to invite you to take part in my research, as based on the provincial data, your school has achieved the first/second highest ranking among all elementary/junior high/senior high schools in East Nusa Tenggara in the last national examination. A face-to-face interview lasting between 60 and 90 minutes will be arranged at any time convenient for you at your school.

If you decide to participate in the research, you need to sign a consent form and send it back to my email address. The interview will be conducted in Bahasa. The interviews will later be transcribed and you will have the opportunity to check your transcript for accuracy. Your feedback will be highly valued, even if you wish to delete some statements. If you change your mind you can just withdraw your participation before the analysis stage, without having to explain the reason.

Neither your name nor any information that would identify you will appear in the research reports, articles and presentations. Only my supervisor, the transcriber and I will have access to your data. I will ensure that your personal information is confidential. All responses will be kept in password-protected files and locked offices at Victoria University of Wellington and will be digitally wiped five years after the completion of the research. My thesis reporting on the research will be deposited in the provincial education office and Victoria University of Wellington's libraries and sent to provincial secretariat in East Nusa Tenggara. A summary of the research findings will be made available upon your request after the completion of this project. I hope that you would find the interview interesting and they might help you to think about your authentic leadership development and your practices.

This research has been approved by Victoria University of Wellington's Faculty of Education Human Ethics Sub-Committee under delegated authority from the Victoria 
University Human Ethics Committee on 14/5/2013. Once my thesis is completed, it will be deposited in the provincial education office in ENT province and Victoria University of Wellington's libraries and a copy sent to the provincial secretariat in ENT province.

If you would like to receive more information regarding my research, please feel free to contact my supervisor at the below address:

Dr Kate Thornton, Senior Lecturer

Phone +64-4-463 9776

Kate.Thornton@vuw.ac.nz

School of Education Policy and Implementation, WA 304

Faculty of Education

Victoria University of Wellington

Donald St, Karori, Wellington 6012

PO Box 17-310, Karori, Wellington 6147

New Zealand

Or you could contact me directly at:

Dwi Purwestri Sri Suwarningsih

Faculty of Education

Victoria University of Wellington

srisuwdw@myvuw.ac.nz

If you have any human ethics concerns about the research, you may contact:

Dr. Allison Kirkman

Chairperson of the Human Ethics Committee

DDI: +644 4635676

allison.kirkman@vuw.ac.nz

Yours faithfully,

Dwi Purwestri Sri Suwarningsih 


\section{Appendix C: Consent form for participants}

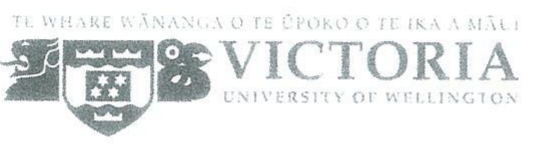

FACULTY OF EDUCATION

Authentic Leadership Development through Leader's life-stories approach in East Nusa Tenggara province-Indonesia

Consent form for school principals

Please read the following information

- I have been given and have understood an explanation relating to the nature and purpose of this project.

- I give permission for our interview between $1^{\text {st }}$ June 2013 until 31 July 2013 to form part of the project data.

- I give permission for our conversation to be recorded in order for the researcher to make transcription and analysis based on the transcription.

- I will receive interview transcription to check for accuracy before the results are analysed.

- I give permission for the researcher to access school data and other relevant documents.

- I understand the material will not be attributed to me and that I will not be identified in any way.

- I understand that this data will be kept secure and destroyed after 5 years period.

Place a tick in the box

$\checkmark$ I agree with all information above and willing to participate in this study

$\checkmark$ I wish to get a summary of the research findings after completion of this project

Name

Signature

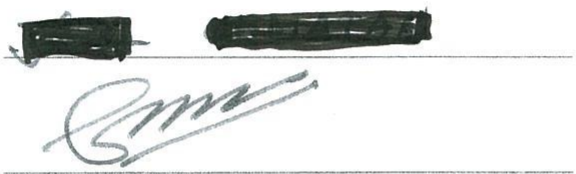

Date

$$
26-06-2013
$$




\section{Appendix D: Permission from the government}

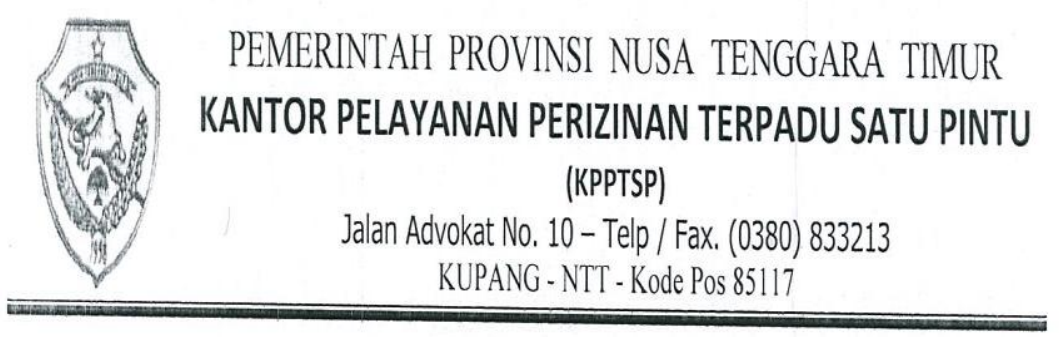

\begin{tabular}{|c|c|c|c|}
\hline & & & Kupang, 10 Juni 2013 \\
\hline & & & Kepada \\
\hline Nomor & : 070/1855/KPPTSP/2013 & Yth. & Kepala Dinas Pendidikan Pemuda dan \\
\hline Sifat & : Biasa & & Olahraga Provinsi Nusa Tenggara Timur \\
\hline Lampiran & : - & & \\
\hline $\mathrm{Hal}$ & : Izin Penelitian & & $\mathrm{di}-$ \\
\hline
\end{tabular}

Menunjuk Surat Dosen Pembimbing School Of Education \& Implementation Victoria University Of Wellington Nomor : 001/EPOL/2013 tanggal 21 Mei 2013, perihal Mohon Izin Pelaksanaan Penelitian dan setelah mempelajari rencana kegiatan/proposal yang diajukan, maka dapat diberikan Izin Penelitian kepada Mahasiswa:

$\begin{array}{ll}\text { Nama } & : \text { DWI PURWESTRI SRI SUWARNINGSIH } \\ \text { NIM } & : 300232075 \\ \text { Jurusan / Prodi } & : \text { Kebijakan dan Pelaksanaan Pendidikan } \\ \text { Kebangsaan } & : \text { Indonesia } \\ \text { Untuk melakukan penelitian dengan judul : }\end{array}$

"MENGEMBANGKAN KEPEMIMPINAN YANG OTENTIK MALALUI PENDEKATAN KISAH HIDUP PEMIMPIN DI PROVINSI NUSA TENGGARA TIMUR, INDONESIA"

$\begin{array}{ll}\text { Lokasi } & : \text { Dinas Pendidikan Pemuda dan Olahraga } \\ & \text { Provinsi Nusa Tenggara Timur } \\ \text { Pengikut } & : \\ \text { Lamanya Penelitian } & : \\ \text { Penanggung Jawab } & 1 \text { (satu) tahun } \\ & : \text { Dosen Pembimbing School Of Education \& } \\ & \begin{array}{l}\text { Implementation Victoria University Of } \\ \text { Wellington }\end{array}\end{array}$

Peneliti berkewajiban menghormati/mentaati peraturan dan tata tertib yang berlaku di 


\section{Appendix E: Leadership journey}

"The journey to authentic leadership begins with understanding the story of your life. Your life story provides the context for your experiences, and through it, you can find the inspiration to make an impact in the world" (George, Sims, McLean \& Myer, 2007, p. 2)

If you wish to participate in this study, you would have a chance to reflect your leadership journey by drawing your life-experience based on this task, before doing the interview. This task will give you more time to reflect your life experience.

1. Sketch your life experience by drawing a time line horizontally on a sheet of paper. Above the line note milestones, transitions and life events and that significantly influenced you. These may be positive or negative.

2. Below the line identify opportunities that made a difference and helped you grow and develop and also any obstacles that got in the way.

3. Insert the names of individuals who contributed to your development along the way.

Please reflect on the following questions:

- What have you learned from these people \& experiences that has contributed to the development of your leadership? 


\section{Appendix F: List of values}

If you wish to participate on this research, you will be asked about your core of values. By reading this list of values, you would have a chance to reflect on your core of values before the interview is conducted. However, please feel free to add more values of your own, if the values are not in this list. Question: What values do you hold that influence your leadership practice (see sheet of possible values)

\begin{tabular}{|c|c|}
\hline INTELLIGENCE & LOYALTY \\
\hline PATIENCE & AUTONOMY \\
\hline DIVERSITY & CHALLENGE \\
\hline FRIENDSHIP & POWER \\
\hline SERVICE & WISDOM \\
\hline SIMPLICITY & HUMOUR \\
\hline PRODUCTIVITY & TRUST \\
\hline STRENGTH & SUCCESS \\
\hline EQUALITY & COMPETITION \\
\hline HARMONY & ACHIEVEMENT \\
\hline DISCIPLINE & RESPECT \\
\hline OPEN-MINDEDNESS & INTEGRITY \\
\hline HONESTY & TEAMWORK \\
\hline
\end{tabular}




\section{Appendix G: Interview questions}

\section{Life-stories}

1) Can you tell me about your leadership reflection? E.g. milestones, transitions and life events either positive or negative, that significantly influenced your leadership development.

2) What have you learned from your experiences based on your leadership reflection?

3) Can you tell me what kind of opportunities you had in the past that helped you grow and develop your leadership capacities?

4) Can you tell me if there were any difficulties in the past, during your leadership journey? What were they? How did you manage/solve those problems?

5) Were there any influential person that contributed to your leadership development? Who were they? What have you learned from these people? In what ways she/he has influenced your leadership development?

6) What values do you hold that influence your leadership practice?

\section{Student-centered leadership}

1. What are your goals and expectations to improve student outcomes?

2. What are your strategies to achieve the goals?

3. How do you ensure the quality of teaching?

4. How do you lead teacher learning and enable teachers for professional development? What kind of professional learning communities are you and your teacher involved in?

5. How do you ensure an orderly and safe environment for staff and students? 


\section{Appendix H: Information sheet for provincial education office}

The head of Provincial Education Office of Nusa Tenggara Timur In Kupang city.

Dear Sir,

The Influence of Life Experiences on Leadership Practices: A Case Study of Indonesian School Principals

My name is Dwi Purwestri Sri Suwarningsih. I am completing a Master of Education at Victoria University of Wellington, New Zealand. My research study aims to explore how individuals' life-stories impact on their leadership development and affect their leadership practices. I am writing to request your permission to access provincial data relate with school ranking based on the student academic achievement results in the last national examination at elementary level, junior high level and senior high level. I will use the data to select my research participant which are school principals from the two higest achieving schools at each level. Therefore following school selection, I need to access school principals' details (name, duration of work, phone number, email, school address, etc).

This research will not affect the reputation of the East Nusa Tenggara government nor of provincial education office. The focus of this research are on the school principals' life-stories and their leadership practices.

I would like to interview 6 school principals from the highest achieving schools which are 2 elementary school principals, 2 junior high school principals, and 2 senior high school principals. Each interview will last between 60 and 90 minutes. All interviews with school principals would be arranged at any time convenient for the participants. The transcription of the interviews results will be sent to all participants to check for accuracy that what in the transcription has the same meaning with the information from the participants.

I will use pseudonyms of the participants in my thesis or other reports from the research. I will ensure that their personal information is kept confidential. Informed consent will be obtained through a signed consent form. The participants would be able to withdraw from participation before the interview analysis, without having to explain. 
Access to the research data will be restricted to my supervisor, Dr Kate Thornton, and me. All responses will be kept in password-protected computer files or locked offices at Victoria University of Wellington and will be destroyed five years after the conclusion of the research.

The research was been approved by the Victoria University of Wellington's Faculty of Education Ethics Committee on 14/05/2013 Once my thesis is completed, it will be deposited in the provincial education office in ENT province and Victoria University of Wellington's libraries and a copy sent to the provincial secretariat in ENT province.

If you would like to receive more information regarding my research, please do not hesitate to contact my supervisor at the below address:

Dr Kate Thornton, Senior Lecturer

Phone +64-4-463 9776

Kate.Thornton@vuw.ac.nz

School of Education Policy and Implementation, WA 304

Faculty of Education

Victoria University of Wellington

Donald St, Karori, Wellington 6012

PO Box 17-310, Karori, Wellington 6147

New Zealand

Or you could contact me directly at:

Dwi Purwestri Sri Suwarningsih

Faculty of Education

Victoria University of Wellington

srisuwdw@myvuw.ac.nz

If you have any concerns about the research, you may contact:

Dr. Allison Kirkman

Chairperson of the Human Ethics Committee

DDI: +644 4635676

allison.kirkman@vuw.ac.nz

Yours faithfully,

Dwi Purwestri Sri Suwarningsih 


\section{Appendix I: Consent form for provincial education office}

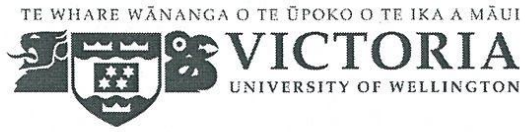

Faculty of Education

FACULTY OF EDUCATION

Authentic Leadership Development through Leader's life-stories approach in East Nusa Tenggara province-Indonesia

Consent form for the head of provincial educational office

Please read the following information

- I have been given and have understood an explanation relating to the nature and purpose of this project.

- I give permission for the researcher to access provincial data related to school ranking in elementary school level, junior high school level and senior high school level to select research participants.

- I give permission to the researcher to access school principals' contact details, in order to invite principals to participate in the research.

- I understand that this information will be kept secure and my records of the data will be destroyed after submission of this thesis.

- I understand that once this research is completed, one copy of this thesis will be deposited in the provincial education office in East Nusa Tenggara Province

Place a tick in the box

o I give my permission for the researcher to access provincial data related to school ranking.

6 I give my permission for the researcher to access selected school principals' contact details, in order to invite them to participate in this research

Name

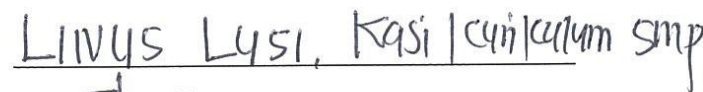

Signature

Date
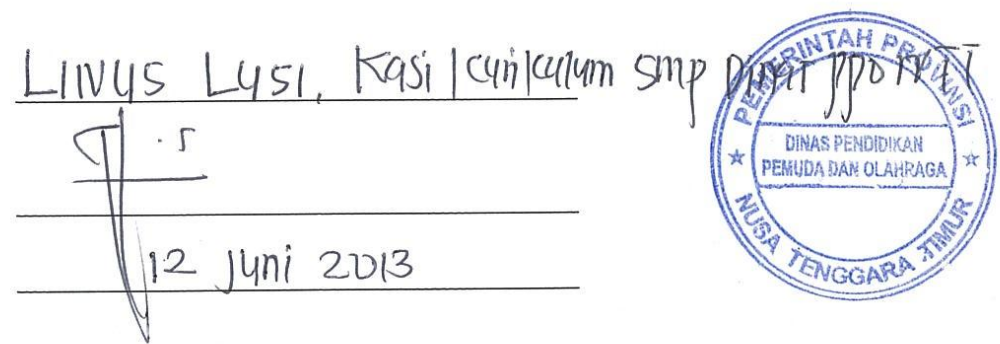


\section{Appendix J: Transcribers confidentiality agreement}

April 2013

\section{TRANSCRIBER CONFIDENTIALITY AGREEMENT}

I, Will be the transcriber for the audio recording from the interviews between the researcher and the school principals in exploring principals' life stories and their practices as part of research project in East Nusa Tenggara.

No names of participants or identification of their schools will be provided to me. Furthermore, all the information that is provided will be deemed confidential and I will ensure that it is not released to any third party.

Signature of the transcriber Name of the transcriber

Date 


\section{Appendix K: Example of coding}

\section{Junior high school principals}

\section{Transcript (Principal 3)}

Me: Can you tell me about your leadership reflection? Were there any life events either positive or negative that significantly influenced your leadership development?

P3:

Mostly economic problems because my parents were farmers, I was always late to pay my school fees. I remember the school distance from my house to the school was about $4 \mathrm{Km}$, and I had to walk to school. It happened (had to walk) since when I was at elementary schools until I was at university. We didn't have public transport at that time and my family was really poor... I was so tired between studying and working. I was sad sometimes, because I'm so tired, due to the distance from home to the university.

Because I was always late to pay the school fees, I was thinking how to get a scholarship. I was studying very hard to get a scholarship; luckily I got a scholarship. Even though the amount of money was small, but it was enough to pay the school fees. My parents were so happy, it helped them a lot to pay my education. My parents wished I could continue my study until higher education, not just to be a farmer like them.

Note: \#Economic problems \#Poor \#Got a scholarship

Transcript (Principal 6)

Me:

Were there any achievements at that time? When you were young? 
P6:

Yes, I was a committee at student association when I was at secondary schools, until I was studying at University, I was one of the executive members of students associations.

Me:

Oh, its good to be the executive member.

P6:

Yes it was good, so that I think I got skill as a leader from student association, it was good to be the one who was trusted by other students, to lead them. It increased my confidence and self-reliance.

Me:

Were there any interesting stories?

P6:

Hmmm, well, what kind of experiences I had in the past....most of them were unpleasant experiences, particularly economics problem, money problem within my family, we were 7 siblings, we had to go to schools at the same time, so I think it was economic problem

Note: \#Unpleasant experiences \#Economic problems 


\section{Appendix L: Summary of life experiences and leadership practices (Vama)}

\begin{tabular}{|c|c|c|c|c|c|}
\hline Life experience & $\begin{array}{c}\text { Previous leadership } \\
\text { experience }\end{array}$ & $\begin{array}{l}\text { Impact on self-awareness } \\
\text { and self knowledge }\end{array}$ & Role models & Values & Leadership practices \\
\hline $\begin{array}{l}\text { - No smooth transition } \\
\text { between her and the } \\
\text { previous principal. } \\
\text { - Tension between her } \\
\text { and her husband } \\
\text { because of time spent } \\
\text { at work. } \\
\text { Good coordination } \\
\text { with parents and the } \\
\text { school committee } \\
\text { Easily managed her } \\
\text { teachers (because the } \\
\text { teachers are younger } \\
\text { than her) }\end{array}$ & $\begin{array}{ll}- & \text { Involved in the } \\
\text { teachers' working } \\
\text { group } \\
\text { Involved in the } \\
\text { examination } \\
\text { development team } \\
\text { - } \quad \text { Shared responsibility } \\
\text { - } & \text { Made personal } \\
\text { approaches to the } \\
\text { teachers }\end{array}$ & $\begin{array}{l}\text { - Never thought to } \\
\text { become a leader } \rightarrow \text { She } \\
\text { realized her potential } \\
\text { because of the } \\
\text { government appreciated } \\
\text { her work } \\
\text { - Creating good } \\
\text { relationship with parents } \\
\text { and the school } \\
\text { committees. } \\
\text { - Shared responsibilities } \\
\text { with teachers. } \\
\text { - Confident to manage } \\
\text { the teachers who have } \\
\text { good spirit }\end{array}$ & $\begin{array}{l}\text { • Husband } \\
\text { Reasons: his } \\
\text { characteristics } \\
\text { (patience, calm, } \\
\text { thinking } \\
\text { positively) }\end{array}$ & $\begin{array}{cl}\text { - } & \text { Self-discipline } \\
\text { - } & \text { Patience } \\
\text { - } & \text { Integrilenge } \\
\text { - } & \text { Trust } \\
\text { - } & \text { Achievement } \\
\text { Other values mentioned } \\
\text { - Honesty } \\
\text { - } \text { Coordination } \\
\text { - } \text { Strength } \\
\text { - Humble }\end{array}$ & $\begin{array}{l}\text { - Goal: To make an effort, to } \\
\text { be creative and motivated: } \\
\text { working together to reach } \\
\text { the goals } \\
\text { - Strategies: morning } \\
\text { prayer, achieving all } \\
\text { indicator, homework, and } \\
\text { book availability. } \\
\text { - Monitoring and } \\
\text { supervision, classroom } \\
\text { observation, together with } \\
\text { school supervisors, } \\
\text { - Encouraged all teachers to } \\
\text { join the teachers working } \\
\text { group. } \\
\text { Safe environment at the } \\
\text { army compound. } \\
\text { Had good coordination } \\
\text { with the community health } \\
\text { center }\end{array}$ \\
\hline
\end{tabular}




\section{Appendix M: Summary of life experiences and leadership practices (Louisa)}

\begin{tabular}{|c|c|c|c|c|c|}
\hline Life experience & $\begin{array}{l}\text { Previous leadership } \\
\text { experience }\end{array}$ & $\begin{array}{l}\text { Impact on self-awareness } \\
\text { and self knowledge }\end{array}$ & Role models & Values & Leadership practices \\
\hline $\begin{array}{l}\text { - Did not get sufficient } \\
\text { support from her } \\
\text { principal, when she was } \\
\text { a teacher. } \\
\text { - Difficulty in managing } \\
\text { some of the teachers } \\
\text { (coordination issues with } \\
\text { teachers). } \\
\text { - High rates of truancy. } \\
\text { - Difficulty in dealing with } \\
\text { the surrounding } \\
\text { communities who used } \\
\text { school facilities. } \\
\text { - Encouraged open } \\
\text { discussion at the school } \\
\text { meeting. } \\
\text { - Invited parents to share } \\
\text { responsibility of their } \\
\text { children attendance. } \\
\text { - Shared responsibility } \\
\text { with the local community } \\
\text { regarding school } \\
\text { facilities. } \\
\text { - Hesitated to join } \\
\text { principal selection } \\
\text { (during } 1999-2009 \text { ), } \\
\text { because her husband } \\
\text { was sick. } \\
\text { - She participated on } \\
\text { principal selection and } \\
\text { then selected in } 2009, \\
\text { after her husband } \\
\text { passed away. }\end{array}$ & $\begin{array}{l}\text { - Her school principal } \\
\text { often sent her to } \\
\text { attend principals' } \\
\text { meeting } \\
\text { Involved in the } \\
\text { women's } \\
\text { organizations Involved } \\
\text { through religious } \\
\text { service in the church } \\
\text { Reading books in } \\
\text { leadership and } \\
\text { professional } \\
\text { development } \\
\text { She makes some } \\
\text { changes in the school } \\
\text { management, as a } \\
\text { result from C level, her } \\
\text { school has improved } \\
\text { to B level school } \\
\text { accreditation. }\end{array}$ & $\begin{array}{l}\text { - She would not treat } \\
\text { her teachers like her } \\
\text { previous principal } \\
\text { had/ she would } \\
\text { respond and well } \\
\text { communicate to her } \\
\text { teachers. } \\
\text { - High motivation to do } \\
\text { variety of jobs } \\
\text { - Comfortable in doing } \\
\text { her responsibilities } \\
\text { - Learnt her teachers' } \\
\text { characteristics to } \\
\text { work with them } \\
\text { effectively } \\
\text { - Learnt how to give } \\
\text { feedback to the } \\
\text { teachers } \\
\text { - Having spiritual } \\
\text { intelligence (strong } \\
\text { faith to God) } \\
\text { - Listen to everybody } \\
\text { Being neutral } \\
\text { - Give Guidance to } \\
\text { teachers on how to } \\
\text { be a good teacher }\end{array}$ & $\begin{array}{l}\bullet \quad \text { Parents } \\
\text { Reason: gave suggestions } \\
\text { about life and studies. } \\
\bullet \quad \text { Husband } \\
\text { Reason: - (no information) } \\
\bullet \quad \text { School } \\
\quad \text { supervisor } \\
\text { Reason: influenced her } \\
\text { how to be a good teacher } \\
\text { (classroom management) } \\
\bullet \quad \text { Other colleagues }\end{array}$ & $\begin{array}{ll}\text { - } & \text { Discipline } \\
\text { - } & \text { Intelligence } \\
\text { - } & \text { Honestly } \\
\text { - } & \text { Trust } \\
\text { - } & \text { Humble } \\
\text { - } & \text { Humour }\end{array}$ & $\begin{array}{l}\text { Goal: To improve } \\
\text { students' quality of } \\
\text { education; good quality of } \\
\text { teaching, qualified } \\
\text { teachers, analysing } \\
\text { students' weakness. } \\
\text { Academic strategies: book } \\
\text { availability for students } \\
\text { and teachers to improve } \\
\text { students' academic } \\
\text { outcomes, provided } \\
\text { interactive teaching, } \\
\text { dismissed classical } \\
\text { method. } \\
\text { Non academic: good } \\
\text { foods intake. } \\
\text { Administration strategies: } \\
\text { developed syllabus, } \\
\text { prepared learning } \\
\text { materials, provided } \\
\text { learning aids. } \\
\text { Enables her teachers to } \\
\text { involve in professional } \\
\text { development, sent her } \\
\text { teacher to join workshops } \\
\text { or trainings. } \\
\text { Participated in the } \\
\text { principals' working group. }\end{array}$ \\
\hline
\end{tabular}




\section{Appendix N: Summary of life experiences and leadership practices (Gerson)}

\begin{tabular}{|c|c|c|c|c|c|}
\hline Life experience & $\begin{array}{c}\text { Previous Leadership } \\
\text { experience }\end{array}$ & $\begin{array}{l}\text { Impact on self-awareness and } \\
\text { self knowledge }\end{array}$ & Role Models (reasons) & Values & Leadership Practices \\
\hline $\begin{array}{ll} & \text { Came from a low socio- } \\
\text { economic background } \\
\text { - } \\
\text { kad to walk about } 4 \\
\text { kilometres to school } \\
\text { Received a scholarship } \\
\text { award } \\
\text { He worked as a teacher } \\
\text { assistant, when he was } \\
\text { at University } \\
\text { When he was a teacher } \\
\text { he asked his school } \\
\text { principal about school } \\
\text { programmes and asked } \\
\text { for some facilities, } \\
\text { however his school } \\
\text { principal never approved } \\
\text { his request } \\
\text { Dilemmas: Variety of } \\
\text { social economic } \\
\text { background among the } \\
\text { students }\end{array}$ & $\begin{array}{l}\text { - } \quad \text { He was an exemplary } \\
\text { teacher (based on the } \\
\text { provincial ranking) } \\
\text { - He was a mathematics } \\
\text { instructor } \\
\text { - When he was a vice } \\
\text { principal, he was } \\
\text { responsible for } \\
\text { supervising the students' } \\
\text { association } \\
\text { When he was a vice } \\
\text { principal, he was } \\
\text { responsible for } \\
\text { managing school } \\
\text { curriculum } \\
\text { He is the secretary in the } \\
\text { principals' working group }\end{array}$ & $\begin{array}{ll}\text { - } & \text { Realized having a } \\
\text { leadership potential } \\
\text { Broadened his leadership } \\
\text { skills } \\
\text { - He realized that self- } \\
\text { discipline was one of the key } \\
\text { successes in leadership. } \\
\text { - } \quad \text { Avoiding procrastination } \\
\text { - He promised never } \\
\text { dismissed his teachers } \\
\text { request }\end{array}$ & $\begin{array}{l}\text { - Mother } \\
\text { Reason: Even though his } \\
\text { mothor was only a housewife, } \\
\text { but she has the ability to lead } \\
\text { their family } \\
\text { - Algebra teacher \& } \\
\text { Geometry } \\
\text { Reasons: good and smart, } \\
\text { concerned with their students, } \\
\text { taught about discipline. } \\
\text { - School principal } \\
\text { Reason: taught about } \\
\text { discipline }\end{array}$ & $\begin{array}{ll} & \text { Self-discipline } \\
\text { - } & \text { Intelligence } \\
\text { - } & \text { Patience } \\
\text { - } & \text { Productivity } \\
\text { - } & \text { Services } \\
\text { - } & \text { Honesty } \\
\text { - } & \text { Open-mindedness } \\
\text { - } & \text { Humour } \\
\text { - } & \text { Integrity } \\
\text { - } & \text { Humble }\end{array}$ & $\begin{array}{l}\text { - Goal: his school has to be the } \\
\text { best in terms of academic } \\
\text { achievement at district, } \\
\text { province and national level. } \\
\text { Students have to obey school } \\
\text { rules, including applied } \\
\text { 'shamed culture' (clarified by } \\
\text { the school document). } \\
\text { Improving school management, } \\
\text { by dividing students classes } \\
\text { based on academic results } \\
\text { Improving academic result, by } \\
\text { giving additional } 90 \text { minutes } \\
\text { lessons with mock exams } \\
\text { Collecting financial support } \\
\text { from government, parents, and } \\
\text { school's alumni to be used to a } \\
\text { cross-subsidy for students from } \\
\text { low economic background (to } \\
\text { pay transportation fees) } \\
\text { Strategy to ensure the quality } \\
\text { of teaching: all teaching } \\
\text { schedules were fixed in the } \\
\text { beginning of the semester, only } \\
\text { the qualified teachers to give } \\
\text { the additional lessons, all the } \\
\text { teachers have to write journal, } \\
\text { monthly evaluation for the } \\
\text { teachers } \\
\text { Had a good relationship with } \\
\text { the community related to the } \\
\text { school security } \\
\text { Received feedback from five } \\
\text { senior teachers and five junior } \\
\text { teachers } \\
\text { Supported his teachers to } \\
\text { involve in the subject teachers' } \\
\text { working group }\end{array}$ \\
\hline
\end{tabular}




\section{Appendix 0: Summary of life experiences and leadership practices (Seran)}

\begin{tabular}{|c|c|c|c|c|c|}
\hline Life experience & $\begin{array}{l}\text { Previous Leadership } \\
\text { experience }\end{array}$ & $\begin{array}{l}\text { Impact on self-awareness and } \\
\text { self knowledge }\end{array}$ & Role Models (reasons) & Values & Leadership Practices \\
\hline $\begin{array}{l}\text { Had financial problem as } \\
\text { he came from low } \\
\text { economic background } \\
\text { (i.e. transportation } \\
\text { problems) } \\
\text { Worked as a high school } \\
\text { teacher at rural school. } \\
\text { Had to promote and } \\
\text { increase the importance } \\
\text { of education at the } \\
\text { suburb communities. } \\
\text { The number of } \\
\text { registered students was } \\
\text { more than the } \\
\text { classrooms capacities. }\end{array}$ & $\begin{array}{l}\text { Executive member at the } \\
\text { students' association at } \\
\text { secondary school and at } \\
\text { the University } \\
\text { a vice school principal } \\
\text { (learnt how to be a good } \\
\text { school principal, and } \\
\text { familiarity with the school } \\
\text { curriculum }\end{array}$ & $\begin{array}{ll}\text { - } & \text { Confidence } \\
\text { - } & \text { Self-reliance } \\
\text { - } & \text { Courage } \\
\text { - } & \text { Paughness } \\
\text { - } & \text { Humble } \\
\text { - } & \text { Good communication } \\
\text { - } & \text { Adills } \\
& \text { Adopted friendship and } \\
\text { - } & \end{array}$ & $\begin{array}{l}\text { - Parents: } \\
\text { Reason: taught him how to be } \\
\text { independent, responsible, } \\
\text { disciplined and honest } \\
\text { - Vice chancellor } \\
\text { Reason: taught him discipline } \\
\text { and respect the school } \\
\text { environment (kept the building } \\
\text { clean without any scratches) } \\
\text { - School principal (when } \\
\quad \text { he was a teacher) } \\
\text { Reason: inspired him to be a } \\
\text { school principal. }\end{array}$ & $\begin{array}{ll}\text { - } & \text { Self-discipline } \\
\text { - } & \text { Service } \\
\text { - } & \text { Honesty } \\
\text { - } & \text { Loyalty } \\
\text { - } & \text { Integrity }\end{array}$ & $\begin{array}{l}\text { - } \quad \text { Goal: working hard to achieve } \\
\text { school goals } \\
\text { Managerial Strategies: Leading by } \\
\text { example (self-discipline and } \\
\text { obeying the school rules); } \\
\text { observing teachers and staff's } \\
\text { characteristics; understanding } \\
\text { everybody's job at school; good } \\
\text { school planning and budgeting. } \\
\text { Academic strategies: Being } \\
\text { involved in the teachers' working } \\
\text { group; developing the schools } \\
\text { extracurricular programmes to give } \\
\text { opportunities for students } \\
\text { increasing their academic and non- } \\
\text { academic skills. } \\
\text { Ensuring teachers' teaching quality } \\
\text { by leading teachers' working group } \\
\text { (workshops, role play, develop daily } \\
\text { lesson plans, evaluate students' } \\
\text { results) } \\
\text { Ensuring all teachers were familiar } \\
\text { with IT } \\
\text { Encouraging teachers to participate } \\
\text { in training and other professional } \\
\text { development. } \\
\text { He managed the school } \\
\text { environment to be clean (school } \\
\text { building is well painted), kept the } \\
\text { school environment physically and } \\
\text { mentally "healthy" (:good } \\
\text { relationship among the school } \\
\text { community) } \\
\text { The leader/chairman at the } \\
\text { principals' working group } \\
\text { Led teachers' working group. }\end{array}$ \\
\hline
\end{tabular}




\section{Appendix P: Summary of life experiences and leadership practices (Fanggidae)}

\begin{tabular}{|c|c|c|c|c|c|}
\hline Life experience & $\begin{array}{c}\text { Previous Leadership } \\
\text { experience }\end{array}$ & $\begin{array}{l}\text { Impact on self-awareness } \\
\text { and self knowledge }\end{array}$ & Role Models (reasons) & Values & Leadership Practices \\
\hline $\begin{array}{l}\text { - } \quad \text { Loss her mother when } \\
\text { she was } 12 \text {. } \\
\text { Had to take care of } \\
\text { her younger siblings. } \\
\text { Difficult time between } \\
\text { studying and doing } \\
\text { housework. } \\
\text { Living separately from } \\
\text { her family at a young } \\
\text { age. } \\
\text { Managed to get a } \\
\text { scholarship. } \\
\text { living separately from } \\
\text { her husband, } \\
\text { look after her two } \\
\text { daughters, while she } \\
\text { was pregnant, } \\
\text { To get to school had } \\
\text { to pass a mountain } \\
\text { where the militia } \\
\text { stayed, often heard } \\
\text { the gun shots }\end{array}$ & $\begin{array}{l}\text { - Had a double roles as } \\
\text { a mother and as a } \\
\text { school principal } \\
\text { (without her husband } \\
\text { around) } \\
\text { Learning how to } \\
\text { manage a school and } \\
\text { how to lead the } \\
\text { teachers from her } \\
\text { previous school } \\
\text { principal (when she } \\
\text { was a teacher) } \\
\text { Being a school } \\
\text { principal in one of the } \\
\text { conflict areas in Timor } \\
\text { Timur (1995-1998); } \\
\text { Leading the school in } \\
\text { a difficult } \\
\text { circumstances }\end{array}$ & $\begin{array}{ll}\text { - } & \text { Courage } \\
\text { - } & \text { Independent } \\
\text { - } & \text { More mature } \\
& \text { Shaping her faith to } \\
\text { - } & \text { God } \\
& \text { } \text { poorking-hard for the } \\
& \text { people } \\
\text { - } & \text { Loyalty, devoted } \\
\text { - } & \text { herself to her country } \\
\text { - } & \text { To love and to protect } \\
\text { - } & \text { To love her job } \\
\text { - } & \text { Never give up } \\
\text { - } & \text { Tolerance } \\
\text { - } & \text { Familial values } \\
\text { - } & \text { Commitment to her } \\
& \text { students }\end{array}$ & $\begin{array}{l}\text { - Father } \\
\text { Reasons: responsible } \\
\text { person, loyal to his family, } \\
\text { discipline, and work } \\
\text { without complaint. } \\
\text { - Husband } \\
\text { Reason: learnt how to } \\
\text { appreciate other people's } \\
\text { work and how to forgive } \\
\text { others' mistakes } \\
\text { - School principal } \\
\text { Reasons: very good as a } \\
\text { leader and as a "father", a } \\
\text { tough man, punctual, } \\
\text { charming, worked whole- } \\
\text { heartedly, naturally, } \\
\text { without coercion } \\
\text { - School supervisor } \\
\text { coordinator and the } \\
\text { head of the provincial } \\
\text { education office } \\
\text { Reason: appreciate other } \\
\text { people works }\end{array}$ & $\begin{array}{ll}\text { - } & \text { Religious values } \\
\text { - } & \text { Honesty } \\
\text { - } & \text { Openness } \\
\text { - } & \text { Tolerance } \\
\text { Additional values: } \\
\text { - } \quad \text { Responsibility } \\
\text { - } \quad \text { Creativity } \\
\text { - } \quad \text { Independence } \\
\text { - } \quad \text { Democracy } \\
\text { - } \quad \text { Curiousness } \\
\text { - } \quad \text { Appreciate other } \\
& \text { people's work, } \\
\text { - } & \text { friendliness } \\
\text { - } & \text { Lovilial } \\
\text { - } & \text { Respecting the } \\
& \text { environment } \\
\text { - } & \text { Patriotism } \\
\text { - } & \text { Faithfulness }\end{array}$ & $\begin{array}{l}\text { - Goal: To improve students' } \\
\text { results; win in academic } \\
\text { competitions, pass the test to } \\
\text { enroll at University } \\
\text { Academic strategies: additional } \\
\text { lessons, analysed every test } \\
\text { result, evaluate academic } \\
\text { challenges with teachers, } \\
\text { academic competition, effective } \\
\text { classroom management, } \\
\text { Non-academic strategies: } \\
\text { spiritual values (taught all five } \\
\text { religions), increase self } \\
\text { discipline for all school's } \\
\text { members, improve the quality } \\
\text { of extracurricular, } \\
\text { Completing all learning plans in } \\
\text { the beginning of each semester } \\
\text { Classroom supervision: worked } \\
\text { with school supervisors and } \\
\text { teachers' instructors. } \\
\text { Supporting subject teachers' } \\
\text { working group. } \\
\text { Developing IT pilot project } \\
\text { Maintaining good relationship } \\
\text { between school and the } \\
\text { community ( created familial } \\
\text { values with the school } \\
\text { community, improved people's } \\
\text { awareness to be the police for } \\
\text { themselves). } \\
\text { Maintaining school to be } \\
\text { physically and mentally healthy } \\
\text { Good relationship with local } \\
\text { communities. } \\
\text { Involved in a principals' working } \\
\text { group (as the treasurer). }\end{array}$ \\
\hline
\end{tabular}




\section{Appendix Q: Summary of life experiences and leadership practices (Ndoen)}

\begin{tabular}{|c|c|c|c|c|c|}
\hline Life experience & $\begin{array}{c}\text { Previous leadership } \\
\text { experience }\end{array}$ & $\begin{array}{l}\text { Impact on self-awareness } \\
\text { and self knowledge }\end{array}$ & Role models & Values & Leadership practices \\
\hline $\begin{array}{l}\text { - He never been } \\
\text { punished when he } \\
\text { was at school, even } \\
\text { though he acted badly } \\
\text { (he thought it was } \\
\text { because he was the } \\
\text { smartest student in } \\
\text { his school) } \\
\text { He is good at } \\
\text { mathematics and } \\
\text { English } \\
\text { From a low socio } \\
\text { economic } \\
\text { background, had to } \\
\text { live with his uncle } \\
\text { Received a } \\
\text { scholarship for two } \\
\text { years } \\
\text { He was able to make } \\
\text { money when he was } \\
\text { young } \\
\text { He was one of the top } \\
\text { five ranking students } \\
\text { at his high school ( } \\
\text { thus, he enrolled at } \\
\text { University without } \\
\text { test) }\end{array}$ & $\begin{array}{l}\text { - } \text { Classroom } \\
\text { representative (when } \\
\text { he was at elementary, } \\
\text { junior and senior high } \\
\text { schools) } \\
\text { Executive committee } \\
\text { in the students' } \\
\text { association when he } \\
\text { was at junior high } \\
\text { school } \\
\text { When he was firstly } \\
\text { appointed as a school } \\
\text { principal, he was the } \\
\text { target of student } \\
\text { demonstrations, } \\
\text { because of previous } \\
\text { principal's policy }\end{array}$ & $\begin{array}{l}\text { Did not feel confident } \\
\text { to take the role of a } \\
\text { school principal, felt } \\
\text { inexperienced (had } \\
\text { never been a vice } \\
\text { principal) } \\
\text { He was a person that } \\
\text { always obeys the rule } \\
\text { (felt that this was one } \\
\text { of his good leadership } \\
\text { qualities) } \\
\text { One of his } \\
\text { weaknesses was his } \\
\text { difficulty for being } \\
\text { straight forward to the } \\
\text { teachers }\end{array}$ & $\begin{array}{l}\text { - School Principal } \\
\text { Reason: diligent man, } \\
\text { discipline, punctual, } \\
\text { - Teachers (algebra \& } \\
\text { mathematics) } \\
\text { Reasons: intelligent, } \\
\text { special ability to memorize } \\
\text { mathematic formulas }\end{array}$ & $\begin{array}{ll}\text { - } & \text { Intelligence } \\
\text { - } & \text { Patience } \\
\text { - } & \text { Humility } \\
\text { - } & \text { Humour } \\
\text { - } & \text { Competition } \\
\text { - } & \text { Respect } \\
\text { - } & \text { Self-discipline } \\
\text { - } & \text { Open- } \\
& \text { mindedness } \\
\text { - } & \text { Honesty }\end{array}$ & $\begin{array}{l}\text { - } \quad \text { Goal: Leading with affection } \\
\text { and teaching student with } \\
\text { care: } \\
\text { Strategies: to understand } \\
\text { teachers and students' } \\
\text { characteristics \& capacities; } \\
\text { informal communication. } \\
\text { Managerial strategies: } \\
\text { working closely with vice } \\
\text { principal and teachers. } \\
\text { Weekly regular meeting: } \\
\text { challenges and how to solve } \\
\text { problems, financial issues, } \\
\text { indiscipline, and other school } \\
\text { mechanism. } \\
\text { Teacher had to obey the } \\
\text { school rule (i.e punctuality } \\
\text { that all teachers arrived on } \\
\text { time at school). } \\
\text { Conducted regular } \\
\text { supervision, unscheduled } \\
\text { supervisions, classroom } \\
\text { observations, feedbacks } \\
\text { Encouraged teachers to learn } \\
\text { how to use technology. } \\
\text { Good coordination with } \\
\text { school community. } \\
\text { Received feedback from staff. }\end{array}$ \\
\hline
\end{tabular}

